\title{
Estudios de desarrollo regional en México
}

Francisco Espinoza Morales, Angélica María Rascón Larios, Francisca Elena Rochín Wong, Georgina Castro Burboa y Amado Olivares Leal (COORDINADORES)

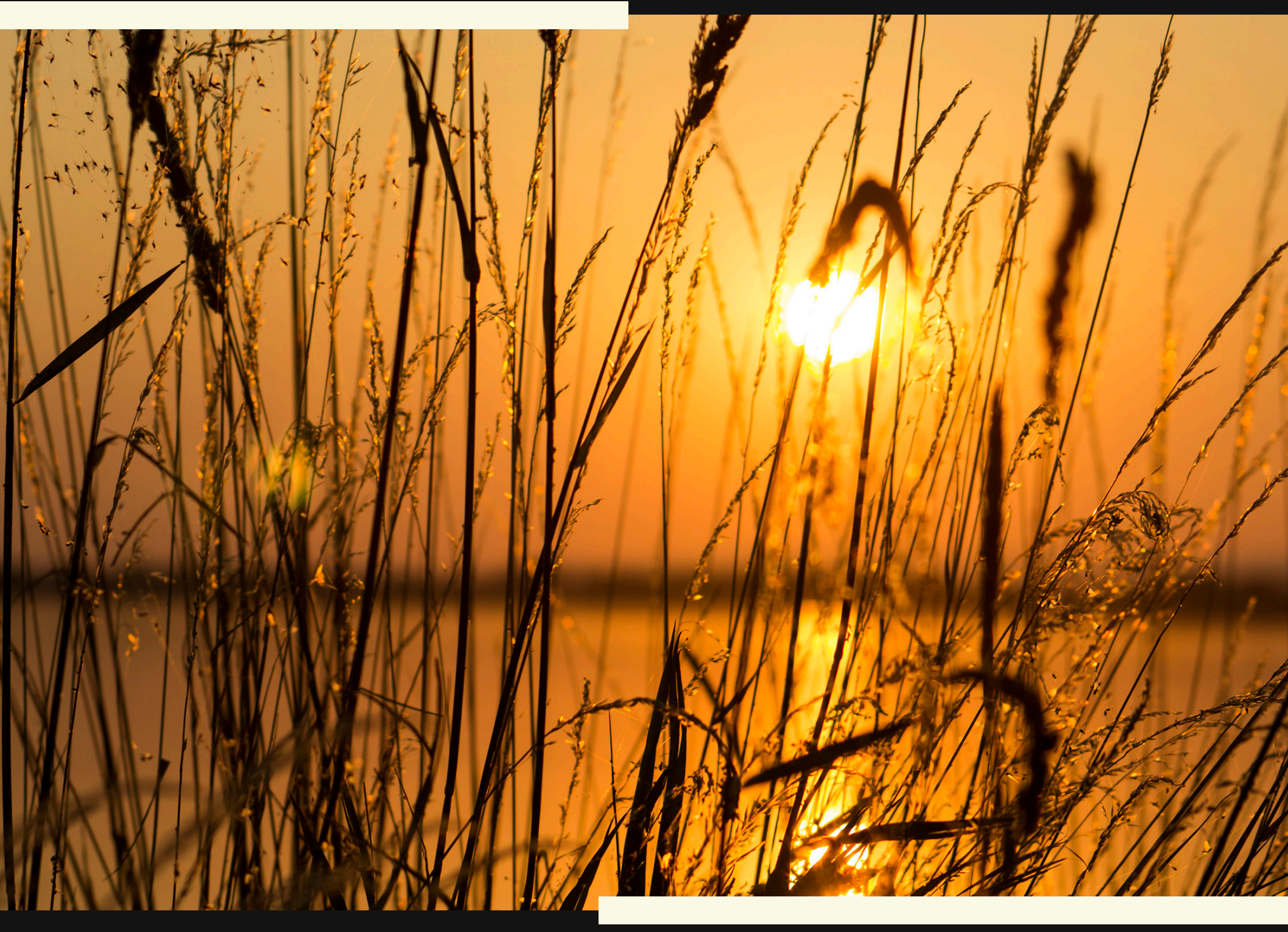





\section{Estudios de desarrollo regional en México}

Francisco Espinoza Morales, Angélica María Rascón Larios,

Francisca Elena Rochín Wong, Georgina Castro Burboa

y Amado Olivares Leal (COORDINADORES) 


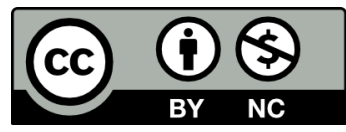

Esta obra está bajo una Licencia Creative Commons Atribución-NoComercial 4.0 Internacional.

https://creativecommons.org/licenses/by-nc/4.0/deed.es

Estudios de desarrollo regional en México

1era. edición, junio 2016.

ISBN 978-607-96359-8-5

DOI 10.29410/QTP.16.04

D.R. () 2016. Qartuppi, S. de R.L. de C.V.

Calle Real 63, Col. Villa Satélite

Hermosillo, Sonora 83200 México

http://www.qartuppi.com

Edición y Diseño: Qartuppi, S. de R.L. de C.V. Fotografía de Portada: León Felipe Irigoyen Morales

Corrección de Estilo: Aline Espíndola Hernández 


\section{Contenido}

\section{Capítulo 1}

Expectativas y percepciones de la calidad en el servicio

de los alumnos de la Licenciatura en Administración

Angélica María Rascón Larios

Francisca Elena Rochín Wong

Georgina Castro Burboa

\section{Capítullo 2}

La ética en las organizaciones para el progreso económico

en el sector comercial de Navojoa

Rosa María Rincón Ornelas

Ma. Teresa González Barajas

Patricia Guadalupe Clark Coronado

\section{Capítulo 3}

La percepción los agricultores del municipio de Benito Juárez, Sonora para implementar un sistema de producción acua-agrícola

Daniel Paredes Zempual

Lizeth Alejandra González Martínez

José Pedro Cabada Jacobo

\section{Capítullo 4}

Factores explicativos de la competitividad en la empresa de manufactura:

caso Navojoa, Sonora

Amado Olivares Leal

José Ángel Coronado Quintana

Josefina Ochoa Ruiz 
Metodología para la planeación de huertos familiares en comunidades rurales Manuel Castro Herrera

Alma Elena Salazar Félix

\section{Capítullo 6}

Derecho al acceso a la información, un derecho humano elemental

para hacer efectiva la transparencia

Leticia María Gonzalez Velásquez

Juan José García Ochoa

Modesto Barrón Wilson

\section{Capítulo 7}

Violación del debido proceso legal de los migrantes en México

Alfredo Islas Rodríguez

María del Rosario Molina González

María de Jesús Camargo Pacheco

\section{Capítullo 8}

La relación entre la popularidad de los cibermedios de Colima

y su oferta informativa

Juan Carlos Flores Carrillo

Rodolfo Antonio Mejía Villaseñor

Juan Flores Preciado

\section{Capítulo 9}

Factores de la contaminación del aire, agua, suelo y normas de regulación

María Magdalena Zayas Esquer

Francisco Espinoza Morales

Lidia Amalia Zallas Esquer

\section{Capítulo 10}

Fundamentos para la elaboración de un proyecto de educación ambiental para la sostenibilidad desde el ámbito municipal

Julio César Duarte Ruiz

Lamberto Castro Arce 


\section{Presentación}

Francisco Espinoza Morales

Líder del Cuerpo Académico

Desarrollo Regional y Competitividad

El presente libro es una obra colectiva, bajo la coordinación del Cuerpo Académico Desarrollo Regional y Competitividad de la División de Ciencias Económica y Sociales de la Unidad Regional Sur de la Universidad de Sonora, que busca integrar al debate distintas problemáticas del desarrollo regional, pero sobre todo planteando soluciones, que permitan avanzar en el análisis y en las respuestas inmediatas.

En esta obra, integrada por diez capítulos, se abordan diferentes temas relacionados al desarrollo regional en México.

Angélica María Rascón Larios, Francisca Elena Rochín Wong y Georgina Castro Burboa en su capítulo Expectativas y percepciones de la calidad en el servicio de los alumnos de la Licenciatura en Administración, abordan un tema de creciente interés para las instituciones educativas que trabajan por lograr y mantener sus procesos en una mejora continua. El Estudio busca promover una cultura de evaluación permanente que de soporte a la toma de decisiones con miras a optimizar el servicio al alumnado.

Rosa María Rincón Ornelas, Ma. Teresa González Barajas y Patricia Guadalupe Clark Coronado en su capítulo La ética en las organizaciones para el progreso económico en el sector comercial de Navojoa, sostienen que las empresas hoy en día deben tener una postura ética, firme y diferente a décadas anteriores, contar con una actitud positiva y ocuparse de que sus acciones sean las correctas en tiempo y forma para salir adelante enfrentando las diferentes turbulencias que se presentan ante la competitividad de los mercados globales; señalan la importancia de hacer las cosas bien y con actuación ética en la diversidad de actividades que se realizan dentro de las organizaciones, ya que éstas operan con personas y para personas racionales y libres. 
Daniel Paredes Zempual, Lizeth Alejandra González Martínez y José Pedro Cabada Jacobo en su contribución a esta obra, La percepción los agricultores del municipio de Benito Juárez, Sonora para implementar un sistema de producción acua-agrícola, señalan que los agronegocios en el siglo XXI son un motor de la economía a nivel mundial y la agricultura es uno de los pilares de la economía en Mexico. Actualmente existen métodos de cultivo que tienen la ventaja de no utilizar fertilizantes, contribuyendo al cuidado del medio ambiente, por tal motivo es importante considerar su implementación en el sector.

Amado Olivares Leal, José Ángel Coronado Quintana y Josefina Ochoa Ruiz, en el capítulo Factores explicativos de la competitividad en las empresas de manufactura: caso $\mathrm{Na}$ vojoa, Sonora, señalan que México en la década actual ha experimentado pérdida de competitividad, y en particular la industria en el estado de Sonora; por este motivo es de vital importancia descubrir las razones de tal situación, planteando como objetivo determinar las variables que miden la competitividad en las empresas y cuantificar el índice de competitividad empresarial en las pequeñas y medianas empresas (PYMES) en el municipio de Navojoa, Sonora.

Manuel Castro Herrera y Alma Elena Salazar Félix en su capítulo Metodología para la planeación de huertos familiares en comunidades rurales realizan una propuesta tendiente a resolver la problemática de desarrollo social y económico de las comunidades rurales del sur del municipio de Benito Juárez, Sonora.

Leticia María González Velásquez, Juan José García Ochoa y Modesto Barrón Wilson en su capítulo Derecho al acceso a la información, un derecho humano elemental para hacer efectiva la transparencia, dicen que entender el derecho al acceso a la información es generar un valor humano, interesarse por los actos gubernamentales y generar una democracia participativa. En nuestro país se hace un gran esmero por ser los impulsores de la transparencia a nivel internacional, generando mecanismos de acceso a la información por medios electrónicos que facilitan a los usuarios obtener información gubernamental.

Alfredo Islas Rodríguez, María del Rosario Molina González y María de Jesús Camargo Pacheco, en su capítulo Violación del debido proceso legal de los migrantes en México, contextualizan un principio jurídico procesal según el cual toda persona tiene derecho a ciertas garantías mínimas tendientes a asegurar un resultado justo y equitativo dentro de un proceso, implícito en ello permitir a todas las personas la oportunidad de ser oídas y hacer valer sus pretensiones frente a un juez o autoridad administrativa imparcial, acogido al criterio universal y progresivo de los derechos humanos y en la condición personal.

Juan Carlos Flores Carrillo, Rodolfo Antonio Mejía Villaseñor y Juan Flores Preciado en su capítulo La relación entre la popularidad de los cibermedios de Colima y su oferta informativa, parten de cuestionar qué hace un cibermedio para hacer diferencia ante una gran diversidad de opciones que tiene el lector; describen algunos puntos teóricos relacionados con el reconocimiento y la popularidad de los cibermedios; y contrastan los resultados que tienen los medios digitales de Colima respecto al ranking que establece el sitio Alexa.com, uno de los más utilizados para medir el tráfico de los cibermedios a nivel nacional, utilizado como referente en el ofrecimiento de publicidad a los anunciantes. 
Magdalena Zayas Esquer, Francisco Espinoza Morales Francisco y Lidia Amalia Zallas Esquer en su capítulo Factores de la contaminación del aire, agua, suelo y normas de regulación comentan que la contaminación atmosférica es un problema del crecimiento industrial y poblacional, señalando que la contaminación de los suelos, agua y atmósfera causa cada vez mayor preocupación entre los ambientalistas, debido al riesgo de gran consideración provocando principalmente impacto en la salud humana y ocasionando grandes desastres ecológicos.

Julio César Duarte Ruiz y Lamberto Castro Arce en su capítulo Fundamentos para la elaboración de un proyecto de educación ambiental para la sostenibilidad desde el ámbito municipal, señalan que se ha escrito mucho acerca de la importancia de la educación ambiental (EA) y el desarrollo sostenible en el mundo; lo cual no es ninguna novedad en México, aunque su implementación ha sido limitada por la falta de políticas públicas impulsoras de programas educativos que contemplen la instrucción sobre el cuidado y el aprovechamiento de los recursos naturales, en el marco de un proyecto gubernamental de desarrollo sostenible que inicie desde el ámbito local.

Esta obra en su conjunto presenta un panorama diverso y complejo, que constituye un esfuerzo teórico empírico por aportar elementos de análisis a las diferentes problemáticas expuestas, así como soluciones prácticas e inmediatas. 


\section{Capítulo 1}

\section{Expectativas y percepciones de la calidad en el servicio de los alumnos de la Licenciatura en Administración}

Angélica María Rascón Larios Francisca Elena Rochín Wong

Georgina Castro Burboa

Universidad de Sonora 


\section{Introducción}

La satisfacción de las necesidades del cliente, es un tema que para muchas organizaciones ha tomado relevancia en los últimos tiempos; para el caso de las instituciones educativas de nivel superior la satisfacción de necesidades del estudiantado ha llevado a la adopción de medidas como la observancia a los criterios de calidad exigidos por organismos externos pero primordialmente con la intención de cumplir con las expectativas que los alumnos tienen de su escuela.

Los gobiernos exigen acciones dirigidas a mejorar y preservar la calidad; por lo que la implementación de proyectos de evaluación institucional, es un fiel reflejo de lo que actualmente están reclamando los sistemas sociales; estas demandas son atribuídas a diferentes causas (González, 2004):

a) La competitividad económica: la educación superior es una pieza clave para afrontar el futuro, como fuente de crecimiento económico, de desarrollo tecnológico y, en consecuencia, de mejora de la competitividad.

b) La exigencia de calidad de los ciudadanos en todos los procesos productivos y en los servicios.

c) La creciente exigencia de calidad por parte de los empleadores respecto al nivel de formación recibida, por lo que la búsqueda de empleo obliga a los universitarios a elevar sus niveles de calidad de la formación impartida.

d) El elevado gasto total, público o privado, de la educación origina en la sociedad una mayor preocupación por controlar la calidad de los servicios que proporcionan las universidades.

Por su parte, Universidad de Sonora (UNISON) interesada por mantenerse a la vanguardia y seguir refrendando su imagen como máxima casa de estudios de la entidad, trabaja arduamente para alcanzar los niveles de calidad exigidos a través de su Sistema de Gestión de Calidad (SGC), razón por la cual se están certificando las diversas áreas y procesos que la conforman.

La política de calidad de la UNISON se enfoca a proporcionar servicios que satisfagan las necesidades de la comunidad universitaria, para el cumplimiento de las funciones de docencia, investigación y extensión, sustentada en personal competente y en la mejora continua de la eficacia del Sistema de Gestión de Calidad (Universidad de Sonora, 2012).

En la Unidad Regional Sur, dos son los procesos del SGC que se dirigen directamente en el campus: la prestación de servicios bibliotecarios y la inscripción del primer ingreso; ésta última bajo la responsabilidad de la Subdirección de Servicios Escolares (SSE), que se somete a evaluación cada año cuando se presenta el proceso de inscripción del primer ingreso; sin embargo, la evaluación que se hace únicamente involucra a los estudiantes nuevos; es decir, considerando que esta subdirección atiende a un gran número de estudiantes, el objetivo es conocer las expectativas que los alumnos reinscritos de la Licenciatura en Administración (estudiantes del segundo al noveno semestre) tienen acerca de la calidad en los servicios que debe de ofrecer una institución de excelencia y compararlos 
con las percepciones que se tienen de esta área en estudio y con base en los resultados identificar brechas para establecer áreas de oportunidad.

\section{Planteamiento del problema}

La SSE de la Unidad Sur, atiende a todos los estudiantes adscritos al campus; brinda servicios como expedición de documentos: constancia con materias, constancias sin materias, constancia especial, kardex, certificado de estudios, certificado de pasante; trámites ante control escolar: equivalencia de materias, conmutación de materias, certificación de documentos académicos, examen con derecho a pasante, examen extraordinario especial, impresión de estado de cuenta; entre otros. Tal atención se les ofrece con la mejor intención de refrendar día a día su compromiso con el estudiantado.

Por lo anterior, resulta conveniente conocer la evaluación emitida a esta subdirección respecto a la calidad en el servicio brindado.

En esta ocasión, el planteamiento se dirigió a los alumnos de la Licenciatura en Administración: ¿Cuáles son las brechas entre las expectativas y percepciones que los alumnos reinscritos de la Licenciatura en Administración (estudiantes del segundo al noveno semestre) tienen acerca de los servicios que reciben de la SSE?

Se estima que los resultados de la investigación permitirían a la SSE determinar los aspectos positivos y negativos, según la impresión de la figura más importante y razón de ser para la universidad: sus alumnos.

\section{Revisión teórica}

La calidad puede ser conceptualizada como sigue:

1. La Norma ISO 8402 define calidad como el conjunto de características de una entidad, que le confieren la aptitud para satisfacer las necesidades establecidas y las implícitas (Miranda, Chamorro y Rubio, 2007).

2. La totalidad de propiedades y características de un producto o servicio que efectúan su capacidad de satisfacer una necesidad dada (Groocok, 1993).

3. El cumplimiento de los requisitos (Hay, 2002).

Otras definiciones de calidad son aportadas por Edward Deming y Philip Crosby; el primer autor la definía como "cero defectos", que implica que la calidad es lo que queda cuando se han eliminado todos los problemas; sin embargo, este concepto no se aplica a los servicios por una de sus características conocida como variabilidad, por lo que se considera de mayor aplicación la definición de Philip Crosby: "conformidad a las especificaciones" (Kotler, 2004, p. 49); es decir, el servicio de calidad se ofrece conforme a las especificaciones solicitadas por el cliente.

Para Águila (2005), la calidad en la educación, hasta comienzos de la década de los sesenta, presuponía la calidad de la enseñanza y el aprendizaje como constitutivos del sistema, se basaba ante todo en la tradición de la institución, en la exclusividad de profesores, en los alumnos y en los recursos materiales. El sistema educativo universitario era 
una suerte de "caja negra"; lo que sucedía en su interior no era objeto de análisis ni por el Estado ni por la sociedad. La universidad era la única guardiana, poseedora y transmisora de los conocimientos. La sociedad asumía que eso era bueno.

Shargel (1997, citado en Caballero, 2002) señala que existen un conjunto de dificultades que acechan a la implantación de la calidad en educación y que a continuación se enumeran (P. 191):

1. Las escuelas no controlan sus propios recursos.

2. La educación no es considerada como algo valiosos por parte de algunos de los clientes.

3. Los centros escolares tienen escaso control sobre las circunstancias externas que inciden en los mismos.

4. Presupuesto insuficiente para educación.

5. El centro no establece sus propios objetivos.

6. Con frecuencia la sociedad no valora la educación.

7. No se ha sentido la necesidad del cambio.

8. Mentalidad de monopolio en el funcionamiento del centro.

9. Formación del profesorado fuera del centro.

10. Rotación anual de clientes.

11. La misión olvidada.

Miquel et al. (1995, citado en Camisón, Gil y Roca, 1999) expresan la necesidad de determinar la calidad de un servicio público administrativo (como el caso de la UNISON), basándose no sólo en indicadores objetivos (elemento formal), sino también subjetivos (análisis de la calidad percibida por el cliente).

Para estos autores la eficacia de las administraciones públicas es un término complicado que posee, al menos, dos dimensiones: la interna y la externa. Además de los tradicionales mecanismos de medición de eficacia interna (coste de recursos utilizados para alcanzar cierta calidad percibida), un enfoque integrador de la productividad requiere una medición externa de la misma, que refleje la satisfacción del cliente y la calidad percibida (eficacia externa). Esta consideración de la calidad de servicio está basada en las expectativas subjetivas del cliente, las cuales constituyen una de las claves para comprender el nuevo modelo de gestión denominado calidad de servicios. (Camisón, Gil y Roca, 1999, p. 72)

Estos autores manifiestan como modelos utilizados para medir la calidad en los servicios universitario: el Modelo de la Imagen (Grönroos, 1984), el Modelo de los Gaps o deficiencias (Parasuraman, Zeithaml y Berry, 1985) y el Modelo SERVPERF desarrollado por Cronin y Taylor (1992).

De acuerdo al Modelo de Gaps existen cuatro deficiencias que constituyen las causas más importantes de las deficiencias en la calidad de los servicios tal y como la perciben los 
clientes. Para facilitar la discusión de las diferentes deficiencias, se denominó a la percibida por los clientes en la calidad en los servicios como la Deficiencia 5 y las que se producen internamente en las organizaciones proveedoras de servicio como las Deficiencias 1 a la 4.

A continuación, se analizan cada una las cuatro deficiencias de los proveedores del servicio que contribuyen a la presencia de la Deficiencia 5.

\section{Gap 1}

Discrepancia entre las expectativas de los usuarios y las percepciones de los directivos. Cuando los directivos de más alto nivel, que ostentan la autoridad y la responsabilidad para asignar las prioridades, no comprenden realmente las expectativas de servicios de los usuarios, pueden provocar el inicio de una cadena de malas decisiones y uso poco eficiente de los recursos, lo que provoca una percepción de baja calidad en los servicios.

El resultado final es que esta deficiente comprensión por parte de los directivos de las expectativas y preocupaciones auténticas de los usuarios, con mucha probabilidad provocarán que el servicio que se presta no satisfaga plenamente sus expectativas. El primer e imprescindible paso en el perfeccionamiento de la calidad de los servicios consiste en que la dirección de la empresa adquiera suficiente información sobre las expectativas de los usuarios que les permita disminuir las discrepancias ocasionadas por la Deficiencia 1.

\section{Gap 2}

Discrepancia entre las percepciones de los directivos y las especificaciones o normas de calidad. Cuando no existen normas estándar para la prestación o cuando las normas que se aplican no reflejan las expectativas del consumidor es muy probable que la percepción de calidad se incremente. En consecuencia, disminuir la dimensión de la Deficiencia 2 estableciendo normas que responden a las expectativas de los clientes debe producir un impacto favorable en las percepciones que tienen los usuarios sobre la calidad del servicio (Deficiencia 5).

\section{Gap 3}

Discrepancia entre las especificaciones de la calidad del servicio y la prestación del servicio. El hecho de que existan las guías para alcanzar un buen nivel de servicio y un trato correcto a los usuarios no asegura la alta calidad en la prestación de un servicio. Una deficiente prestación del servicio puede tener su origen en una amplia variedad de limitaciones (por ejemplo, empleados no suficientemente capacitados, insuficiente capacidad para dar el servicio). Para ser efectivas, las normas estándar no sólo deben reflejar las expectativas del consumidor, sino que también deben estar apoyados por recursos adecuados y apropiados (personal, sistema, tecnología). Además, para que las normas sean efectivas deberán establecerse los mecanismos que aseguren su cumplimiento, es decir, la actuación de los empleados debe ser medida y compensada con base al cumplimiento de esas normas. Cuando la prestación del servicio no cumpla con las normas (Deficiencia 3), tampoco cumplirá con las expectativas de los usuarios respecto a la calidad del servicio. 


\section{Gap 4}

Discrepancia entre la prestación del servicio y la comunicación externa. Las comunicaciones externas pueden no sólo afectar a las expectativas del usuario sobre el servicio en sí, sino, además su percepción sobre la prestación del servicio mismo. La discrepancia entre la prestación de un servicio y las comunicaciones externas que se hacen sobre ella afectan negativamente la evaluación que hacen los clientes sobre la calidad del servicio. La Deficiencia 4 refleja, en esencia, una ruptura fundamental en la coordinación que debe existir entre los responsables de prestar el servicio y los responsables de describirlo y/o promocionarlo. Coordinar eficazmente las características reales de la prestación del servicio con la comunicación externa reducirá la Deficiencia 4 y, en consecuencia, también afectará positivamente a la Deficiencia 5.

Este modelo constituye el resultado del análisis sistemático de las evaluaciones realizadas en varios sectores del servicio y conforman una representación precisa de los criterios que utilizan los usuarios para evaluar la calidad de los servicios y que a continuación se definen (Zeithaml, Parasuraman y Berry, 1993):

- Elementos tangibles. Apariencia de las instalaciones físicas, equipos, personal y materiales de comunicación.

- Fiabilidad. Habilidad para realizar el servicio prometido de forma fiable y cuidadosa.

- Capacidad de respuesta. Disposición y voluntad para ayudar a los usuarios y proporcionar un servicio rápido.

- Seguridad. Conocimiento y atención mostrados por los empleados y sus habilidades para inspirar credibilidad y confianza.

- Empatía. Atención individualizada que ofrecen las empresas a sus consumidores.

\section{Metodología}

Los alcances de esta investigación se definieron considerando las propuestas metodológicas planteadas por Hernández, Fernández y Baptista (2000), donde explican que los estudios descriptivos se centran en medir con la mayor precisión posible, diversos aspectos, dimensiones o componentes del fenómeno a investigar; además de ser un estudio transversal en relación a la temporalidad (Bernal, 2010). En este caso, se examinaron los datos para contrastar las expectativas y percepción de los estudiantes de la licenciatura de Administración, por lo que este estudio se consideró el más apropiado; además, se definió la categoría "no experimental" pues se realiza sin manipular deliberadamente las variables y se observan los fenómenos tal cual se dan en su contexto natural para después analizarlos (Hernández, Fernández y Baptista, 2000, p. 184).

Se trabajó con el muestreo probabilístico compuesto por 97 estudiantes de Administración participantes en el estudio.

Para la recopilación de la información, se retomaron las preguntas de los cuestionarios de percepciones y de expectativas propuestos por Zeithaml, Parasuraman y Berry (1993) para medir la calidad en el servicio al cliente denominado Servqual, ambos constituidos 
por 22 declaraciones agrupadas en función de los cinco criterios, tal como se muestra a continuación:

Tabla 1. Declaraciones correspondientes al criterio.

\begin{tabular}{|l|l|}
\hline \multicolumn{1}{|c|}{$\begin{array}{c}\text { Criterio } \\
\text { (dimensiones de la calidad en el servicio) }\end{array}$} & \multicolumn{1}{c|}{$\begin{array}{c}\text { Declaraciones } \\
\text { correspondientes al criterio }\end{array}$} \\
\hline Elementos tangibles & Declaraciones 1 a 4 \\
\hline Fiabilidad & Declaraciones 5 a 9 \\
\hline Capacidad de respuesta & Declaraciones 10 a 13 \\
\hline Seguridad & Declaraciones 14 a 17 \\
\hline Empatía & Declaraciones 18 a 22 \\
\hline
\end{tabular}

En ambos cuestionarios el formato de respuesta fue ponderado del 1 al 5 en donde:

1. Estoy en total desacuerdo con esta aseveración.

2. Estoy en desacuerdo con esta aseveración.

3. No estoy ni de acuerdo ni en desacuerdo con esta aseveración.

4. Estoy de acuerdo con esta aseveración.

5. Estoy totalmente de acuerdo con esta aseveración.

Se realizó el análisis de brechas a través de la diferencia entre las medias de las expectativas por carrera, menos las percepciones de los estudiantes en cada una de las aseveraciones planteadas por Sevqual; finalmente se elaboró la base de datos y usando el paquete computacional Statistical Package For de Social Sciences (SPSS) se realizaron análisis estadísticos (Castañeda, Cabrera, Navarro y De Vries, 2010); también se apoyó con tablas y gráficos en Excel.

\section{Presentación y discusión de resultados}

Se muestra a continuación las brechas resultantes al contrastar las expectativas con las percepciones: 
Tabla 2. Diferencia entre las expectativas y percepciones de los alumnos de la Licenciatura en Administración.

\begin{tabular}{|c|c|c|c|c|c|c|}
\hline$\#$ & Expectativas & $\mathbf{N}$ & $\begin{array}{c}\text { Media } \\
\text { de las } \\
\text { expectativas }\end{array}$ & Percepciones & $\begin{array}{c}\text { Media } \\
\text { de las } \\
\text { percepciones }\end{array}$ & Brecha \\
\hline 1 & $\begin{array}{l}\text { Las instituciones educa- } \\
\text { tivas excelentes tienen } \\
\text { equipo de apariencia } \\
\text { moderna. }\end{array}$ & 97 & 4,93 & $\begin{array}{l}\text { El equipo con que } \\
\text { cuenta el Departa- } \\
\text { mento de Servicios Es- } \\
\text { colares tiene aparien- } \\
\text { cia de ser moderno. }\end{array}$ & 3,28 & $-1,65$ \\
\hline 2 & $\begin{array}{l}\text { Las instalaciones físicas } \\
\text { de las instituciones edu- } \\
\text { cativas excelentes son } \\
\text { visualmente atractivas. }\end{array}$ & 97 & 5,00 & $\begin{array}{l}\text { Las instalaciones } \\
\text { físicas donde se ubica } \\
\text { el Departamento de } \\
\text { Servicios Escolares } \\
\text { son visualmente } \\
\text { atractivas. }\end{array}$ & 3,38 & $-1,62$ \\
\hline 3 & $\begin{array}{l}\text { Los empleados de las } \\
\text { instituciones educativas } \\
\text { excelentes tienen una } \\
\text { apariencia pulcra. }\end{array}$ & 97 & 5,00 & $\begin{array}{l}\text { Los empleados del } \\
\text { Departamento de Ser- } \\
\text { vicios Escolares tienen } \\
\text { una apariencia pulcra. }\end{array}$ & 3,67 & $-1,33$ \\
\hline 4 & $\begin{array}{l}\text { En una institución } \\
\text { educativa excelente los } \\
\text { elementos materiales } \\
\text { relacionados con el ser- } \\
\text { vicio (folletos, recibos, } \\
\text { entre otros) son visual- } \\
\text { mente atractivos. }\end{array}$ & 97 & 3,06 & $\begin{array}{l}\text { Los materiales relacio- } \\
\text { nados con el servicio } \\
\text { que utiliza el Depto. } \\
\text { de Servicios Escolares } \\
\text { (kardex, constancias, } \\
\text { entre otros) son vi- } \\
\text { sualmente adecuados. }\end{array}$ & 4,10 & 1,04 \\
\hline 5 & $\begin{array}{l}\text { Cuando las instituciones } \\
\text { educativas excelentes } \\
\text { prometen algo en de- } \\
\text { terminado tiempo, lo } \\
\text { hacen. }\end{array}$ & 97 & 5,00 & $\begin{array}{l}\text { Cuando en el Depto. } \\
\text { de Servicios Escola- } \\
\text { res promete algo en } \\
\text { determinado tiempo, } \\
\text { lo hace. }\end{array}$ & 3,42 & $-1,58$ \\
\hline 6 & $\begin{array}{l}\text { Cuando un cliente tiene } \\
\text { un problema las ins- } \\
\text { tituciones educativas } \\
\text { excelentes muestran un } \\
\text { sincero interés en solu- } \\
\text { cionarlo. }\end{array}$ & 97 & 5,00 & $\begin{array}{l}\text { Cuando tienes un } \\
\text { problema que tenga } \\
\text { que ser resuelto por } \\
\text { el Departamento de } \\
\text { Servicios Escolares, } \\
\text { muestran un sincero } \\
\text { interés en solucionar- } \\
\text { lo. }\end{array}$ & 3,52 & $-1,48$ \\
\hline
\end{tabular}


Tabla 2. Diferencia entre las expectativas y percepciones de los alumnos de la Licenciatura en Administración (continuación).

\begin{tabular}{|c|c|c|c|c|c|c|}
\hline$\#$ & Expectativas & $\mathbf{N}$ & $\begin{array}{c}\text { Media } \\
\text { de las } \\
\text { expectativas }\end{array}$ & Percepciones & $\begin{array}{c}\text { Media } \\
\text { de las } \\
\text { percepciones }\end{array}$ & Brecha \\
\hline 7 & $\begin{array}{l}\text { Las instituciones educa- } \\
\text { tivas excelentes realizan } \\
\text { bien el servicio desde la } \\
\text { primera vez. }\end{array}$ & 97 & 5,00 & $\begin{array}{l}\text { En el Departamento } \\
\text { de Servicios Esco- } \\
\text { lares realizan bien } \\
\text { el servicio desde la } \\
\text { primera vez. }\end{array}$ & 3,47 & $-1,53$ \\
\hline 8 & $\begin{array}{l}\text { Las instituciones educa- } \\
\text { tivas excelentes con- } \\
\text { cluyen el servicio en el } \\
\text { tiempo prometido. }\end{array}$ & 97 & 5,00 & $\begin{array}{l}\text { En el Departamento } \\
\text { de Servicios Esco- } \\
\text { lares terminan el } \\
\text { servicio en el tiem- } \\
\text { po que prometen } \\
\text { hacerlo. }\end{array}$ & 3,60 & $-1,40$ \\
\hline 9 & $\begin{array}{l}\text { Las instituciones educa- } \\
\text { tivas excelentes insisten } \\
\text { en mantener sus regis- } \\
\text { tros exentos de errores. }\end{array}$ & 97 & 5,00 & $\begin{array}{l}\text { En el Depto. de Ser- } \\
\text { vicios Escolares se } \\
\text { preocupan por man- } \\
\text { tener sus registros } \\
\text { exentos de errores. }\end{array}$ & 3,55 & $-1,45$ \\
\hline 10 & $\begin{array}{l}\text { En una institución } \\
\text { educativa excelente los } \\
\text { empleados comunican } \\
\text { a los clientes cuando } \\
\text { concluirán la realización } \\
\text { del servicio. }\end{array}$ & 97 & 4,38 & $\begin{array}{l}\text { Los empleados del } \\
\text { Departamento de } \\
\text { Servicios Escolares } \\
\text { te informan con } \\
\text { precisión cuando } \\
\text { concluirán cada } \\
\text { servicio. }\end{array}$ & 3,37 & $-1 ., 01$ \\
\hline 11 & $\begin{array}{l}\text { En una institución } \\
\text { educativa excelente los } \\
\text { empleados ofrecen un } \\
\text { servicio rápido a sus } \\
\text { clientes }\end{array}$ & 97 & 5,00 & $\begin{array}{l}\text { Los empleados del } \\
\text { Departamento de } \\
\text { Servicios Escolares } \\
\text { te sirven con rapi- } \\
\text { dez. }\end{array}$ & 3,39 & $-1,61$ \\
\hline 12 & $\begin{array}{l}\text { En una institución edu- } \\
\text { cativa excelente los em- } \\
\text { pleados siempre están } \\
\text { dispuestos a ayudar a los } \\
\text { clientes. }\end{array}$ & 97 & 5,00 & $\begin{array}{l}\text { Los empleados del } \\
\text { Departamento de } \\
\text { Servicios Escolares } \\
\text { siempre se mues- } \\
\text { tran dispuestos a } \\
\text { ayudarte. }\end{array}$ & 3,62 & $-1,38$ \\
\hline
\end{tabular}


Tabla 2. Diferencia entre las expectativas y percepciones de los alumnos de la Licenciatura en Administración (continuación).

\begin{tabular}{|c|c|c|c|c|c|c|}
\hline$\#$ & Expectativas & $\mathbf{N}$ & $\begin{array}{c}\text { Media } \\
\text { de las } \\
\text { expectativas }\end{array}$ & Percepciones & $\begin{array}{c}\text { Media } \\
\text { de las } \\
\text { percepciones } \\
\end{array}$ & Brecha \\
\hline 13 & $\begin{array}{l}\text { En una institución } \\
\text { educativa excelente los } \\
\text { empleados nunca están } \\
\text { demasiado ocupados } \\
\text { para responder a las pre- } \\
\text { guntas de los clientes. }\end{array}$ & 97 & 5,00 & $\begin{array}{l}\text { Los empleados del } \\
\text { Departamento de } \\
\text { Servicios Escolares } \\
\text { nunca están de- } \\
\text { masiado ocupados } \\
\text { para responder a tus } \\
\text { preguntas. }\end{array}$ & 3,41 & $-1,59$ \\
\hline 14 & $\begin{array}{l}\text { El comportamiento de } \\
\text { los empleados de una } \\
\text { institución educativa } \\
\text { excelente trasmiten con- } \\
\text { fianza a sus clientes. }\end{array}$ & 97 & 5,00 & $\begin{array}{l}\text { El comportamiento } \\
\text { de los empleados del } \\
\text { Depto. de Servicios } \\
\text { Escolares te trasmite } \\
\text { confianza. }\end{array}$ & 3,48 & $-1,52$ \\
\hline 15 & $\begin{array}{l}\text { Los clientes de las ins- } \\
\text { tituciones educativas } \\
\text { excelentes se sienten se- } \\
\text { guro con sus transaccio- } \\
\text { nes con la organización. }\end{array}$ & 97 & 5,00 & $\begin{array}{l}\text { Te sientes seguro } \\
\text { con tus transaccio- } \\
\text { nes con el Departa- } \\
\text { mento de Servicios } \\
\text { Escolares. }\end{array}$ & 3,71 & $-1,29$ \\
\hline 16 & $\begin{array}{l}\text { En una institución } \\
\text { educativa excelente los } \\
\text { empleados son siempre } \\
\text { amables con los clientes. }\end{array}$ & 97 & 5,00 & $\begin{array}{l}\text { Los empleados del } \\
\text { Departamento de } \\
\text { Servicios Escolares } \\
\text { son siempre amables } \\
\text { contigo. }\end{array}$ & 3,63 & $-1,37$ \\
\hline 17 & $\begin{array}{l}\text { En una institución } \\
\text { educativa excelente los } \\
\text { empleados tienen cono- } \\
\text { cimiento suficiente para } \\
\text { responder las preguntas } \\
\text { de los clientes. }\end{array}$ & 97 & 5,00 & $\begin{array}{l}\text { Los empleados del } \\
\text { Depto. de Servicios } \\
\text { Escolares tienen co- } \\
\text { nocimiento suficien- } \\
\text { te para contestarte } \\
\text { las preguntas que les } \\
\text { haces. }\end{array}$ & 3,64 & $-1,36$ \\
\hline 18 & $\begin{array}{l}\text { Las instituciones edu- } \\
\text { cativas excelentes dan a } \\
\text { sus clientes una aten- } \\
\text { ción individualizada. }\end{array}$ & 97 & 5,00 & $\begin{array}{l}\text { En el Departamento } \\
\text { de Servicios Escola- } \\
\text { res te dan una aten- } \\
\text { ción individualizada. }\end{array}$ & 3,52 & $-1,48$ \\
\hline
\end{tabular}


Tabla 2. Diferencia entre las expectativas y percepciones de los alumnos de la Licenciatura en Administración (continuación).

\begin{tabular}{|l|l|c|c|c|c|c|}
\hline \# & \multicolumn{1}{|c|}{ Expectativas } & $\mathbf{N}$ & \multicolumn{1}{|c|}{$\begin{array}{c}\text { Media } \\
\text { de las } \\
\text { expectativas }\end{array}$} & \multicolumn{1}{|c|}{ Percepciones } & $\begin{array}{c}\text { Media } \\
\text { de las } \\
\text { percepciones }\end{array}$ & Brecha \\
\hline $\begin{array}{l}\text { Las instituciones educa- } \\
\text { tivas excelentes tienen } \\
\text { un horario de trabajo } \\
\text { conveniente para todo } \\
\text { los clientes. }\end{array}$ & 97 & 5,00 & $\begin{array}{l}\text { En el Departamento } \\
\text { de Servicios Escola- } \\
\text { res tienen un hora- } \\
\text { rio de trabajo conve- } \\
\text { niente para todo los } \\
\text { alumnos. }\end{array}$ & 3,40 & $-1,60$ \\
\hline 20 & $\begin{array}{l}\text { Una institución edu- } \\
\text { cativa excelente tiene } \\
\text { empleados que dan una } \\
\text { atención personalizada } \\
\text { a sus clientes. }\end{array}$ & 97 & 5,00 & $\begin{array}{l}\text { Los empleados del } \\
\text { Departamento de } \\
\text { Servicios Escolares } \\
\text { te dan una atención } \\
\text { personalizada. }\end{array}$ & 3,54 & $-1,46$ \\
\hline $\begin{array}{l}\text { Las instituciones edu- } \\
\text { cativas excelentes se } \\
\text { preocupan por los } \\
\text { mejores intereses de sus } \\
\text { clientes. }\end{array}$ & 97 & 5,00 & $\begin{array}{l}\text { En el Depto. de } \\
\text { Servicios Escolares } \\
\text { se preocupan por tus } \\
\text { mejores intereses. }\end{array}$ & 3,43 & $-1,57$ \\
\hline $\begin{array}{l}\text { Los empleados de las } \\
\text { instituciones educativas } \\
\text { excelentes comprenden } \\
\text { las necesidades específi- } \\
\text { cas de sus clientes. }\end{array}$ & 97 & 5,00 & $\begin{array}{l}\text { Los empleados del } \\
\text { Depto. de Servicios } \\
\text { Escolares compren- } \\
\text { den tus necesidades } \\
\text { específicas. }\end{array}$ & 3,58 & $-1,42$ \\
\hline
\end{tabular}

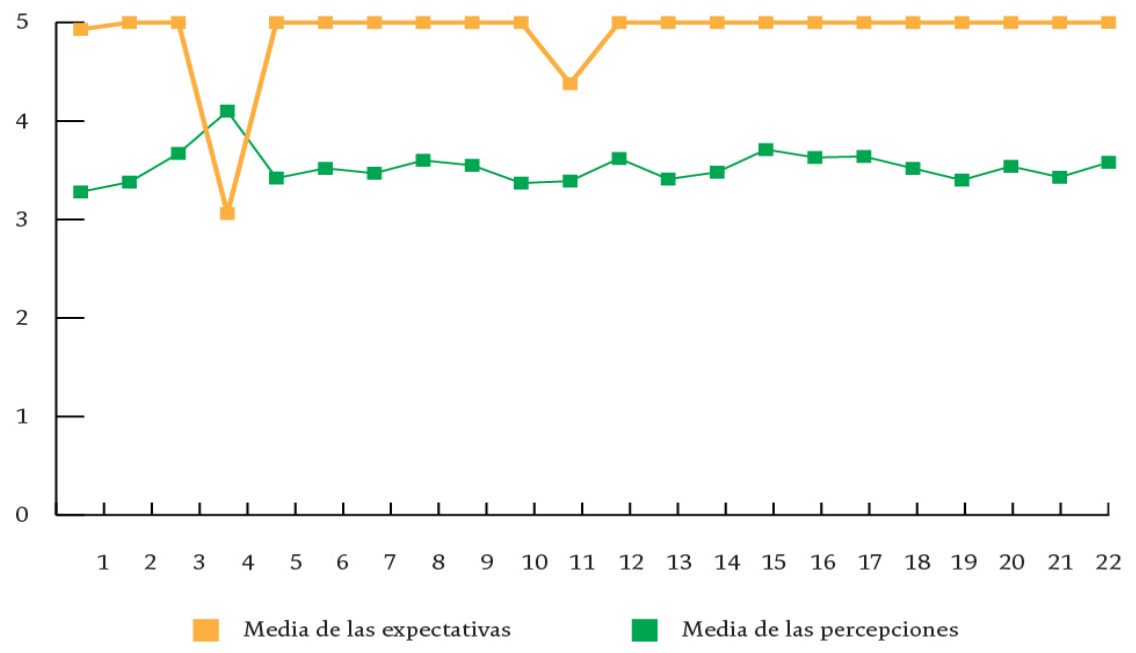

Figura 1. Comparativo de expectativas y percepciones por cada aseveración. 
Tabla 3. Promedios de las percepciones por dimensión de los alumnos de la Licenciatura en Administración.

\begin{tabular}{|l|c|c|c|c|c|}
\hline $\begin{array}{l}\text { Licenciatura en } \\
\text { Administración }\end{array}$ & $\begin{array}{c}\text { Elementos } \\
\text { tangibles } \\
(\mathbf{1 - 4 )}\end{array}$ & $\begin{array}{c}\text { Fiabilidad } \\
\mathbf{( 5 - 9 )}\end{array}$ & $\begin{array}{c}\text { Capacidad } \\
\text { de respuesta } \\
\mathbf{( 1 0 - 1 3 )}\end{array}$ & $\begin{array}{c}\text { Seguridad } \\
\mathbf{( 1 4 - 1 7 )}\end{array}$ & $\begin{array}{c}\text { Empatía } \\
\mathbf{( 1 8 - 2 2 )}\end{array}$ \\
\hline $\begin{array}{l}\text { Promedio de las } \\
\text { percepciones }\end{array}$ & 3,6 & 3,51 & 3,44 & 3,61 & 3,49 \\
\hline $\begin{array}{l}\text { Promedio por } \\
\text { carrera }\end{array}$ & 3,53 & \multicolumn{5}{|l}{} \\
\cline { 1 - 5 }
\end{tabular}

Tabla 4. Promedios de las expectativas por dimensión de los alumnos de la Licenciatura en Administración.

\begin{tabular}{|l|c|c|c|c|c|}
\hline $\begin{array}{l}\text { Licenciatura en } \\
\text { Administración }\end{array}$ & $\begin{array}{c}\text { Elementos } \\
\text { tangibles } \\
(\mathbf{1 - 4 )}\end{array}$ & $\begin{array}{c}\text { Fiabilidad } \\
\mathbf{( 5 - 9 )}\end{array}$ & $\begin{array}{c}\text { Capacidad } \\
\text { de respuesta } \\
\mathbf{( 1 0 - 1 3 )}\end{array}$ & $\begin{array}{c}\text { Seguridad } \\
\mathbf{( 1 4 - 1 7 )}\end{array}$ & $\begin{array}{c}\text { Empatía } \\
\mathbf{( 1 8 - 2 2 )}\end{array}$ \\
\hline $\begin{array}{l}\text { Promedio de las } \\
\text { expectativas }\end{array}$ & 4,49 & 5 & 4,84 & 5 & 5 \\
\hline $\begin{array}{l}\text { Promedio por } \\
\text { carrera }\end{array}$ & 4,86 & \multicolumn{5}{|l}{} \\
\cline { 1 - 5 }
\end{tabular}

Tabla 5. Promedios de las brechas por dimensión de la Licenciatura en Administración.

\begin{tabular}{|l|c|c|c|c|c|}
\hline $\begin{array}{l}\text { Licenciatura en } \\
\text { Administración }\end{array}$ & $\begin{array}{c}\text { Elementos } \\
\text { tangibles } \\
(\mathbf{1 - 4 )}\end{array}$ & $\begin{array}{c}\text { Fiabilidad } \\
\mathbf{( 5 - 9 )}\end{array}$ & $\begin{array}{c}\text { Capacidad } \\
\text { de respuesta } \\
\mathbf{( 1 0 - 1 3 )}\end{array}$ & $\begin{array}{c}\text { Seguridad } \\
\mathbf{( 1 4 - 1 7 )}\end{array}$ & $\begin{array}{c}\text { Empatía } \\
\mathbf{( 1 8 - 2 2 )}\end{array}$ \\
\hline $\begin{array}{l}\text { Promedio de las } \\
\text { brechas }\end{array}$ & $-0,89$ & $-1,48$ & $-1,39$ & $-1,38$ & $-1,50$ \\
\hline $\begin{array}{l}\text { Promedio por } \\
\text { carrera }\end{array}$ & $-1,32$ & \multicolumn{4}{|l}{} \\
\cline { 1 - 5 }
\end{tabular}




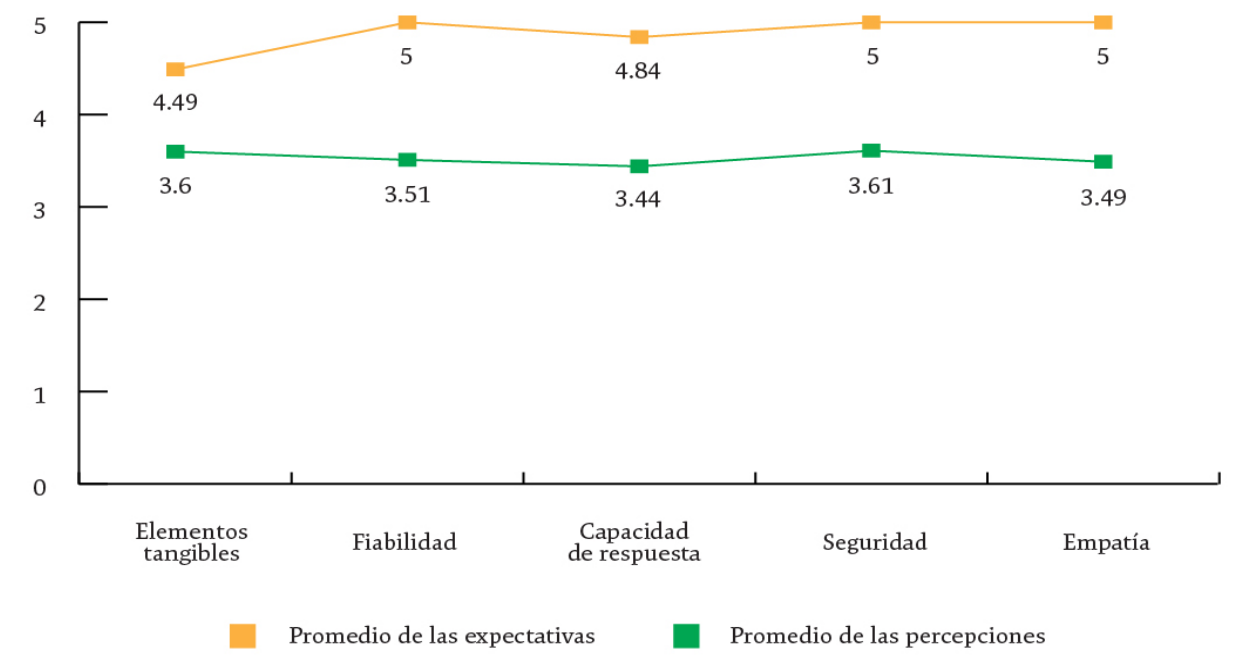

Figura 2. Comparativo de promedios de las expectativas y percepciones de los alumnos de la Licenciatura en Administración.

\section{Conclusiones}

Respecto a los resultados específicos del estudio realizado para la SSE de la Unidad Regional Sur de la UNISON, se concluye que la apreciación que los estudiantes de la Licenciatura en Administración tienen acerca de la calidad en el servicio es buena; indicando una calificación positiva para las dimisiones: elementos tangibles, fiabilidad, capacidad de respuesta, seguridad y empatía.

Pese a que el resultado fue bueno para cada dimensión, existen brechas como producto de la diferencia entre el grado de percepción que resultó menor que el nivel de expectativas que todos los estudiantes dieron a la calidad en el servicio.

Las brechas con mayor amplitud se registraron en aspectos como la apariencia del equipo, instalaciones y de los empleados, la rapidez y el cumplimiento en tiempo de los servicios, así como la disposición para responder a sus preguntas, dar una atención individualizada, preocuparse por sus mejores intereses, tratar de satisfacer sus necesidades y el establecimiento de horarios pertinentes.

La única brecha positiva para los alumnos resultó en la aseveración relativa a los materiales que se usan en el servicio como los kardex, certificados, constancias, etc. que para la mayor parte de ellos no representó una expectativa alta.

Obtener brechas negativas, es un indicador de la necesidad de mejorar la calidad en el servicio que la SSE ofrece a los estudiantes de la Licenciatura en Administración en todas las dimensiones, resultando ser áreas de oportunidad para la mejora continua de la Subdirección de Servicios Escolares. 


\section{Referencias bibliográficas}

Águila, V. (2005). El concepto: calidad en la educación universitaria, clave para el logro de la competitividad institucional. OEI-Revista Iberoamericana de Educación - De los lectores, 35(5).

Bernal, C. (2010). Metodología de la investigación. Colombia: Pearson.

Caballero, J. (2002). Calidad y satisfacción del cliente en las instituciones de formación. Enseñanza, 20, pp. 175-197.

Camisón, C., Gil, M.T., \& Roca, V. (1999). Hacia modelos de calidad de servicio orientados al cliente en las universidades públicas: el caso de la Universitat Jaume I. Investigaciones Europeas de Dirección y Economía de la empresa, 5(2), pp.69-92. Recuperado de http:// www.aedem-virtual.com/articulos/iedee/v05/052069.pdf

Castañeda, M., Cabrera, L., Navarro, Y., \& De Vries, W. (2010). Procesamiento de datos y análisis estadístico utilizado en SPSS. Porto Alegre: ediPUCR.

Cronin, J., \& Taylor, S. (1992). SERVPERF Versus SERVQUAL: Reconciling Performancebased and Perceptions - Minus - Expectations Measurement of Service Quality. Journal of Marketing, 58, pp.125-131.

González, I. (2004). Calidad en la Universidad: Evaluación e indicadores. Salamanca: Universidad de Salamanca.

Groocok, J. (1993). La cadena de la calidad. México: Diaz de Santos.

Hay, E. (2002). Justo a tiempo: La técnica japonesa que genera mayor ventaja competitiva. Bogotá: Norma.

Hernández R., Fernández, C., \& Baptista, P. (2010). Metodología de la investigación. Ciudad de México: McGraw-Hill.

Kotler, P.E. (2004). El Marketing de servicios profesionales. España: Paidos.

Miranda, F., Chamorro, A., \& Rubio, S. (2007). Introducción a la gestión de la calidad. Madrid: Delta publicaciones.

Parasuraman, A., Zeithaml, V., \& Berry, L. (1985). A Conceptual Model of Service Quality and Its Implications for Future Research. Journal of Marketing, 49, pp. 41-50.

Universidad de Sonora. (Enero de 2012). Política de Calidad. Recuperado de http://www. sga.uson.mx/sgc.htm

Zeithaml, V., Parasuraman, A.; \& Berry, L. (1993). Total en la Gestión del Servicio. España: Diaz de Santos. 
26 Estudios de desarrollo regional en México 


\title{
Capítulo 2
}

\section{La ética en las organizaciones para el progreso económico en el sector comercial de Navojoa}

\author{
Rosa María Rincón Ornelas \\ Ma. Teresa González Barajas \\ Patricia Guadalupe Clark Coronado
}

Universidad de Sonora 


\section{Introducción}

El fin del siglo XX fue testigo, entre otras cosas, del surgimiento de una serie de discursos en torno a la ética empresarial y a la responsabilidad de las organizaciones. Estos discursos han sido acompañados por el nacimiento de distintos organismos "independientes" a nivel mundial, cuyo propósito central es el de fomentar en las empresas un comportamiento ético y responsable (Crespo, 2003).

Esta investigación surge por la necesidad de conocer los beneficios de la ética en las organizaciones para el progreso económico del sector comercial de Navojoa, Sonora, México.

Adela Cortina, de quien se puede decir, al menos en el mundo del habla hispana, que es la máxima representante y promotora de la ética empresarial, ha realizado varias investigaciones importantes como "Ética Comunicativa en concepción de la ética" (1992), "Ética sin Moral" (2000), "Ética de las Empresas" (1994), en donde deja ver la importancia del tema a tratar.

\section{Planteamiento del Problema}

Hoy en día, las empresas mexicanas se ven integradas a un entorno de mayor competitividad debido a la globalización y a la apertura de los mercados en el mundo, por lo cual los sectores productivos en México, deben de actuar de una manera firme y decidida a ser competitivo.

La ética en las organizaciones debe estar presente, no aislarse de ella como se percibe en algunas empresas, se debe operar en la diversidad de acciones que se realicen en toda la estructura organizacional que se tiene. Es favorable la práctica de la ética en los quehaceres para que se dé la competitividad con fluidez para el beneficio interno y externo de toda organización comercial de Navojoa, Sonora.

Trabajar con ética es una necesidad y es viable, queriendo hacer las cosas bien, con actitud positiva, apegándose a la normatividad con la voluntad, con la armonía de hacer lo que se quiere y se dice, haciéndolo de una buena manera en la organización se puede contagiar a los empleados, directivos, socios y proveedores entre otros, facilitando el mandato y duplicando esfuerzos de las personas que se suman a esta encomienda, cosechando frutos favorecedores para la entidad económica donde se trabaja y para quienes se tiene contacto. Aguilera, González y Rodríguez (2011) dicen que las estrategias orientan las decisiones y permiten que los planes operativos se realicen de forma concurrente al logro de los objetivos de la empresa con la finalidad de incrementar las posibilidades de cumplimiento de objetivos y metas.

La ética en la empresa es un tema que preocupa cada vez más a directivos y académicos. Sin ella se puede ganar a corto plazo, pero una empresa guiada por principios poco éticos no perdurará en el mercado actual (Ruiz y Ruiz, 2011).

Por lo tanto la presente investigación pretende responder al siguiente cuestionamiento: ¿Cuáles son los beneficios de la ética en el desarrollo de las empresas? 


\section{Justificación}

La ética es una acción importante, la cual se debe de dar constantemente en la vida cotidiana y en su existencia permite pensar y analizar sobre la moral, el surgimiento y los efectos de los valores. La ética orienta el buen comportamiento del ser humano, originándose como uno de los efectos positivos en el progreso económico en el sector comercial.

La empresa es una institución relevante para la sociedad, con capacidades propias no sólo para producir bienes o servicios, sino para participar en la edificación de la comunidad (Paladino, Debeljuh y del Bosco, 2005).

La exigencia social no siempre coincide con la exigencia ética, y no sólo porque puedan existir exigencias sociales poco éticas, sino también porque las empresas que cuentan con políticas de Responsabilidad Social Empresarial (RSE) no necesariamente se comportan siempre con calidad ética (Bañón-Gómis, Guillén-Parra y Ramos-López, 2011).

Al presentarse la ética en una organización, beneficia a quien está participando o tiene relación alguna con ella y a la sociedad misma.

El ser humano libre y racional ha buscado determinar su comportamiento identificando lo que está bien y lo que está mal, con el objeto de actuar bajo los principios esenciales de convivencia y dentro de un marco aceptado por la sociedad en la época que se vive. El objeto material de la ciencia ética reside en la acción humana, es fácilmente comprensible que toda propuesta ética debe tener como sustento un modelo básico de hombre y, sobre todo, de su forma de comportarse y tomar decisiones (Rodríguez y Aguilera, 2005).

La reflexión sobre la ética en la empresa ha sido prolífera desde los años setenta, incidió con la reivindicación de la necesidad de pasar de las palabras a los hechos. Esta necesidad de institucionalizar y hacer operativa toda esa reflexión en la praxis empresarial se concretó principalmente en el desarrollo de códigos de éticos y otros documentos de autocontrol, los cuales tienen el objetivo fundamental de mejorar la actuación ética de las personas en la organización y así generar mayor legitimidad social y una cultura corporativa coherente (Soto y Cárdenas, 2007).

La presente investigación servirá de apoyo a los empresarios de la región y beneficiará a los trabajadores y a la sociedad. Se considera que el comercio que se realiza en las empresas éticas trae beneficios, como se ilustra en la Figura 1.

\section{Organizaciones Éticas}

\section{Progreso Económico}

Beneficio a la Sociedad

Figura 1. Beneficios de las empresas éticas. Fuente: Elaboración propia. 
Las organizaciones resultan de la aplicación de la racionalidad a la actividad social humana. Son sistemas relativamente tardíos en la historia de la humanidad que surgen cuando es posible generalizar la motivación (Rodríguez, 2005). Por lo tanto una organización ética, crea confianza en los clientes y se deciden a realizar operaciones en ellas, acarreando beneficios al aumentarse las utilidades, así como en el pago de contribuciones por el lado de la misma entidad económica por lo cual el beneficio también lo percibe la sociedad misma.

\section{Objetivos}

\section{Objetivo General}

- Conocer los beneficios de la ética en el desarrollo de las empresas.

\section{Objetivos específicos}

- Identificar los hábitos en el desarrollo humano para tomar medidas.

- Identificar factores que benefician el desarrollo de las empresas.

\section{Marco Teórico}

\section{Ética}

La ética se entiende como un cuerpo de conceptos filosóficos, un grupo de principios que involucra los comportamientos humanos (correctos e incorrectos), el mundo espiritual y la vida diaria. El objetivo de la ética es el mejoramiento de la existencia humana, y para ello se tiene en cuenta que las personas viven en sociedad, dentro de un entorno. Por lo tanto, de acuerdo a Rodríguez y Bustamante (2008), la ética influye la responsabilidad por los efectos de nuestros actos y en el medio ambiente.

Barradas y Ortiz (2012) dicen que:

Por ética entendemos a la ciencia que estudia la moral, es decir, el conjunto de valores morales o moralidad de una época, de una cultura o bajo un determinado contexto; el campo de la ética es, entonces, la moralidad. Por valor moral, aquel principio o norma que rige el comportamiento moral de la sociedad; comportamiento o conducta moral es aquella actitud o hecho no coercitivo sino libre y voluntario, que beneficia o perjudica a un tercero, a un con junto de personas, a una sociedad entera, o, incluso, al mundo mismo. (P. 1)

Se puede decir que la ética es el arte de vivir bien en sociedad, como arte no admite declaraciones y sus teorías no son un compendio de recetas para alcanzar el bien del ser humano, sino que busca, en esencia, un fin que va más allá de la materialización y que persigue el desarrollo integral de la persona como ser humano que convive con otros seres en toda sociedad. Se puede rescatar que al analizar una empresa el funcionamiento depende del comportamiento que tienen sus dirigentes, directivos, y/o sus propios líderes. 
En décadas atrás se realizaban negocios efímeros, con gran éxitos pero por corto tiempo, y lo que se requiriere es de negocios perdurables, que se organicen bien para permanecer en el mercado. Existiendo diversos factores que intervienen en el comportamiento ético de las organizaciones.

Existe la creencia en algunos directivos de que la principal finalidad de la ética en las organizaciones es cambiar las conductas de los individuos, y no reflexionan en que lo que realmente hace la ética es mejorar las decisiones en lo que se refiere a los grupos (Soto y Cárdenas, 2007).

A veces, se piensa que hablar de ética de los negocios es una contradicción, porque hay incompatibilidad implícita entre la moral y la búsqueda egoísta del lucro. Cuando la ética entra en conflicto con el lucro, se aduce, los negocios siempre prefieren el lucro a lo ético; sin embargo, al menos a largo o mediano plazo, puede existir un conflicto inherente entre el comportamiento ético y la búsqueda del lucro. (Barradas y Ortiz, 2012, p. 2)

\section{Clima ético}

El clima ético organizacional define la organización en sus relaciones internas y externas, y le permea como un todo. A través de las declaraciones, de la misión, de los códigos de ética y las políticas sobre asuntos particulares es que se articula el clima ético, afectando así las actitudes y actividades de las personas de la organización (Arango, 2011).

\section{Líder Ético}

El papel del "líder" empresarial, no es por tanto el de decidir si una empresa será ética o no (es decir, si tendrá un ethos -carácter- o no), en todo caso lo que pueden, $y$ deben hacer los líderes empresariales, es orientar ese comportamiento para que sea moral. (Crespo,2003, p. 310)

En toda organización, el liderazgo, es indispensable, debe estar presente de la mejor manera, en armonía con los ideales de los dueños, accionistas y empleados, así como con los objetivos y metas trazadas. Se debe de ser líder de la mejor manera, considerando las diferentes necesidades que se pueden presentar en el quehacer normal, pudiéndose presentar situaciones en donde no se sepa qué hacer o no se cuente con el conocimiento necesario, reconocerlo y ocuparse de ello. Pudiendo tomar decisiones de reconocer y solicitar ayuda o asesorías para poder actuar de la mejor manera.

El liderazgo, por esta razón, constituye una fuente de poder adicional, que se produce en las relaciones humanas al interior de la organización, pero que resiste ser planificado. El liderazgo puede consistir en un importante factor dentro de la organización y, muchas veces, puede oponerse al poder formal. Las organizaciones tratan habitualmente de conseguir domesticar el liderazgo, utilizando así toda su fuerza tras los fines y objetivos 
formalmente establecidos. El conocimiento de las fuentes, mecanismos y formas de operar del liderazgo en una organización es, entonces, fundamental tanto para buscar hacerlo coincidente con los objetivos organizacionales, como para reconocer los eventuales obstáculos que este liderazgo puede ofrecer al logro de dichos objetivos (Rodríguez, 2005).

\section{Documentación indispensable para la presencia de la ética en las organizaciones}

Para que esté presente la ética en las organizaciones es conveniente que se trabaje en ello, que se realicen algunas acciones o se plasme la forma como se deben realizar las actividades de la empresa para cumplir con la misión deseada al igual que las metas trazadas. Se requiere la presencia de documentación formal que contenga: filosofía de la empresa, declaración de valores, conductas reguladas con normas, código de ética y una estructura organizacional bien definida.

Tabla 1. Documentación formal requerida para la presencia de la ética en las organizaciones.

\begin{tabular}{|c|l|}
\hline$\square$ & Filosofía de la empresa \\
\hline$\square$ & Declaración de valores \\
\hline$\square$ & Conductas reguladas con normas \\
\hline$\square$ & Código de ética \\
\hline$\square$ & Estructura organizacional bien definida y distribuida \\
\hline
\end{tabular}

Fuente: Elaboración propia.

Código de ética

"[...] la incorporación de un código ético supondría el establecimiento formal de los principios corporativos de la compañía que afectan a la responsabilidad con empleados, accionistas, consumidores, al entorno o a cualquier otro aspecto de la sociedad" (García, Rodríguez y Gallardo, 2008, p. 93).

\section{Organización}

La organización siendo un grupo de individuos y medios establecidos con un fin determinado, que toma decisiones, se apoya en el recurso humano y en la diversidad de recursos que puede utilizar para realizar sus actividades. Realiza cambios en beneficio de ella misma y encausándose al desarrollo económico.

La relación entre los seres humanos genera procesos psicosociales -tanto de grupos como individuales- que contribuyen a modificar el devenir organizacional, incluso más, 
constituyen parte de él. El análisis organizacional deberá, por consiguiente, indicar cuál es la situación de la organización, cómo se relacionan los individuos y los grupos, y qué potencialidades pueden ser explotadas, así como cuáles son las dificultades que enfrenta el sistema organizacional (Rodríguez, 2005).

Las organizaciones se han reestructurado en los últimos tiempos, y su posición es importante como elementos principales de generación de progreso y desarrollo, por lo que es necesario que en este siglo que apenas comienza desempeñen un papel de mayor responsabilidad social (Soto y Cárdenas, 2007).

Las organizaciones ejercen su responsabilidad social cuando satisfacen las expectativas que sobre su comportamiento tienen los diferentes grupos de interés. En términos prácticos, esto supone la formalización de políticas y sistemas de gestión en ámbitos como los siguientes: relaciones con accionistas, relaciones con empleados, relaciones con la comunidad y acción social, gestión ambiental, relaciones con clientes, y la extensión de estas políticas a la cadena de abastecimiento, todo ello integrado con la estrategia global de la empresa. Por lo tanto, se trata de un concepto normativo que tiene que ver con la conducta humana y las políticas que las empresas deben adoptar.

De acuerdo a Rodríguez (2005):

Las configuraciones organizacionales se caracterizan por una identidad que no puede quedar capturada en términos generalizadores. Las particularidades propias de cada organización, las premisas del decidir organizacional, los modos acostumbrados de conceptualizar el trabajo, la verdad, lo bueno, etc., son características centrales del quehacer organizacional y lo constituyen como un quehacer con identidad propia. También la cultura de la sociedad en que está inserta la organización debe ser considerada, dado que ella permitirá, dificultará o, incluso, impedirá modos concretos de relación organizacional. En esta medida, el estudio de la cultura y el de las relaciones organización-ambiente son muy cercanos. (P. 62)

En esta categoría Rodríguez (2005, p. 62) considera:

i. Mitos acerca del trabajo, definición de lo que es trabajo, definición de un buen o un mal trabajador.

ii. Creencias acerca de las relaciones laborales, cuáles deberían ser y cuáles son las relaciones de trabajo en esta organización.

iii. Creencias acerca de los plazos, corto o largo plazo.

iv. Héroes y villanos, personas que han marcado un estilo en la organización.

v. Héroes anónimos: ¿Cuál es el hombre-símbolo, el esforzado, el valiente, en esta organización?

vi. Valores compartidos, sistema normativo, grado de consenso respecto a las normas, características de la organización ideal.

vii. Estilo de vida inducido por la organización, contradicciones con el estilo de vida deseado y con el estilo de vida propio de la sociedad. 
Todas las organizaciones, lo sepan o no, cuentan con unos estándares éticos más o menos programados, que son inherentes a sus culturas, sistemas y procesos organizativos (Brenner, 1992 citado en Bañon-Gómis et al., 2011).

Las organizaciones o empresas éticamente excelentes serían aquellas que entienden la ética en sentido de calidad humana integral, de excelencia moral, aquellas que "se esfuerzan permanentemente por contribuir al pleno desarrollo humano de todos sus miembros, de todas las personas implicadas en el logro de su misión y de todos los afectados por su actividad" (Guillén, 2006 citado en Bañón-Gómis et al., 2011).

\section{Estructura}

El propósito de la estructura de la organización es reunir a la persona y al trabajo de una manera armoniosa. Según Hodgetts y Altman (1993), cuando se conoce la estructura organizacional se debe estar capacitado para:

1. Identificar las características básicas de una burocracia ideal.

2. Explicar el efecto de la teoría Universal de diseño en las estructuras de la organización moderna.

3. Relacionar la importancia de las descripciones del puesto de trabajo en el diseño de la organización

4. Describir las formas básicas de departamentalización.

5. Analizar el efecto del tramo de control de la estructura.

6. Especificar algunas de las maneras de determinar un tramo de control óptimo.

7. Relacionar efectos estructurales y conductuales de la descentralización.

De acuerdo a Rodríguez (2005, pp. 62-63):

Bajo este encabezado se agrupan variables que habitualmente son entregadas como información. Se trata devariables quepermiten visualizar el perfil de la organización.

1. Descripción de los miembros de la organización, en términos de edad, sexo, educación, antecedentes laborales, nivel y calidad de capacitación, lugar de residencia.

2. Descripción de la estructura organizacional, organigrama, diagrama de la planta (flujo de trabajo), organización del trabajo, adecuación entre fuerza de trabajo y cantidad de trabajo.

3. Identificación de departamentos y grupos formales de trabajo, tamaño y número de departamentos.

4. Descripción de subunidades; se trata de una organización: funcional, divisional, matricial, híbrida; niveles y pesos relativos de la línea y el staff. 
De acuerdo a Crespo (2003):

[...] lo que brinda unidad a la "estructura moral" de las empresas es, valga la redundancia, su estructura para la toma de decisiones. En efecto, dado que las organizaciones tienen una estructura para tomar decisiones colectivas, tienen que tomar una conciencia sobre los valores y metas que deben orientar esas decisiones, ello le permitirá ir formándose una identidad. Además tiene que hacerse responsable de dichas decisiones y de sus consecuencias. (Pp. 312-313)

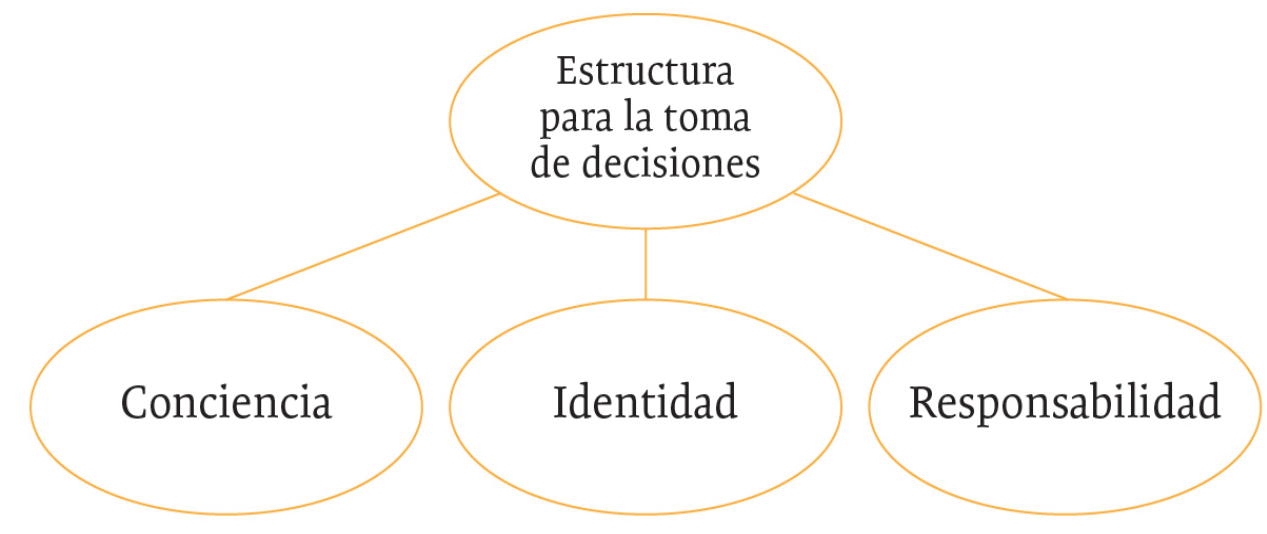

Figura 2. "Estructura moral" de las empresas.

Fuente: Crespo, 2003.

\section{Progreso económico, los negocios y la ética}

El progreso siempre se debe de buscar y trabajar para conseguirlo, se considera que nunca se debe de culminar con el progreso mismo.

$\mathrm{Al}$ referirnos al progreso económico es mejorar en lo concerniente al dinero, bienes tangibles, a los activos que poseemos, entre otros.

Por otro lado, el comercio ha formado parte importante del desarrollo económico de Sonora, y su papel dentro de este proceso ha sido de integrador de los mercados entre las ciudades del estado, y el ámbito regional, nacional e internacional, al representar el eslabón necesario para el intercambio de mercancías entre productos y consumidores individuales. En la década de los ochenta y noventa, la actividad comercial continuó con la misma tendencia de acoplamiento a las actividades económicas, pero con una variante, el gran inversionista comercial que marcó nuevas pautas de consumo, ya no es el empresario local, sino el extranjero, que trajo consigo una serie de innovaciones tecnológicas, administrativas, organizacionales y laborales, que transformaron la vida al detalle (Bocanegra, 2008).

Friedman y Savage (1998 citados en Soto y Cárdenas, 2007) argumentaron que existen por lo menos cuatro modelos para explicar la relación entre la ética y los negocios: 
1. Si se toma en cuenta que los directivos de alto nivel son agentes o funcionarios de los accionistas propietarios de la empresa, la función única del directivo es aumentar el valor de la acción incrementando el valor de la organización.

2. El directivo utiliza un proceso de razonamiento moral para la toma de decisiones de la gestión empresarial. Tomando en cuenta que en este modelo la moralidad se considera intrínsecamente buena y como un fin más que un medio, en un conflicto entre generación de riqueza y moralidad.

3. La ética constituye un veto moral obligatorio sobre el imperativo de generar riqueza u obtener utilidades. Así, los negocios no generan obligaciones morales que superen las del directivo como persona.

4. La conducta ética en los negocios se fundamenta en conciliar los derechos de los grupos de interés, basada en estándares de justicia distributiva.

Es conveniente que en toda organización se cuente con una formalidad en sus acciones para un progreso económico basado en la ética, para lo cual se pueden basar en sus normas establecidas para que se cumpla con la razón de ser.

Es conveniente ofrecer en todo proyecto a realizar en las organizaciones un plan de trabajo, que señale los plazos dentro de los cuales se realizará el trabajo o los trabajos como puede ser el diagnóstico y los de sus diversas etapas. Es recomendable utilizar aquí tiempos medidos en semanas y meses, dejándose además la necesaria flexibilidad para posibles cambios y postergaciones no predecibles anticipadamente (Rodríguez, 2005).

El comercio es una de las actividades más antiguas en la historia del hombre. Si bien éste comenzó con el trueque de bienes para la supervivencia diaria, con el transcurso de los siglos ha alcanzado un alto grado de complejidad, expresado, entre otras cosas, en el tipo y volumen de mercancías que se intercambian, así como las características de los establecimientos en los cuales se lleva a cabo el proceso de oferta-demanda (Bocanegra,2010). Platón, el filósofo, consideraba al comercio una actividad peligrosa para la moral, y denotaba:

[...] si el ciudadano debe abstenerse tanto de la artesanía como del comercio, es sólo por la superioridad que respecto a esas dos actividades presentan la búsqueda de la virtud y el arte de gobernar; de las que se deberán ocupar exclusivamente los ciudadanos...todas las especies de revendedores, traficantes y posaderos son mal vistos. (Platón, citado en Tozzi, 1968, p. 83)

Platón consideraba que las personas dedicadas a estas actividades deberían ser extranjeros, dado que era una actividad propia de ciudadanos con una escasa moral: "Nadie, se vuelve comerciante al menudeo ni mercader al por mayor, ni preste servicio alguno a personas privadas, quienquiera que desee ejercer la profesión de revendedor debe ser extranjero, el comercio era actividad exclusiva de los extranjeros" (Platón, citado en Tozzi, 1968). 
En México se tiene una economía muy lastimada, con una crisis financiera arrastrada desde administraciones gubernamentales de sexenios anteriores; en algunos han sido demasiado graves las acciones que se han dado y que han repercutido hasta tiempos actuales, afectando a los ciudadanos por el desequilibrio que se tiene en los ingresos y egresos que se perciben para llevar a cabo una vida normal.

En Sonora los inversionistas comerciales eran locales y regionales. Mismos que obtenían sus mercancías principalmente del interior del país (Bocanegra, 2008). Actualmente se puede decir que los comerciantes sonorenses no precisamente adquieren sus productos para vender del interior; sino que debido a la globalización y apertura comercial se ha podido ingresar a otros mercados y, aún con la lejanía, se presenta como buena opción sin dañar agresivamente los costos.

El comercio se puede clasificar en comercio minorista y mayorista. El comercio minorista en el Estado de Sonora se encuentra cada vez más diversificado, tanto en capital de origen como en tipos de establecimientos. Estos cambios son la expresión de movimientos en la dinámica comercial mundial, nacional y regional, que han permitido que el comerciante de la localidad se vaya adecuando a este nuevo ritmo (Bocanegra, 2010).

La mayoría de las empresas pequeñas se dedican a la actividad comercial y aún aquellas que se dedican a la actividad de la transformación de sus productos se dedican a la actividad comercial; son ellas mismas las que se encargan de comercializar los productos que elaboran, logrando con ello un mayor acercamiento con sus consumidores.

Las nuevas formas de ofrecer las mercancías, con publicidad en precios bajos, mediante diferentes formatos como folletos, prensa, radio, televisión e internet; la gran diversidad de productos fabricados en diversos países y ofrecidos en los mercados locales, innovados en lapsos no mayores a tres meses; la infraestructura cada vez más sofisticada en cuanto a anaqueles, pasillos, cajas registradoras más rápidas y con menos margen de error; la reducción total de bodegas y sus inventarios, así como el control total de la mercancía desde que sale del proceso productivo hasta que es adquirida por el consumidor final, entre otros, son cambios que se observan en las grandes cadenas comerciales a nivel mundial y que en Sonora se producen con sus homólogas de igual manera (Bocanegra, 2010).

Se puede decir que:

[...] sobrevivir en el mercado no ha sido tarea fácil para las empresas del comercio moderno. Hacerlo implica innovar en sistemas tecnológicos y administrativos, así como en la relación con sus empleados llamados en algunos casos "colaboradores" $y$ en otros "asociados", posibilidad que no todos los agentes de la actividad comercial pueden presumir. (Vázquez, 2008)

De acuerdo a De la Cuesta (2010):

La empresa es un proyecto creado por el ser humano, con y para él mismo. Del resultado agregado del comportamiento social de las empresas va a depender en gran medida el progreso de la sociedad, y, como consecuencia, la legitimidad social de aquéllas. (P. 58) 


\section{Metodología}

La presente investigación es exploratoria y descriptiva, no experimental; se analizó el comportamiento de los empleados y el resultado de sus labores, como los efectos que éstos tendrán. Se ha elegido al sector comercial. Ante las grandes dimensiones que sería el hacer el estudio a nivel nacional, y ante la práctica imposibilidad de acometerlo, se decide acotar la población objeto de estudio a los empleados de las empresas agremiadas a la Cámara Nacional de Comercio (CANACO), dedicadas a la compra-venta de artículos en Navojoa, Sonora; es decir, el comercio al por menor, enfocándonos en empresas con un rango de 6 a 10 empleados, constituyendo un total de 10 empresas las cuales están en el centro comercial de Navojoa, por tal motivo se encuestaron a todas.

\section{Resultados}

De acuerdo a las encuestas que se ejecutaron para obtener información sobre trabajadores de empresas comerciales al por menor en la Ciudad de Navojoa, Sonora, se tienen los siguientes resultados:

Sobre el tiempo laborando, el 50\% tienen una antigüedad menor de un año y el menor porcentaje (10\%) corresponde a trabajadores que tienen antigüedad en el rango de 12 años un mes a 15 años. Concluyendo que la mayoría de los empleados que trabajan en empresas de comercio al por menor tienen menos de un año de antigüedad.

Respecto a la formación, el 40\% tienen el nivel de formación secundaria, el 30\% preparatoria, el 20\% tienen una carrera técnica y sólo el 10\% tienen cursada una carrera de licenciatura.

Otro dato importante que arroja la encuesta es que el $80 \%$ de los trabajadores son de género femenino y solamente un $20 \%$ masculino, de ellos el $60 \%$ son solteros y el resto (40\%) casados y/o en unión libre.

Cuando se les preguntó sobre la percepción que tienen de su gerente o jefe de la empresa opinaron lo siguiente:

- La fuerte preocupación por la ética y la moral, un $80 \%$ estuvo totalmente de acuerdo, un $10 \%$ muy de acuerdo y otro $10 \%$ en desacuerdo.

- Comunica normas éticas claras para los miembros de la empresa, un 60\% totalmente de acuerdo, un $40 \%$ muy de acuerdo.

- Mantiene sus acciones en consonancia con sus valores "hace lo que dice", el 90\% está totalmente de acuerdo y $10 \%$ de acuerdo, es decir, que los gerentes de las empresas al por menor generalmente hace lo que dice.

- Es justo e imparcial en la asignación de tareas a los miembros de la empresa, 80\% totalmente de acuerdo, $10 \%$ muy de acuerdo y $10 \%$ estuvo en desacuerdo.

- Establece un ejemplo de dedicación y sacrificio para la organización, un 70\% estuvo totalmente de acuerdo, $20 \%$ muy de acuerdo y solamente un $10 \%$ en desacuerdo.

- Se opone a la utilización de prácticas poco éticas para aumentar el rendimiento, el $50 \%$ está muy de acuerdo, $40 \%$ está totalmente de acuerdo y un $10 \%$ está muy en desacuerdo. 
- Es justo y objetivo con los empleados cuando evalúa el rendimiento y proporciona recompensas, $70 \%$ totalmente de acuerdo y $20 \%$ muy de acuerdo y $10 \%$ muy en desacuerdo.

- Pide a sus empleados que sean responsables de utilizar prácticas éticas en su trabajo, $90 \%$ totalmente de acuerdo y el $10 \%$ totalmente de acuerdo.

- De los encuestados el 80\% consideró que tenían utilidades para un progreso económico en el sector que se encontraban.

\section{Conclusiones y propuestas}

Después de la aplicación del cuestionario a empleados de empresas del sector comercial agremiados a la CANACO en la ciudad de Navojoa, Sonora, se llegó a la conclusión que las empresas del sector comercio no cuentan con control interno de sus operaciones ni con un código de ética para guiar sus acciones.

Las organizaciones hoy en día deben de tener una postura ética, firme y diferente a décadas atrás. La ética es importante para que los negocios funcionen adecuadamente y se obtengan las ganancias esperadas. Al estar laborando dentro de una empresa, se debe de ser ético, tener una conducta aceptable y respetar los códigos de ética, normas y políticas que exigen en las empresas.

La ética y la cultura son puntos importantes para un buen funcionamiento, no sólo económico sino personal, fortaleciendo sociedades respetuosas entre los trabajadores, clientes, proveedores, empresarios, o la competencia misma.

Se concluye en general que los gerentes en este tipo de empresas en Navojoa sí tienen ética en el desempeño de su labor, de acuerdo a la percepción de los trabajadores de su empresa a cargo. Favoreciendo lo anterior a generar un progreso económico.

\section{Propuestas de acción}

$\mathrm{Al}$ actuar con ética las organizaciones se tienen efectos positivos, reflejándose en el progreso económico. Por lo cual las propuestas de acciones para que las empresas operen con ética son las siguientes:

- Actuar éticamente en las organizaciones porque operan con y para personas.

- Tener un código de ética en la organización.

- Tener con un control interno de la organización.

- Contratar personas íntegras con conductas apegadas a la normatividad legislativa.

- Contratar personas con actitud positiva para realizar tareas, cambios o acciones dentro de las responsabilidades adquiridas por el puesto a desempeñar.

- Realizar reuniones regularmente para analizar situaciones presentadas o experiencias vividas en el trabajo, analizar y reflexionar para un enriquecimiento como persona trabajando en equipo por beneficios comunes y con objetivos definidos dentro de la estructura a la que pertenecen. 


\section{Referencias bibliográficas}

Aguilera, L., González, M., \& Rodríguez, T. (2011). Estrategias empresariales para la competitividad y el crecimiento de las PYMES. Una evidencia empírica. Investigación y Ciencia, 19(53), 39-48.

Arango, G.L. (2011). Clima ético en organizaciones de salud: revisión de la literatura. Colombia. Revista de Bioética, 6(1), pp. 145-164. Recuperado de http://www.redalyc. org/pdf/1892/189219032010.pdf

Bañon-Gómis, A., Guillén-Parra, M., \& Ramos-López, N. (2011). La Empresa Ética y Responsable. Universia Business Review, 30, 32-43. Recuperado de http://www. redalyc.org/articulo.oa?id=43318798003

Barradas, M.R., \& Ortiz, I. (2012). Ética empresarial y responsabilidad social de la empresa familiar. Un caso para reflexionar: Ciudad de Huajuapan de León, Oaxaca. Revista Ciencia Administrativa, 2, pp. 1-10. Recuperado de http://www.uv.mx/iiesca/ files/2013/04/01CA201202.pdf

Bocanegra, C.O. (2008). El comercio en México y su encuentro con la globalización. Hermosillo: Universidad de Sonora

Bocanegra, C.O. (2010). Comercio minorista y tecnologías de la información y comunicación. Hermosillo: Universidad de Sonora

Brenner, S.N. (1992). Ethics Programs and Their Dimensions. Journal of Business Ethics, 11(5-6), pp. 391-399.

Crespo, M.F. (2003). Lo ético de la ética empresarial. Revista Venezolana de Gerencia, 8(22), 307-32. Recuperado de http://www.redalyc.org/pdf/290/29002207.pdf

De la Cuesta, M. (2010). RSC: Una nueva forma de gestión. En I. Saavedra (Coord.). Introducción a la sostenibilidad y a la RSC. La Coruña: Netbiblo.

García, I., Rodríguez, L., \& Gallego, I. (2008). La influencia del consejo de administración en la adopción de un código ético. Revista de Contabilidad, 1(2), pp. 93-120. Recuperado de http://www.redalyc.org/pdf/3597/359733632004.pdf

Hodgetts, R.M., \& Altman, S. (1993). Comportamiento en las organizaciones. Ciudad de México: McGraw-Hill.

Paladino, M., Debeljuh, P., \& Del Bosco, P. (2005). Integridad: respuesta superadora de los dilemas éticos del hombre de empresa. Journal of Economics, Finance and Administrative Science, 10(18-19), 9-37. Recuperado de http://www.redalyc.org/ pdf/3607/360733600001.pdf

Rodríguez, A., \& Aguilera, J.C. (2005). Persona ética y organización: hacia un nuevo paradigma organizacional. Cuadernos de Difusión, 10(18-19), pp.61-77.

Rodríguez,M.P.,\&Bustamante,U.(2008).Desarrollo decompetenciasparaelcomportamiento ético gerencial: un enfoque de responsabilidad. Cuadernos de Administración, 21(35), pp. 205-228. Recuperado de http://www.redalyc.org/pdf/205/20503509.pdf

Rodríguez, D. (2005). Diagnóstico Organizacional. Ciudad de México: Alfaomega. 
Ruiz, P., \& Ruiz, C. (2011). Factores determinantes del comportamiento ético/no ético del empleado: una versión de la literatura. Investigaciones Europeas de Dirección y Economía de la Empresa, 17(3), 29-45. Recuperado de http://www.redalyc.org/ $\mathrm{html} / 2741 / 274120128002 /$

Soto, E., \& Cárdenas, J.A. (2007). Ética en las Organizaciones. Ciudad de México: McGrawHill.

Tozzi, G. (1968). Economistas griegos y romanos. Ciudad de México: Fondo de Cultura Económica.

Vázquez, R.M. (2008). Reseña bibliográfica: El comercio en México y su encuentro con la globalización. El caso Sonora, de Carmen O. Bocanegra Gastélum. Revista Frontera Norte, 22(44), pp. 277-288. Recuperado de https://www.colef.mx/fronteranorte/ articulos/FN44/11-f44.pdf 


\section{Capítulo 3}

\section{La percepción de los agricultores del municipio de Benito Juárez, Sonora para implementar un sistema de producción acua-agrícola}

Daniel Paredes Zempual Lizeth Alejandra González Martínez José Pedro Cabada Jacobo

Universidad Estatal de Sonora 
44 Estudios de desarrollo regional en México 


\section{Introducción}

Los agronegocios en el siglo XXI son un motor de la economía a nivel mundial en los diferentes países que poseen la geografía para poder desarrollar esta actividad; este sector es determinante en México, debido a que aporta 3.1\% del PIB según SAGARPA (2014), y en el estado de Sonora el 5.8\%.

El agronegocio tiene como finalidad identificar actores, procesos, relaciones y efectos socioeconómicos de la agricultura, la ganadería, la pesca, la porcicultura, ente otras actividades del sector primario, donde se deben de desarrollar estrategias para el fomento del comercio nacional e internacional (Villagómez, Mora, Barradas y Vázquez, 2014).

Por lo tanto, la agricultura es uno de los pilares de la economía en México y en el estado de Sonora, por ello es importante ir diversificando los métodos de producción en el sector agrícola; actualmente se cuentan con alternativas que benefician los sistemas de producción de manera económica para los agricultores y ambientalmente para la sociedad.

Se puede decir que la agricultura es la principal actividad económica en el Municipio de Benito Juárez ubicado en el Sur de Sonora, ya que generan 3,411 empleos que representan el 64 por ciento de la población ocupada.

Esta actividad se desarrolla en una superficie de 24,360 hectáreas, de las cuales el tipo de tenencia corresponde al sector ejidal 9,744 hectáreas, pequeños propietarios 13,398 hectáreas, colonos 1,218 hectáreas, los principales cultivos agrícolas son trigo, maíz y hortalizas (INAFED, 2010).

Una alternativa de cultivo son los Sistema de Producción Acua-Agrícola, estos tienen la ventaja de no utilizar fertilizantes para el producto, este método de cultivo contribuye al cuidado del medio ambiente y no contamina la tierra con productos químicos; este método de producción incluye la incorporación de dos o más componentes que son los peces y plantas en un diseño basado en el ahorro y recirculación de agua.

Contando con dicha alternativa de producción se decidió realizar una investigación de mercado para ayudar a tomar la mejor decisión con la menor incertidumbre posible y orientarse hacia la decisión sobre un proyecto.

El presente estudio muestra los resultados de una investigación de mercado que se realizó con el fin de conocer la opinión de los agricultores del Municipio de Benito Juárez, acerca de su disposición en un futuro de incursionar en el empleo del sistema de producción acua-agrícolas como parte de sus actividades.

\section{Antecedentes}

El Municipio de Benito Juárez fue constituido el 26 de diciembre de 1996 de acuerdo a la Ley No. 253 publicada en el Boletín Oficial del gobierno del Estado, siendo gobernador el Lic. Manlio Fabio Beltrones Rivera. Cuenta con una extensión de 3631.65 km2, su cabecera municipal es el poblado conocido actualmente como Villa Juárez, localizado al sur del estado (INAFED, 2010).

En el Municipio de Benito Juárez se ubica la Universidad Estatal de Sonora (UES), llamada anteriormente Centro de Estudios Superiores del Estado de Sonora (CESUES), 
fundada en el año de1983 por la Ley número 28, publicada el 3 de octubre en el Boletín Oficial del Gobierno del Estado, con el fin general de participar en el proceso de formación de profesionales demandados por el desarrollo social, económico, cultural y político de la entidad.

Para el año 2001 se estableció la Unidad Académica Benito Juárez y para el 2008 se creó en ella la carrera de Licenciatura en Agronegocios (UES, 2015). Aquí se desarrolla investigación con el proyecto Sistema de Producción Acua-Agrícola (SIPROAA).

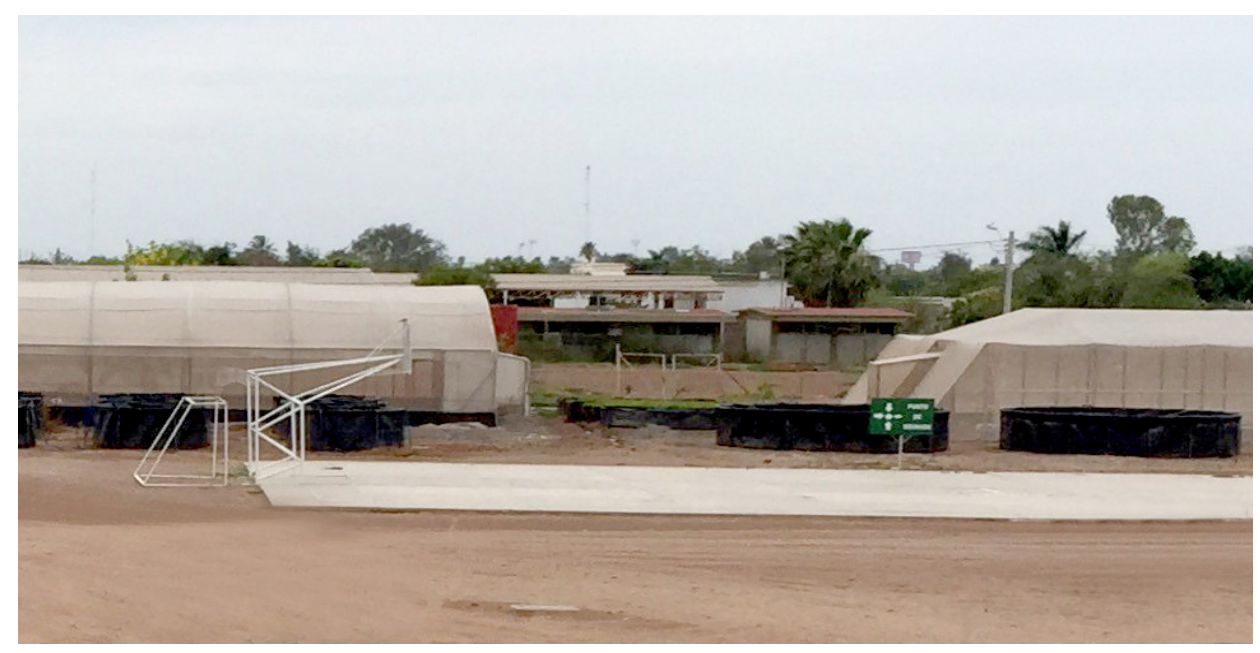

Figura 1. Vista del sistema de producción Acua-Agrícola. ${ }^{1}$

El proyecto se desarrolla en un sistema de producción acuapónico a pequeña escala para producir de manera integral tilapia, tomate, pepino europeo, lechuga y forraje verde hidropónico principalmente, pero cabe destacar que se puede realizar una combinación de producción de diferentes productos marinos y agrícolas (Mariscal, Páez, Esquer, Guerrero, Del Vivar y Félix, 2012).

La acuaponía constituye una integración entre un cultivo de peces y uno hidropónico de plantas, éstos se unen en un único sistema de recirculación, en el cual se juntan, el componente acuícola y el componente hidropónico; en este sistema los desechos metabólicos generados por los peces y los restos de alimento, son utilizados por los vegetales y transformados en materia orgánica vegetal, de esta forma se genera un producto de valor

1 Imagen de SIPROAA dentro de la UES Unidad Académica Benito Juárez, en la región del Municipio de Benito Juárez cuenta con distintos tipos de cultivos, entre los cuales destacan trigo, apio, tomatillo, maíz, papa, rábano, frijol, sandía, coliflor, cártamo, pepino, brócoli, tomate, garbanzo, melón, lechuga, cilantro, cebolla, repollo, acelga, calabaza, zanahoria, espinaca. 
a través de un subproducto desechable, con la ventaja de que el agua libre ya de nutrientes, queda disponible para ser reutilizada, gracias a esto, los sistemas Acuapónico trabajan sobre dos puntos de gran interés en producción, rentabilidad y tratamiento de desechos (Caló, 2011).

Sin embargo, este sistema tiene diferencia del cultivo tradicional, algunas ventajas son conservación de agua, fertilización orgánica, menos recursos necesarios para producir, mercado y sitio de producción cercano, aumento de la bioseguridad; por otro lado sus desventajas son gastos iniciales para producir, es un sistema complejo, alto costo por energía, requiere de personal calificado y la producción de plantas se encuentra limitado por el número de peces (Stover, 2015).

\section{Revisión de literatura}

La mercadotecnia hoy en día es una poderosa herramienta para dar a conocer lo productos y servicios de las empresas. Fisher y Espejo (2004), argumentan que la mercadotecnia es una herramienta que sirve para reconocer que los consumidores se agrupan en segmentos bien definidos, aceptar que la principal misión de una empresa es satisfacer las necesidades y/o deseos de los mercados meta que identifica y coordinar las actividades de mercadeo (desde la investigación de mercados hasta las actividades de control y monitoreo de las actividades que se realizan).

La investigación de mercados especifica la información requerida para abordar cuestiones del diseño del método para recoger la información, además dirige y lleva a cabo el proceso de recogida de datos, a su vez analiza los resultados y comunica sus hallazgos y sus implicaciones.

También la investigación de mercado permite conocer aspectos del consumidor, sin embargo, los datos por sí mismos no son información, dichos datos deben ser analizados adecuadamente para poder extraer de ellos todo su contenido informativo; por último, la investigación de mercados aporta los métodos y técnicas adecuados para la captura y el análisis de los datos, a su vez puede proporcionar los estudios necesarios que permitan elaborar estrategias de marketing efectivas (Mestre, 2012).

Por otro lado Sanz (2015), afirma que la investigación de mercados se ha convertido en un motor de la generación de la información para las grandes marcas internacionales ya que necesitan información fresca y reciente para la toma de decisiones estratégicas.

En la Tabla 1 se muestran las metodologías propuestas por diversos autores para la realización de una investigación de mercados, en la cual se observa que todos ellos avanzan sobre el mismo planteamiento para realizarla, por tal motivo se procedió a formar una estructura para la presente investigación. 
Tabla 1. Estructuras de investigación de mercados propuestas por diferentes autores.

\begin{tabular}{|c|c|c|c|}
\hline $\begin{array}{c}\text { Malhotra } \\
(2004)\end{array}$ & $\begin{array}{c}\text { Kinnear, Taylor, } \\
\text { Kresge, Fadul y Ferro } \\
\text { (1981) }\end{array}$ & $\begin{array}{l}\text { Pujals } \\
(2001)\end{array}$ & $\begin{array}{l}\text { Kootler y Hair } \\
\text { (2001) }\end{array}$ \\
\hline $\begin{array}{l}\text { 1. Definición del } \\
\text { problema. } \\
\text { 2. Elaboración } \\
\text { de un método } \\
\text { para resolver el } \\
\text { problema. } \\
\text { 3. Diseño de la } \\
\text { investigación. } \\
\text { 4. Determinación de } \\
\text { la muestra. } \\
\text { 5. Diseño del } \\
\text { cuestionario. } \\
\text { 6. Trabajo de campo o } \\
\text { acopio de datos. } \\
\text { 7. Preparación y } \\
\text { análisis de datos. }\end{array}$ & $\begin{array}{l}\text { 1. Establecer las } \\
\text { necesidades de } \\
\text { información. } \\
\text { 2. Especificar } \\
\text { objetivos. } \\
\text { 3. Determinar el } \\
\text { diseño de la } \\
\text { investigación. } \\
\text { 4. Desarrollar el } \\
\text { procedimiento } \\
\text { para la recolección } \\
\text { de datos. } \\
\text { 5. Diseñar la } \\
\text { muestra. } \\
\text { 6. Recopilar los } \\
\text { datos. } \\
\text { 7. Procesar los datos. } \\
\text { 8. Analizar los datos. } \\
\text { 9. Presentar los } \\
\text { resultados de la } \\
\text { investigación. }\end{array}$ & $\begin{array}{l}\text { 1. Definición de } \\
\text { la cuestión a } \\
\text { investigar. } \\
\text { 2. Determinación } \\
\text { de los objetivos } \\
\text { generales y } \\
\text { específicos. } \\
\text { 3. Examinar el valor } \\
\text { de la información. } \\
\text { 4. Diseño del estudio } \\
\text { o metodología. } \\
\text { 5. Determinación de } \\
\text { la muestra. } \\
\text { 6. Diseño del } \\
\text { cuestionario. } \\
\text { 7. Recogida de los } \\
\text { datos. } \\
\text { 8. Análisis de los } \\
\text { datos. }\end{array}$ & $\begin{array}{l}\text { 1. Determinación de } \\
\text { las necesidades de } \\
\text { información. } \\
\text { 2. Determinación de } \\
\text { los objetivos de la } \\
\text { investigación. } \\
\text { 3. Diseñar la } \\
\text { investigación y las } \\
\text { fuentes de datos. } \\
\text { 4. Determinar el } \\
\text { procesamiento } \\
\text { para la recolección } \\
\text { de datos. } \\
\text { 5. Diseñar la } \\
\text { muestra. } \\
\text { 6. Recopilación de } \\
\text { los datos. } \\
\text { 7. Procesamiento de } \\
\text { los datos. } \\
\text { 8. Análisis de los } \\
\text { datos. } \\
\text { 9. Análisis de los } \\
\text { resultados. }\end{array}$ \\
\hline
\end{tabular}

\section{Estado del arte y estudios empíricos}

Moreno (2007) expone en su estudio de agricultura urbana que esta actividad contribuye a reducir la huella ecológica de la ciudad, aprovechando sus residuos para materializarse y constituye especialmente para las comunidades urbanas empobrecidas la posibilidad de una mejor alimentación, una mejor calidad del hábitat en el cual residen y a fuentes estables de empleo e ingresos, conformando una oportunidad cierta para romper el círculo de la pobreza.

También otro modelo de negocio sustentable es la acuaponía, que se presenta como una alternativa viable, que se puede integrar a los sistemas de circulación cerrados en la acuicultura; también como alternativa viable para la reducción de costos y para la 
diversificación productiva de las unidades de acuicultura. Sin embargo, la acuaponía aún requiere de una mayor investigación para establecer procedimientos más asequibles a los pequeños productores acuícolas (Mateus, 2009).

La acuaponía tiene un lazo cerrado con la recirculación de los sistemas de agua dulce en el cual las plantas y peces crecen juntos en simbiosis, esta actividad asemeja a un río natural o cuenca del lago en el que los residuos de los peces sirve como nutrientes para las plantas, que a su vez limpian el agua para los peces; la tilapia y las verduras o hierbas son, respectivamente, peces y plantas comunes que crecen en un sistema de acuaponía. (Marklin, Mathison, Mayer, Nagurka, Cariapa, y Schabelski 2013).

Este tipo de proyectos sustentables son de gran importancia para las naciones en vías de desarrollo, ya que generarían otra alternativa de autoproducción de productos fresco y orgánicos, sumado a ello estarían generando sus propios empleos e ingresos extras a sus familias para tener una mejor calidad de vida; se debe desarrollar y promover este tipo de alternativas con los productores a gran escala para generar productos más sanos para la comunidad.

En un estudio empírico Vorhies y Morgan (2005) mencionan que es importante el uso de técnicas de investigación de mercados para desarrollar programas de marketing eficaces; y aunque la evaluación comparativa se ha identificado como una herramienta clave de aprendizaje basado en el mercado, ha habido poca evidencia empírica que corrobore que ha dado resultado, por ello una mejor alternativa es desarrollar investigaciones de mercado bien planeadas que ayuden a una mejor toma de decisiones.

\section{Metodología}

\section{Objetivo general}

Determinar mediante la aplicación de una investigación de mercados si los productores del Municipio de Benito Juárez considerarían a futuro implementar un sistema de producción acua-agrícola, y con ello, la UES pueda comercializarlo como proyecto productivo, social o a través de cursos de educación continua.

\section{Objetivos específicos}

- Analizar la situación actual de los sistemas de producción acua-agrícola.

- Establecer el marco técnico para la sustentación de la investigación.

- Diseñar un instrumento que permita recabar información confiable.

- Aplicar el cuestionario con los productores del Municipio de Benito Juárez.

- Procesar la información recabada para determinar si los productores estarían dispuestos a iniciar en su ciclo de cultivo un sistema de producción.

\section{Justificación, planteamiento del problema y pregunta de investigación}

Hoy en día es normal incluir el tema de la crisis global debido a la escases mundial del agua, también es importante mencionar que para el desempeño de la agricultura y la 
acuacultura forma parte fundamental este problema, debido a que el papel de las empresas en gestión de activos con instituciones financieras para la adquisición de materia prima es otro problema latente, sin embargo la financiación de toda la cadena de suministro agroalimentaria, incluyendo los sectores de servicios al por menor y de los alimentos a veces no es suficiente para producir (Burch y Lawrence, 2013).

Es por ello que la UES desarrolla investigación con el proyecto productivo SIPROAA, el cual es operado por maestros investigadores de diferentes áreas y alumnos que realizan sus proyectos y prácticas profesionales. Se decidió realizar una investigación de mercado, realizando una serie de preguntas a los agricultores de la región para obtener información acerca de su disposición a implementar el sistema acua-agrícola en un futuro en su ciclo de producción.

Derivado del análisis y estudio realizado dentro del área de los sistemas de producción acua-agrícola surge la siguiente interrogante de investigación: ¿Estarían dispuestos los productores del Municipio de Benito Juárez a implementar en un futuro en sus ciclos de cosecha un sistema de producción acua-agrícola?

\section{Procedimiento}

Para realizar la investigación de mercado y determinar el impacto del sistema de producción acua-agrícola con los agricultores del Municipio de Benito Juárez, se establecieron los siguientes pasos:

- Determinar la necesidad de la investigación.

- Establecer objetivos.

- Identificar la información que se va a recolectar.

- Determinar las fuentes de información.

- Desarrollar las técnicas de recolección de información.

- Determinar la muestra.

- Elaborar el cuestionario.

- Realizar una prueba piloto.

- Establecer la encuesta definitiva.

- Recolectar la información.

- Analizar la información.

- Establecer conclusiones.

- Determinar recomendaciones.

\section{Necesidades de información}

Actualmente contar con fuentes de información primarias es una parte importante en las empresas ya que les permite contar con caminos a seguir más fundamentados en sus procesos y futuros proyectos.

Por ello, anteriormente se realizó una investigación similar enfocada a las familias de la comunidad de Benito Juárez, en la que se obtuvo información precisa para la toma de decisión acerca de la implementación del sistema de producción acua-agrícola a traspatio 
en los hogares de la región, para que las mismas familias manejen y administren su producción, ésta podría ser para autoconsumo, comercialización o recreación mediante un proyecto respaldado por el gobierno federal o estatal (Paredes, Quintana, González, Calderón y Espinoza, 2014).

Para dar continuidad a dicha investigación se estableció determinar si los agricultores del municipio de Benito Juárez, Sonora, estarían dispuestos a implementar el sistema de producción acua-agrícola en sus ciclos de producción futuros.

\section{Hipótesis}

HA (Hipótesis Alternativa): Los agricultores del municipio de Benito Juárez sí están dispuestos a implementar el sistema de producción acua-agrícola.

HO (Hipótesis Nula): Los agricultores de la comunidad de Benito Juárez no están dispuestas a implementar el sistema de producción acua-agrícola.

\section{Universo y Población}

El universo de esta investigación son todos los agricultores establecidos dentro del municipio de Benito Juárez, Sonora y la población de esta investigación son todos los agricultores morales del municipio de Benito Juárez el cual cuenta con un número de 150 productores.

\section{Muestra}

El muestreo fue probabilístico y la fórmula para calcular el tamaño de la muestra cuando se conoce el tamaño de la población, según Medina (2003), es la siguiente:

Donde:

$$
\mathrm{n}=\frac{\mathrm{N}^{*} \sigma 22^{*} \mathrm{Z} 2}{(\mathrm{~N}-1)^{*} \mathrm{e} 2+\sigma 2^{*} \mathrm{Z} 2}
$$

$\mathrm{n}=$ Tamaño de la muestra.

$\mathrm{N}=$ Tamaño de la población (150).

$\sigma=$ Desviación estándar de la población que cuando no se tiene su valor, suele utilizarse un valor constante de 0.5

$Z=$ Valor obtenido mediante niveles de confianza (95\%).

e = Límite aceptable de error muestral que cuando no se tiene su valor, suele utilizarse un valor que varía entre el 1\% (0.01) y $9 \%$ (0.09).

Sustituyendo:

$$
\begin{aligned}
& \mathrm{n}=\frac{(150)\left(0.5^{\star} 2\right)\left(1.19^{\star} 2\right)}{(150-1)\left(0.05^{\star} 2\right)+\left(0.5^{\star} 2\right)\left(1.19^{\star} 2\right)}=\frac{(150)(0.25)(3.8416)}{\left(149^{*} 0.0025\right)+\left(0.25^{\star} 3.8416\right)} \\
& \mathrm{n}=\frac{144.06}{1.3329}=\frac{144.06}{1.3329}=108.0846 \quad \begin{array}{l}
\mathbf{1 0 9} \text { encuestas a } \\
\text { aplicar }
\end{array}
\end{aligned}
$$




\section{Cuestionario, limitación y tabulación}

Se formularon una serie de preguntas con el fin de obtener información y determinar si los agricultores estarían dispuestos a implementar en un futuro un sistema de producción acua-agrícola. En cuanto a las limitaciones, se encontró que la mayoría de los agricultores no cuentan con el suficiente conocimiento sobre el funcionamiento de estos sistemas y también se encontraron situaciones donde el agricultor no se encontraba disponible o fue difícil localizarlo para la realización de la aplicación del cuestionario. Para la tabulación se esquematizaron los datos obtenidos de las encuestas aplicadas a los agricultores del municipio de Benito Juárez, mediante una hoja de cálculo de Microsoft Excel para obtener el total de datos para graficar.

\section{Resultados}

A continuación se muestran los resultados de la encuesta aplicada a los agricultores del Municipio de Benito Juárez, Sonora.

La Gráfica 1 muestra los resultados de la pregunta: ¿cuáles son los últimos tres cultivos que ha sembrado en su ciclo de producción? El 54\% de los encuestados indicó que el trigo, $43 \%$ el maíz y $38 \%$ el cártamo, siendo éstos los más representativos.

Sin embargo, como se puede observar en la gráfica se siembra también productos como: tomatillo,papa, apio, frijol, lechuga, brócoli, pepino, chile, tomate, cebolla, garbanzo, repollo, calabaza y sandía.

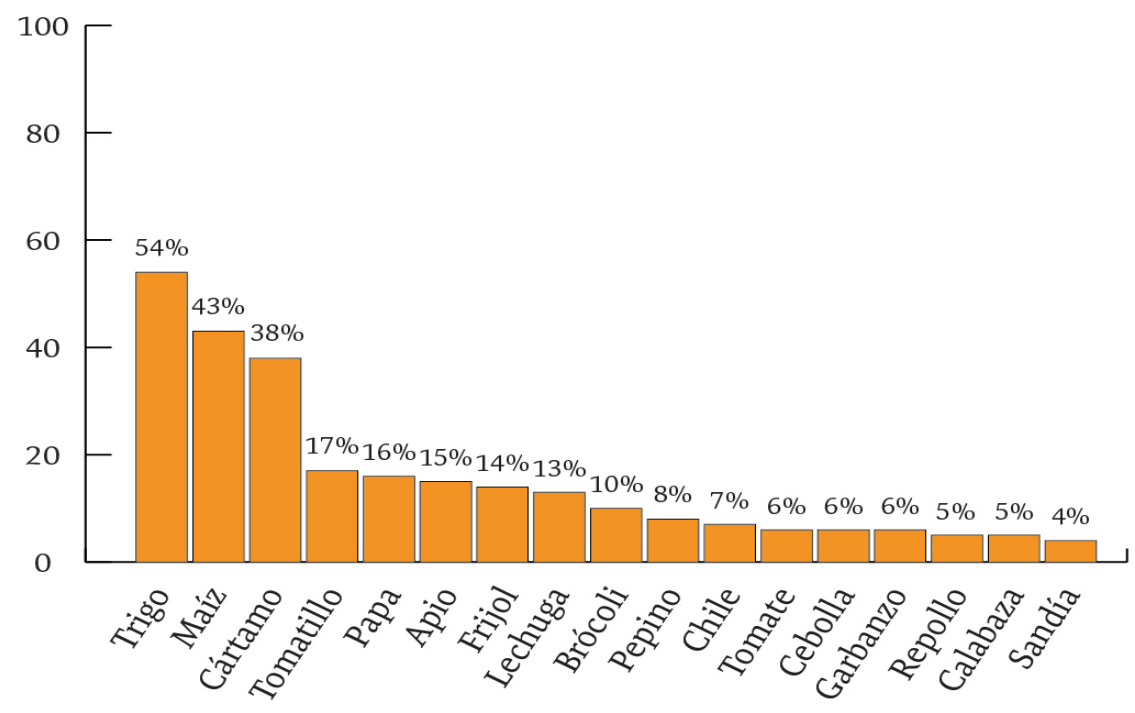

Gráfica 1. Cultivos y siembra de los agricultores. 
La Gráfica 2 muestra que 24\% de los agricultores siembran de 1 a 20 hectáreas, 25\% de 21 a 50 hectáreas, $20 \%$ de 51 a 100 hectáreas y 31\% de 100 hectáreas en adelante por año.

En la Gráfica 3 se puede apreciar el número de ciclos de producción que los agricultores realizan al año: el $78 \%$ realizan 1 ciclo de producción y sólo el $22 \%$ realizan 2 ciclos de producción, esto último debido a que cuentan con mayores recursos económicos, materiales y humanos para la realización de los cultivos.

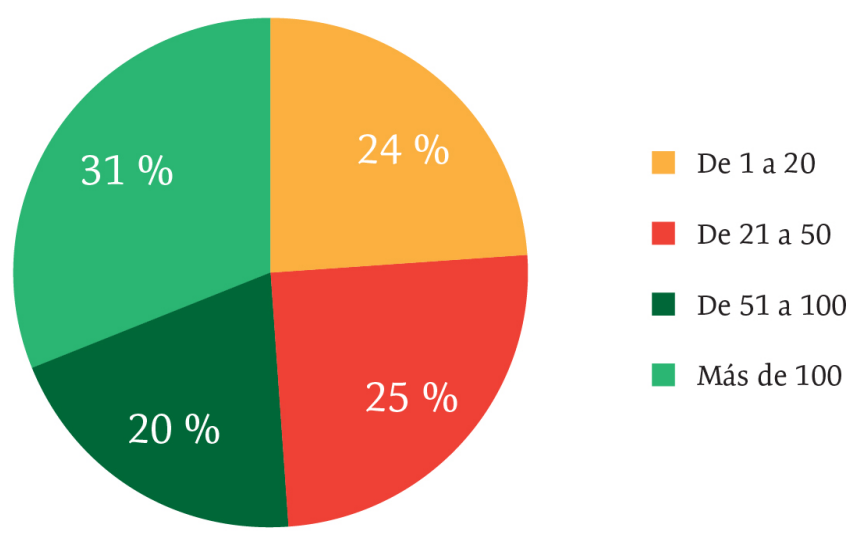

Gráfica 2. Hectáreas sembradas por año.

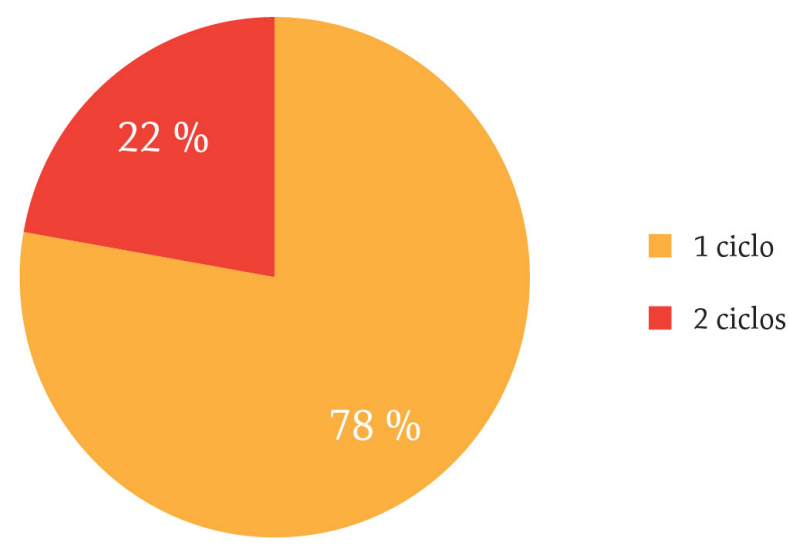

Gráfica 3. Ciclos de producción por año. 
Se preguntó a los agricultores si las hectáreas que utilizaban para siembra eran propias, rentadas o de ambos esquemas. En la Gráfica 4 se puede apreciar que el 15\% de los agricultores siembran en hectáreas propias, $27 \%$ en hectáreas rentadas y el $58 \%$ contestaron que realizan su ciclo de cultivo en ambos esquemas, debido a que estos últimos poseen una mayor capacidad económica y de financiamiento para cultivar sus tierras.

Respecto a este último punto, el 100\% de los encuestados indicaron que sí utilizan algún tipo de financiamiento para poder llevar a cabo su ciclo de producción. En la Gráfica 5 se aprecian los tipos de financiamientos utilizados: $37 \%$ de los agricultores solicitan financiamiento al Fideicomisos Instituidos en Relación con la Agricultura (FIRA), 38\% utilizan avío o habilitación y 25\% utilizan la Unión de Crédito.

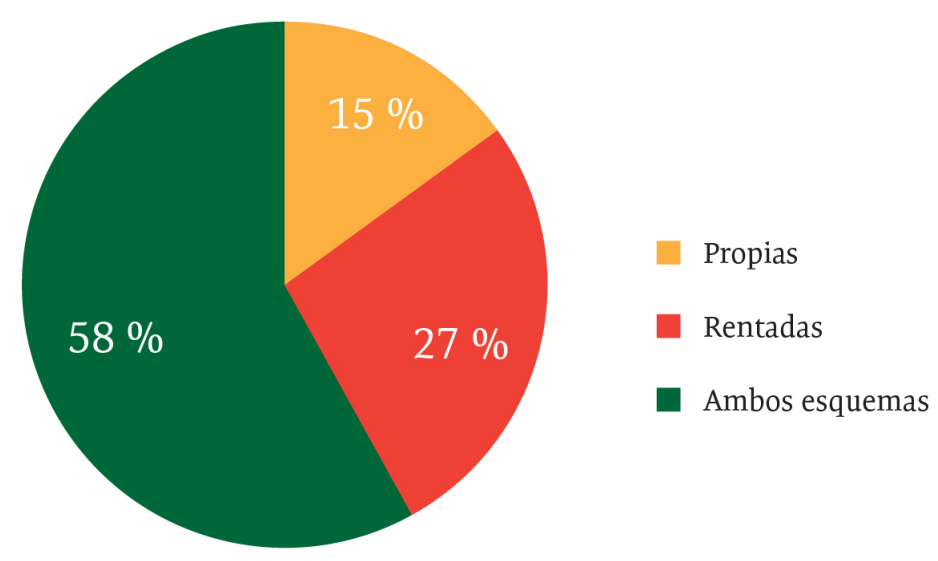

Gráfica 4. Hectáreas de siembra.

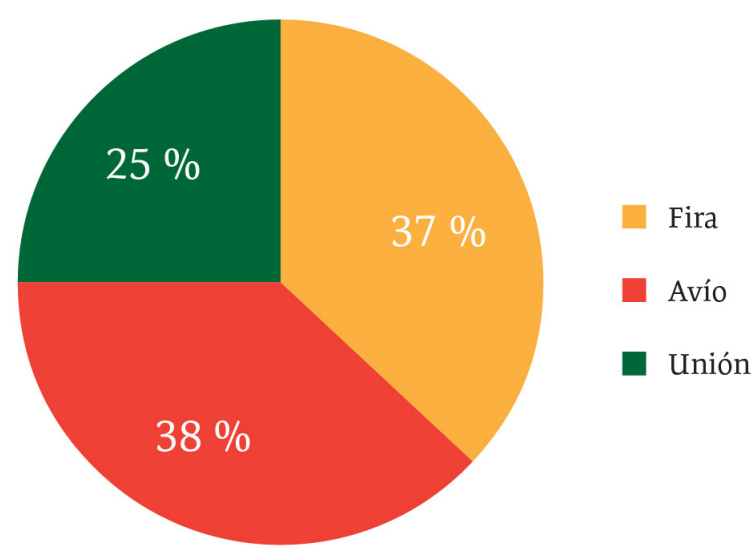

Gráfica 5. Tipos de financiamientos. 
Referente a pérdidas de cosecha, se preguntó a los agricultores si habían tenido alguna por causa del clima. En la Gráfica 6 se puede apreciar que muy pocos agricultores han tenido pérdidas por esta razón; sólo el 18\% indicó que sí, mientras que el $82 \%$ que no.

Al preguntar si había pérdidas de cosecha por otras causas, como se muestra en la Gráfica 7, sólamente el 9\% indicó que sí han tenido pérdidas por causas ajenas al clima, como por ejemplo, enfermedades de las plantas, plagas, retraso en la siembra, mala calidad de la materia prima, entre otras; el 91\% de los agricultores indicó que no.

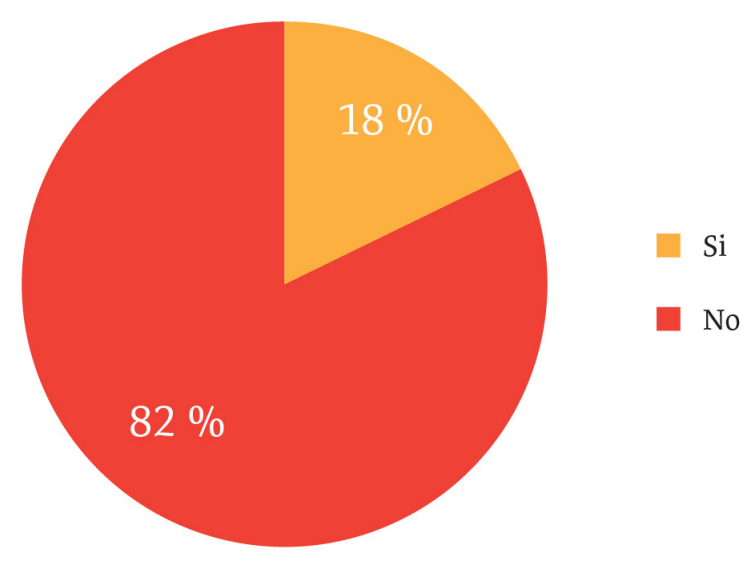

Gráfica 6. Pérdidas de cosecha por causas del clima.

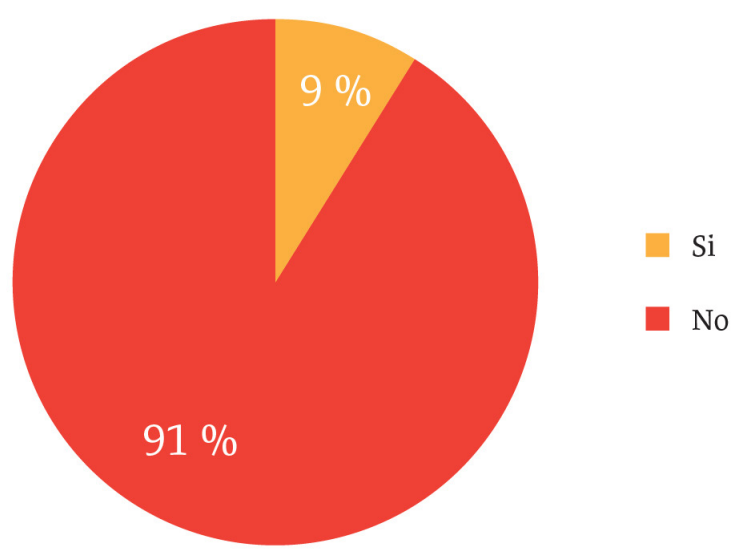

Gráfica 7. Pérdidas de cultivo ajenas al clima. 
En relación con el ahorro del agua, se preguntó a los agricultores si utilizan alguna estrategia con este fin en sus cultivos. Como se observa en la Gráfica 8, menos de la mitad utilizan alguna estrategia para ahorrar agua; el 37\% contestó que sí utilizan alguna estrategia y $63 \%$ contestaron que no.

Respecto a la producción de cultivos orgánicos, el 100\% de los agricultores encuestados contestaron que no han cultivado este tipo de productos en sus ciclos de producción.

En lo referente a los sistemas de producción acua-agrícola, se preguntó a los agricultores si habían escuchado acerca de este tipo de sistemas; más de la mitad de los agricultores indicaron que no (61\%), tal como se muestra en la Gráfica 9.

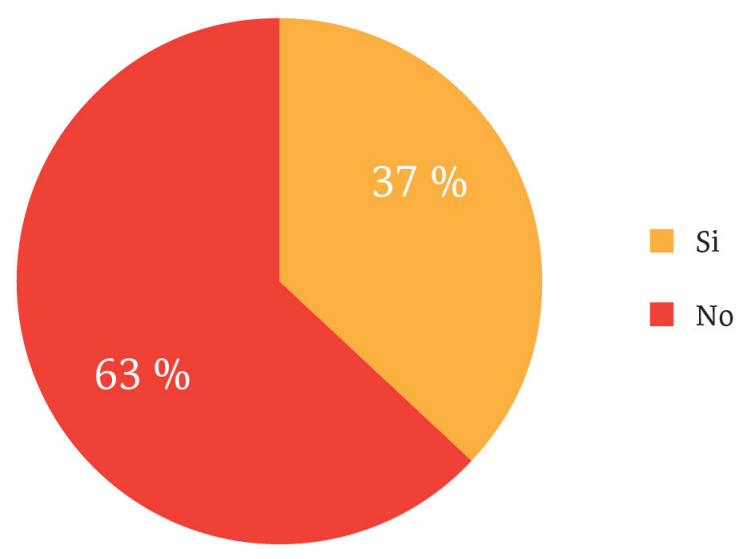

Gráfica 8. Ahorro de agua.

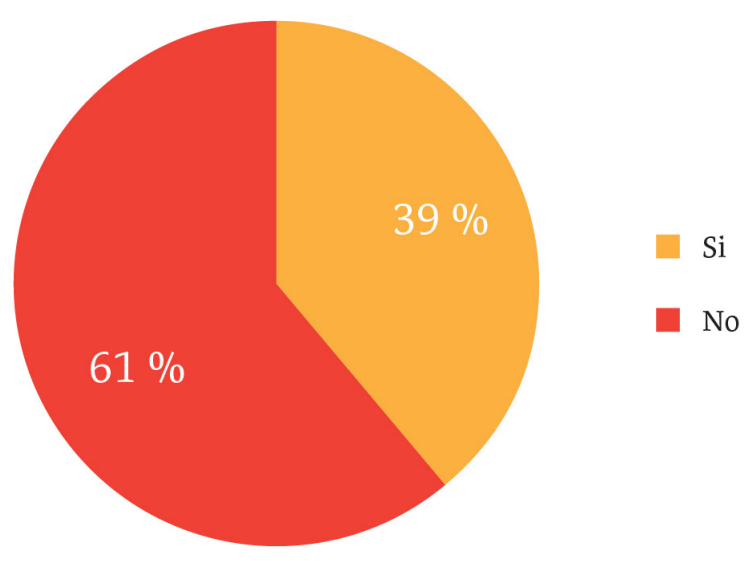

Gráfica 9. Promoción del sistema de producción acua- agrícola. 
Al cuestionar a los agricultores acerca de la disposición para implementar a futuro un sistema de producción acua-agrícola, como se aprecia en la Gráfica 10, la mayoría sí está dispuesto a recibir una capacitación para poder implementarlo (76\%); sólo el 24\% contestó que no.

Respecto al tiempo disponible para recibir capacitación para poder implementar el sistema de producción acua-agrícola, en la Gráfica 11 se puede apreciar que el $76 \%$ de los encuestados indicaron que sí contarían con tiempo disponible para recibirla y el $24 \%$ indicaron que no lo tendrían.

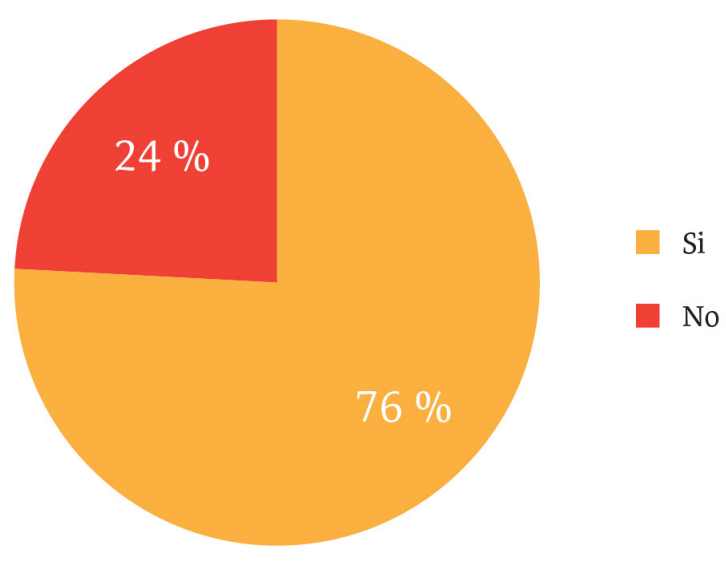

Gráfica 10. Implementación de SIPROAA.

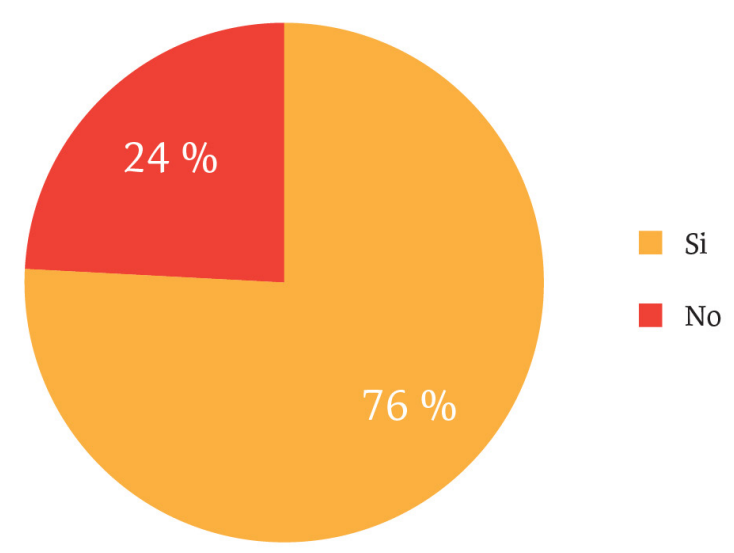

Gráfica 11. Tiempo para recibir capacitación. 
En la Gráfica 12 se puede observar la disposición de los encuestados para ofrecer una capacitación a sus empleados para la implementación de un sistema acua-agrícola; el $87 \%$ contestó que sí estaría dispuesto y sólo el 13\% contestó negativamente.

Se preguntó además, si considerarían implementar a futuro un sistema de producción acua-agrícola como una alternativa viable en sus ciclos de producción; como se observa en la Gráfica 13 los agricultores contestaron positivamente, el 95\% de los encuestados contestaron que sí y sólo el 5\% contestó que no lo implementaría, esta respuesta negativa se debe a que no se sienten cómodos al empezar a implementar una nueva forma de cultivar su producto.

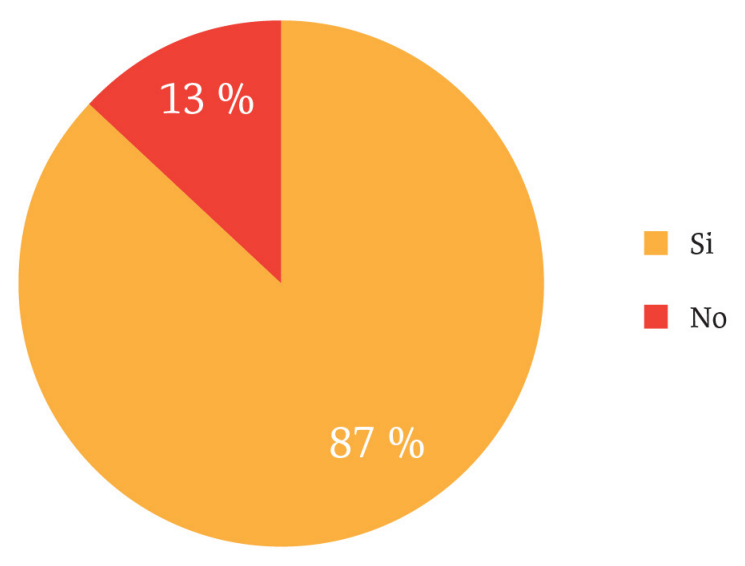

Gráfica 12. Capacitación a empleados.

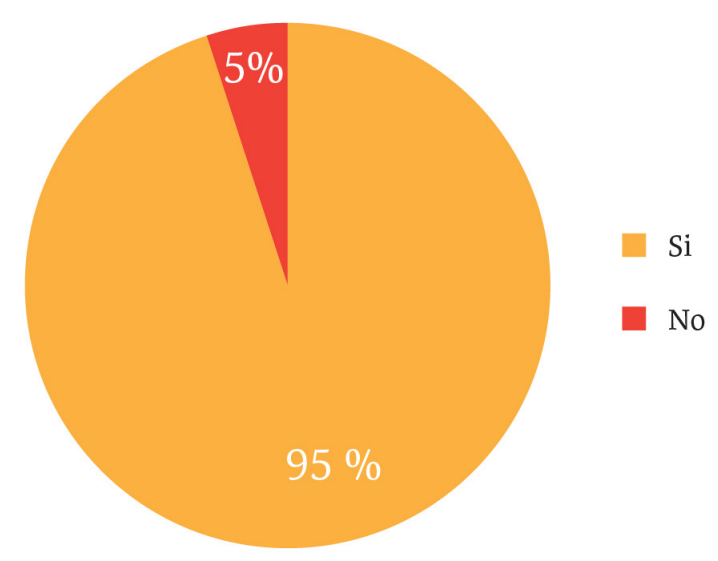

Gráfica 13. Implementación a futuro de SIPROAA. 


\section{Conclusión}

El Estado de Sonora cuenta con grandes recursos naturales, como su valle, que es uno de los mejores trazados del mundo con 400,000 hectáreas, y su costa de $1207.81 \mathrm{~km}$; estos dos sectores son el detonante económico más importante del estado, es por ello que se utilizó la investigación de mercados con base en un proyecto llamado SIPROAA que se está desarrollando en la UES ubicado en el municipio de Benito Juárez. Dicha investigación arrojó resultados positivos, tomando en cuenta que los agricultores no tienen el suficiente conocimiento del funcionamiento del sistema; sin embargo, sus respuestas fueron favorables, es por ello que se piensa que el proyecto es viable, ya que el agricultor sí estaría dispuesto a implementar el sistema en sus ciclos de producción en un futuro.

Derivado del análisis de los resultados obtenidos se concluyó que los agricultores del municipio de Benito Juárez están de acuerdo en buscar alternativas sustentables de producción que traigan beneficios en la calidad de vida de la comunidad y a su vez que detonen la economía regional generando más empleos.

Como recomendaciones surgen algunos puntos que a continuación se detallan:

- Promocionar el sistema de producción acua-agrícola con los agricultores de la región y en un futuro darlo a conocer a nivel estatal.

- Realizar un plan de negocios para solicitar un apoyo del gobierno federal o estatal e implementarlo como proyecto productivo a gran escala en la región.

- Implementar el sistema de producción acua-agrícola con un programa de desarrollo social como proyecto a traspatio con las familias de la comunidad de Benito Juárez.

- Realizar investigaciones con los alumnos y maestros involucrados en el proyecto para establecer posibles combinaciones de producción y beneficios de estos sistemas. 


\section{Referencias bibliográficas}

Burch, D., \& Lawrence, G. (2013). Financialization in agri-food supply chains: private equity and the transformation of the retail sector. Agriculture and human values, 30(2), 247-258.

Caló, P. (2011). Introducción a la acuaponía. Buenos Aires: Centro Nacional de Desarrollo acuícola (CENADAC)- Ministerio de Agricultura, Ganadería y Pesca.

Fisher, L., \& Espejo, J. (2004). Mercadotecnia. Ciudad de México: Editorial McGraw-Hill.

Instituto Nacional para el Federalismo y el Desarrollo Municipal (INAFED). (2010). Enciclopedia de los Municipios de México. Estado de Sonora. Benito Juárez. Recuperado de http://www.inafed.gob.mx/work/enciclopedia/EMM26sonora/municipios/26071a. html

Kinnear, T., Taylor, J., Kresge, S., Fadul, G., \& Ferro, A. (1981). Investigación de mercados. Bogotá: McGraw-Hill.

Kootler, P. \& Hair, K. (2001). Introducción a la investigación de mercados: un enfoque para América Latina. Ciudad de México: Editorial Pearson Education.

Marklin, R., Mathison, M., Mayer, B., Nagurka, M., Cariapa, V., \& Schabelski, J. (2013). Aquaponics: A Sustainable Food Production System that Provides Research Projects for Undergraduate Engineering Students. World Engineering Education Forum (WEEF) 2013. Cartagena de Indias, Colombia. Recuperado de http://www.acofipapers.org/ index.php/acofipapers/2013/paper/viewFile/188/77

Mateus, J. (2009). Acuaponía: hidroponía y acuacultura, sistema integrado de producción de alimentos. RED hidroponía. Boletín, (44), 7-10.

Malhotra, N. (2004). Investigación de mercados. Ciudad de México: Pearson Educación.

Mariscal, M., Páez, F., Esquer, J., Guerrero, I., Del Vivar, A. \& Félix, R. (2012). Integrated culture of white shrimp (Litopenaeus vannamei) and tomato (Lycopersicon esculentum Mill) with low salinity groundwater: Management and production. Aquaculture, 366, 76-84.

Medina, H. (2003). Determinación del tamaño de muestra en encuestas complejas de propósitos múltiples. Décimo Taller Regional: La Práctica del Muestreo para el Diseño de las Encuestas de Hogares. Buenos Aires, Argentina. Recuperado de http://repositorio. cepal.org/bitstream/handle/11362/31804/S2003682_es.pdf?sequence $=1$

Mestre, M.S. (2012). Aplicación de la investigación de mercados al análisis de problemas de marketing. Revista Icade. Revista de las Facultades de Derecho y Ciencias Económicas y Empresariales, (83-84), 339-359.

Moreno, O. (2007). Agricultura Urbana: Nuevas Estrategias de Integración Social y Recuperación Ambiental en la Ciudad. Revista Electrónica DU\&P. Diseño Urbano y Paisajes, 4(11), 1-14. Recuperado de http://www.ucentral.cl/du\&p/pdf/11_ agricultura_urbana.pdf 
Paredes, D., Quintana, R., González, L., Calderón, Z., \& Espinoza, P. (2014). Investigación de mercados para implementar a traspatio un sistema de producción AcuaAgrícola sustentable en la comunidad en Benito Juárez, Sonora, México. Global de Negocios, 125. Recuperado de ftp://ftp.repec.org/opt/ReDIF/RePEc/ibf/rgnego/rgnv2n2-2014/RGN-V2N2-2014-10.pdf

Pujals, P. (2001). Investigación de mercados. Cataluña: Universidad Autónoma de Barcelona. Sanz, M. (2015). Introducción a la investigación de mercados. Madrid: ESIC Editorial.

Secretaría de Agricultura, Ganadería, Desarrollo Rural, Pesca y Alimentación (SAGARPA). (2014). Recuperado de http://www.gob.mx/sagarpa

Stover, S. (2015). Lechugas por acuaponía. Recuperado de http://www.hortalizas.com/ horticultura-protegida/lechugas-por-acuaponia/

Universidad Estatal de Sonora (UES). (2015). Historia. Recuperado de http://www.ues.mx/ pagina. $a s p x ? \mathrm{p}=7$

Villagómez, J., Mora, A., Barradas, D., \&Vázquez, E. (2014). El análisis FODA como herramienta para la definición de líneas de investigación. Revista mexicana de agronegocios, 35, 1021-1031.

Vorhies, D., \& Morgan, N. (2005). Benchmarking Marketing Capabilities for Sustainable Competitive Advantage. Journal of Marketing, 69(1), 80-94. 


\title{
Capítulo 4
}

\section{Factores explicativos de la competitividad en la empresa de manufactura: caso Navojoa, Sonora}

\author{
Amado Olivares Leal \\ José Ángel Coronado Quintana \\ Josefina Ochoa Ruiz
}

Universidad de Sonora 
64 Estudios de desarrollo regional en México 


\section{Antecedentes}

En México, el sector industrial ha desempeñado un rol fundamental en la economía nacional; no obstante, la liberalización comercial ha propiciado profundos cambios que no han sido asimilados del todo por gran parte de las empresas mexicanas, en particular por las pequeñas y medianas empresas (PyMES). El sector industrial en algunas regiones de Sonora, México presenta un buen desarrollo en los procesos de industrialización y en otras un menor avance, por lo que una de las acciones prioritarias es impulsar el Nivel de la Competitividad Empresarial de acuerdo al Plan Nacional de Desarrollo de México 2013-2018; dada la pérdida de competitividad que se presenta, requiere de:

[...] innovación de productos y procesos de producción, así como de sistemas de producción flexible, para responder rápidamente a los cambios en el entorno, poniendo mayor énfasis en la reducción de costos y en el aumento de la productividad, la búsqueda permanente de nichos de mercado y el impulso a la mano de obra calificada, para insertarse al mercado global. (Cervantes, 2005)

En este contexto resulta de vital importancia realizar un estudio acerca de la determinación de las variables e indicadores que impulsan la competitividad de las PyMES, así lo han señalado como prioridad estratégica McCarthy y Perreault (2014), Kotler y Lane (2006), Porter (2007), entre otros.

\section{Problemática}

Si se considera la composición de la empresa en México, existe un total de 5,654,014 de unidades productivas, de las cuales el $94.3 \%$ son microempresas, $4.7 \%$ son pequeñas, 0.8\% medianas, y 0.2\% empresas grandes; y se genera en total en México de 29,642,421 empleos (INEGI, 2014), y aportan las PyMES el 43\% del empleo, aunque en Estados Unidos de América y en Europa está entre 62 y 68\%, por tal motivo para México es un imperativo estratégico impulsar las PyMES, y la competitividad en estas empresas es un medio para impulsar su nivel de competencia y de vida (COPARMEX, 2014).

La política económica actual de México, promueve el interés empresarial por el sector manufactura que representa sólo un $11.54 \%$, el sector servicios es el $35.45 \%$, y el sector comercio el 53\%, cuando en las naciones desarrolladas, las manufacturas son el sector privilegiado (COPARMEX, 2014).

Las razones de los bajos niveles de competitividad en México, se asocian al uso de factores que demandan las PyMES y es que usualmente no propician innovación ni impacto en las estrategias, lo que significa mantenerse sólo con ventajas comparativas, sin avance en competitividad, otras causas están relacionadas y asociadas al diseño de deficiencias de producto, rezagos tecnológicos, baja responsabilidad de investigación y desarrollo, mientras que en la producción vemos holguras de energía, abastecimientos en las líneas, y en mercadotecnia y finanzas esquemas muy tradicionales de comercialización y niveles de rendimiento y retorno bajos, etc. (McCarthy y Perreault, 2014; Kotler y Lane, 2006). 
Para mantener la ventaja competitiva se consideran tres premisas claves:

a) Nivel de competencia y uso de factores,

b) La innovación, $y$

c) Cadenas productivas de valor.

Ante el reto que representa la competitividad para las PyMES, se plantean las siguientes preguntas: ¿Cuál es el nivel o Índice de Competitividad Empresarial (ICE) de las PyMES en Navojoa, Sonora y con qué opciones cuentan para mejorar su competitividad? ¿Cuál es la posición competitiva de Navojoa, Sonora respecto a los demás municipios considerados en esta investigación?

\section{Marco conceptual}

Aunque tradicionalmente se hablaba de ventajas comparativas al referirse a países y ventajas competitivas al referirse a empresas, de acuerdo a Porter (1991) y su amplia investigación empírica concluye que la ventaja de una nación no se puede medir más que por la suma de las ventajas de sus empresas, lo cual explica el título de su libro: La Ventaja Competitivas de las Naciones.

De acuerdo a Porter (1986), los mercados imperfectos, información y movilidad de factores no se dan con pureza y las empresas toman sus decisiones bajo incertidumbre; el estado de la tecnología de cada industria en las diferentes naciones, permite producir con rendimientos marginales crecientes implicando que a mayores volúmenes de producción es más intenso el aprovechamiento de los factores, lo cual trae consigo ahorros sociales. Sin embargo, el peligro de aumentar la oferta para disminuir los costos unitarios es el de sobrepasar la demanda interna propiciando una acumulación de inventarios, siendo la salida a este problema la colocación de los excedentes de oferta en los mercados internacionales, lo que implica una alta productividad interna para alcanzar una alta competitividad externa, una ventaja competitiva.

En el presente capítulo, de acuerdo a un análisis teórico, se plantea un modelo de competitividad industrial que permitirá medir y cuantificar el ICE por municipio en el estado de Sonora. De los resultados, se destaca la importancia que tiene la definición de la Calidad de las Estrategias y la Calidad Operacional en las empresas, lo cual les permite establecer una medida que sea posible ente ellas integrar estas dimensiones en torno a fortalecer la industria, y a obtener ventajas competitivas en su entorno municipal, regional y estatal.

Para determinar el Îndice de Competitividad Empresarial se seguirá el enfoque sistémico de competitividad, el cual presenta cuatro determinantes de ventajas competitivas nacionales (Porter, 1991), y sus interrelaciones generan industrias competitivas en las naciones:

1. Condiciones de los factores. En la empresa qué tipo de factores demandan y aplican para lograr estrategias y operación de calidad que les de ventajas competitivas sostenibles. 
2. Industrias relacionadas y de apoyo. Las empresas horizontalmente relacionadas se conforman en un segmento o clusters de empresas competitivas dentro de una industria, y a menudo éstas se relacionan y comparten actividades dentro de la cadena de valor o fabrican productos complementarios.

3. Estructura y rivalidad industrial. Se relaciona con la intensidad de la rivalidad, lo cual obliga a las industrias a competir en forma más agresiva e innovadora.

4. Condición de la demanda. Es contar con una demanda local atractiva, definida más por su composición y características, su tamaño y la rapidez para identificar las necesidades de sus compradores.

Además se consideran dos variables auxiliares que completan el marco de análisis:

- Otros agentes. El gobierno, la banca mexicana, centros de investigación, instituciones de educación superior, entre otros, impulsan a las empresas a entrar en el proceso hacia las ventajas competitivas sostenibles.

- Los hechos fortuitos o casuales. La invención y la actitud empresarial forman el núcleo de ventajas competitivas, su formación inicial a menudo es un hecho fortuito y los atributos de un país actúan directamente.

Respecto al primer determinante (condiciones de los factores), en las empresas éstos se conciben en forma dinámica, se considera a la escasez como fuente generadora de ventajas competitivas y contribuyen al éxito de una industria por su impacto en la estrategia, dado que propicia la innovación. Los factores pueden separarse en generales vs. especializados y en básicos vs. avanzados. Los factores generales son comunes a todas las industrias y por lo tanto no generan ventajas sostenibles, mientras que los factores especializados -infraestructura, investigación y desarrollo, educación, habilidades, tecnología de punta-, son específicos para cada industria o segmento. Dado el tiempo que lleva generarlos y su difícil acceso, estos factores contribuyen significativamente a la creación de ventajas competitivas sostenibles (Figura 1).

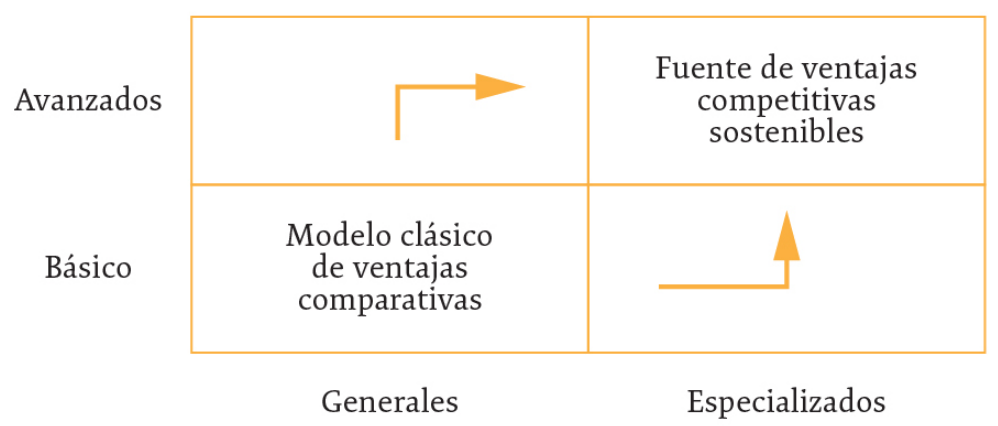

Figura 1. La empresa: condición de los factores. Fuente: Porter (1991). 
El Foro Económico Mundial (2014) cuenta con dos índices que evalúan por una parte los niveles microeconómicos: Índice del Crecimiento de Competitividad Empresarial (ICE) y por otra los niveles macroeconómicos: Índice de Competitividad Global para una nación (ICG); estos índices son publicados anualmente y buscan medir la capacidad de la economía para lograr el crecimiento económico, así como las condiciones que hacen sostenible la productividad y competitividad empresarial y presentan un crecimiento sostenido en los mercados nacionales e internacionales.

No existe una definición única de competitividad, pero la que se utiliza en esta investigación se puede resumir en: la capacidad de las empresas de un país para sostener y expandir su participación en los mercados locales y/o internacionales y obtener ventajas competitivas, elevando el nivel de vida de las personas. Esto implica:

a) Aumentar la productividad y, por ende, innovación y creación de nuevos negocios.

b) Incrementar el ingreso per-cápita y la calidad de vida de la población.

c) Bajar costos y la capacidad de adaptarse a demandas variadas.

d) Lograr rentabilidad, posición competitiva, relaciones inter-empresariales de éxito, y aprovechar adecuadamente la infraestructura regional del sector que se trate.

e) Enfrentar nuevos retos: globalización e internacionalización.

En este contexto, es fundamental para las PyMES diseñar e instrumentar acciones para el desarrollo de su competitividad y de la misma región en la que se encuentran ubicadas; gestando el cambio del paradigma de competitividad, pasando de las ventajas comparativas a las ventajas competitivas de las industrias y por supuesto de las regiones.

\section{Determinación de las variables e indicadores de la competitividad empresarial}

A partir de las variables del modelo de competitividad generadas (Tabla 1), la metodología que se utilizará será la del ICE del Foro Económico Mundial, a través de un cuestionario que permite generar el posicionamiento de Competitividad de la PyME.

El modelo de competitividad empresarial resultante es presentado en la Figura 2, en el que se consideran dos dimensiones, una la Calidad de las Estrategias definido en el eje de las "Y" y otra la Calidad en la Operación en las empresas definido en el eje de las "X", de tal manera que este cuadrante cartesiano permite medir el nivel de la competitividad en la empresa y establecer su posicionamiento respecto a su competencia.

En esta visión acerca de la competitividad, es importante reconocer los indicadores de desempeño, que se refieren a la capacidad de mantener mercados y penetrar en nuevos, a la eficiencia en el uso de los recursos clave (financieros, materia prima, tiempo), a la actualización de las técnicas organizacionales y de las tecnologías. Pero es igualmente importante saber cuáles son los valores y las metas estratégicas que se plantea la organización y sobre todo, cuáles son los conceptos de gestión de recursos humanos utilizados.

Las empresas tienen metas específicas dependiendo las condiciones en las que se desenvuelven, como ganar más mercado, disminuir costos, producir con calidad, innovar 
Tabla 1. Variables e indicadores del modelo de competitividad empresarial.

\begin{tabular}{|c|c|c|c|}
\hline Dimensiones & Variables & Indicadores & Preguntas \\
\hline \multirow{9}{*}{$\begin{array}{l}\text { Calidad de la } \\
\text { estrategia }\end{array}$} & $\begin{array}{l}\text { Planeación } \\
\text { estratégica }\end{array}$ & $\begin{array}{l}\text { Visión, misión, FODA,objetivos, } \\
\text { estrategias, recursos humanos, } \\
\text { procedimiento. }\end{array}$ & $\begin{array}{l}\text { ¿Hay un plan? } \\
\text { ¿es correctivo o } \\
\text { preventivo? }\end{array}$ \\
\hline & \multirow{2}{*}{$\begin{array}{l}\text { Estructura y } \\
\text { comunicación } \\
\text { organizacional }\end{array}$} & Número de nivel jerárquico & $\begin{array}{l}\text { ¿Su estructura organiza- } \\
\text { cional es plana? }\end{array}$ \\
\hline & & Comunicación interpersonal & ¿Hay eficiencia? \\
\hline & \multirow{3}{*}{$\begin{array}{l}\text { Compromiso } \\
\text { directivo }\end{array}$} & Valores & $\begin{array}{l}\text { ¿Institucionales, } \\
\text { sociales y ecológicos? }\end{array}$ \\
\hline & & Políticas y normas & $\begin{array}{l}\text { ¿Industrial, educativa, } \\
\text { ambientales? }\end{array}$ \\
\hline & & Programas e innovaciones & $\begin{array}{l}\text { ¿Metas medibles? } \\
\text { ¿Innovación en } \\
\text { proceso-producto? }\end{array}$ \\
\hline & \multirow[t]{2}{*}{ Competitividad } & $\begin{array}{l}\text { Uso de los recursos básicos, gene- } \\
\text { rales, avanzados y especializados, } \\
\text { clusters. }\end{array}$ & $\begin{array}{l}\text { ¿Logran ventajas } \\
\text { comparativas } \\
\text { y competitivas? }\end{array}$ \\
\hline & & Apoyos públicos y privados, IES. & $\begin{array}{l}\text { ¿Logran ventajas } \\
\text { competitivas? }\end{array}$ \\
\hline & Recuso humano & $\begin{array}{l}\text { Programa de capacitación, } \\
\text { entrenamiento e incentivos, RSE. }\end{array}$ & $\begin{array}{l}\text { ¿Cumplen con las } \\
\text { exigencias legales? }\end{array}$ \\
\hline \multirow{5}{*}{$\begin{array}{l}\text { Calidad en la } \\
\text { Operación }\end{array}$} & $\begin{array}{l}\text { Innovación } \\
\text { tecnológica }\end{array}$ & $\begin{array}{l}\text { Innovación en producto, proceso, } \\
\text { I\&D e informática. }\end{array}$ & $\begin{array}{l}\text { ¿Innova o invierte para } \\
\text { un mejor futuro? }\end{array}$ \\
\hline & $\begin{array}{l}\text { Proceso } \\
\text { productivo }\end{array}$ & $\begin{array}{l}\text { Costos mínimos, proceso manual, } \\
\text { mecanizado, estándar, cadena, } \\
\text { continua. }\end{array}$ & $\begin{array}{l}\text { ¿Está cerca o lejos de la } \\
\text { competencia? }\end{array}$ \\
\hline & $\begin{array}{l}\text { Logística y } \\
\text { cadena de valor }\end{array}$ & $\begin{array}{l}\text { Contratos de seguros, } \\
\text { de transporte, } \\
\text { tiempo de respuesta (TAT). }\end{array}$ & $\begin{array}{l}\text { ¿Hay eficiencia en su } \\
\text { logística y cadena de } \\
\text { valor? }\end{array}$ \\
\hline & $\begin{array}{l}\text { Estrategia } \\
\text { financiera }\end{array}$ & $\begin{array}{l}\text { Valor presente Neto (VPN), Re- } \\
\text { torno sobre la inversión (ROI), } \\
\text { Margen de Utilidad (MgUt), valor } \\
\text { de acción, porcentaje y/o montos } \\
\text { de inversión. }\end{array}$ & $\begin{array}{l}\text { ¿Hay utilidad, aumenta } \\
\text { su valor, el retorno es } \\
\text { alto, invierte en } \\
\text { infraestructura, I\&D, } \\
\text { y/o Tecnología? }\end{array}$ \\
\hline & $\begin{array}{l}\text { Estrategia de } \\
\text { mercadotecnia }\end{array}$ & $\begin{array}{l}\text { Participación de mercado, } \\
\text { industrias relacionadas, rivalidad } \\
\text { industrial, competencia, precio, } \\
\text { posicionamiento, satisfacción del } \\
\text { cliente. }\end{array}$ & $\begin{array}{l}\text { ¿Porcentaje bajo/alto de } \\
\text { participación en el } \\
\text { mercado, avance vs } \\
\text { competencia, porcenta- } \\
\text { je bajo/alto de quejas? }\end{array}$ \\
\hline
\end{tabular}

Fuente: Elaboración propia a partir de la información revisada. 


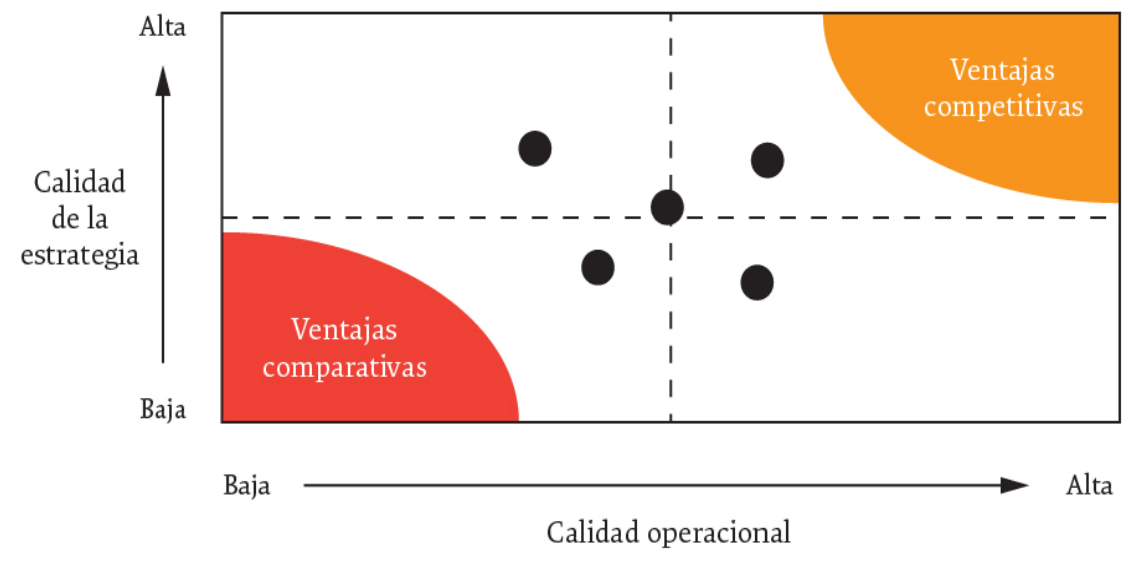

Figura 2. Modelo de competitividad empresarial.

Fuente: Elaboración propia a partir de la información revisada.

en productos y mejorar el servicio posventa. Los objetivos y la ponderación en los indicadores es diferente en distintos países; los norteamericanos, por ejemplo, dan gran importancia al retorno de capital empleado, el retorno de inversión y al valor para el accionista, mientras que los japoneses destacan la participación de mercado y el capital intelectual (Biasca, 2000).

\section{Metodología}

La investigación es esencialmente exploratoria, se apoya en la utilización de un cuestionario como instrumento para obtener la información; es de tipo transversal, el estudio se realizó en un solo momento en el tiempo (2014-2015). Se aplicaron encuestas en 4 municipios del estado de Sonora para hacer evaluaciones comparativas, entre ellos Navojoa, y se realizó un muestreo aleatorio simple a PyMES.

Para la recolección de datos se utilizó la metodología ICE del FEM y el enfoque de competitividad sistémica de Michael Porter; a continuación se describe el procedimiento:

Nivel de Competitividad Industrial (Empresarial) $=f(V 1, V 2, V 3, V 4, V 5, V 6, V 7, V 8, V 9 y$ V10) Donde:

$V 1=$ Estrategia de Planeación Empresarial (EPE)

$V 2=$ Estrategia de Organizacional $(E O)$

V3= Estrategia de Administración (EA)

$V 4=$ Estrategia de Competitividad (EC)

V5 = Estrategia Recuso Humano $(R H)$

V6 = Estrategia de Producción (EP)

$V 7=$ Estrategia de Tecnología

$V 8=$ Logística $(E L)$

$V 9=$ Estrategia Financiera (EF)

$V 10=$ Estrategia de Mercadotecnia (EM) 
En un inicio se definen los municipios del estado de Sonora (Hermosillo, Navojoa, Nogales y Caborca) y el proceso metodológico utilizado, el cual permite analizar las diferentes variables independientes $(V I)$, obteniendo su valor por la sumatoria del valor promedio de sus indicadores entre el número de indicadores, como se expresa a continuación:

$$
\begin{aligned}
& \begin{array}{l}
\text { Valor promedio de las Variable Independiente (VI) } \\
\text { por empresa (VPVIE) }
\end{array} \\
& =\frac{\sum \text { indicadores }}{\text { Número de indicadores }}
\end{aligned}
$$

El segundo paso es la sumatoria del valor de cada una de las VI por empresa entre el número de empresas, que permite identificar el valor promedio de cada VI por empresa, como se expresa a continuación:

\section{Valor promedio (VI) por municipio (VPVIM) \\ Número de empresas}

$\Sigma$ VPVIE

Como las medidas de distancia son sensibles a las diferencias de escalas o magnitudes hechas entre variables, es necesaria la estandarización de datos para evitar que las variables con gran dispersión tengan un mayor efecto en la similaridad. La forma de estandarización más común es restarle a cada observación la media de la variable y este resultado dividirlo entre su desviación estándar (Anderson, Sweeney, William, Camm y Cochran, 2013). Lo que se consigue con ello es eliminar las diferencias introducidas por las diferencias de escalas de las distintas variables (atributos) usados en el análisis. Se utiliza el paquete SPSS (Statistic Packaged Social Science) versión 21 para obtener las frecuencias, la media y desviación estándar. Una vez estandarizados los datos se analizan y presentan las tablas y gráficas correspondientes por municipio y a nivel estatal.

\section{Objetivo}

Realizar un diagnóstico para la determinación de variables e indicadores que definan y midan la competitividad de la PyMES en los municipio de Hermosillo, Navojoa, Nogales y Caborca, del estado de Sonora, para hacer una detección estratégica de soluciones que permita a las empresas en cuestión alcanzar el nivel de competitividad que requieren para permanecer, crecer o desarrollarse en el mercado.

\section{Hipótesis}

Se considera que el valor de competitividad empresarial de las PyMES de los municipios seleccionados del estado de Sonora se encuentrán en un nivel medio-alto. 


\section{Análisis y discusión de los datos}

En la Figura 3 se puede apreciar qué municipios están en la media de competitividad (60\%), o por encima, respecto a la calidad de la estrategia y la operación competitiva. En el caso de Hermosillo y Guaymas están muy cerca de la media, por lo que sus empresas deben tomar acciones de mayor competencia que impulsen la obtención de ventajas competitivas, como el caso de los municipios de Navojoa y Ciudad Obregón. La situación de Agua prieta, Nogales, Caborca y San Luis Río Colorado es similar, tienen que revalorar sus ventajas comparativas, es decir, las que se derivan de sus costos o disponibilidad de factores, tal como la disponibilidad de materias primas, costo de insumos, cercanía; y sus ventajas competitivas, las que se desarrollan de habilidades particulares, tal como tecnología, marca, equipos de trabajo.

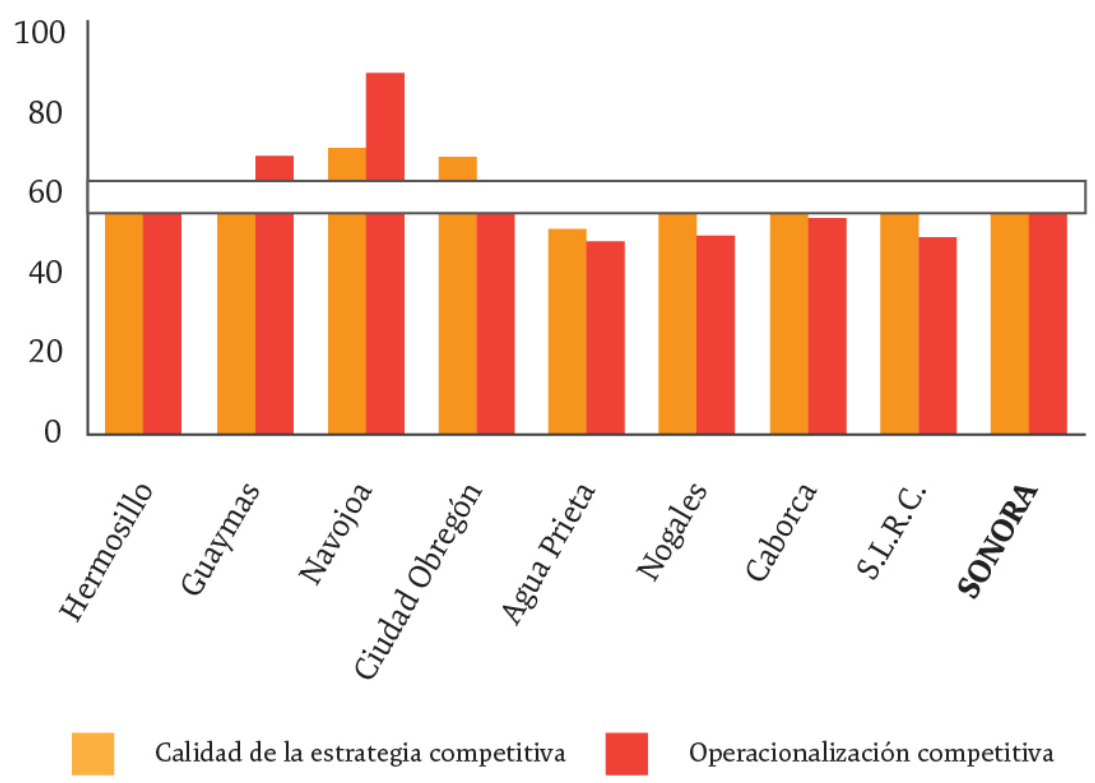

Figura 3. Calidad de la Estrategia y Operación por municipios.

Fuente: elaboración propia a partir de los datos.

A continuación se presentan en la Tabla 2 el orden de los municipios de acuerdo al Índice de Competitividad Empresarial (ICE) con valores estandarizados. De acuerdo a estos valores, el municipio con mayor ICE es Navojoa, donde los subsectores que sobresalen son los de alimentos y bebidas; el de madera, plásticos, envases; y metálica básica. Aparece en segundo lugar Hermosillo, en el cual sobresalen los subsectores de alimentos y bebidas; papel, imprenta y editoriales; madera y sus productos; y transporte. En tercer lugar, se encuentra Caborca, donde los subsectores que sobresalen son alimentos agropecuarios; $y$ manufactura de maquila. Y finalmente Nogales, donde los sectores que sobresalen son la manufactura de productos y de maquila. 
Tabla 2. Índice de Competitividad Empresarial, valores estandarizados.

\begin{tabular}{|l|c|c|c|c|c|c|c|c|c|c|c|c|}
\hline & $\begin{array}{l}\text { V1 } \\
\text { EPE }\end{array}$ & $\begin{array}{c}\text { V2 } \\
\text { EO }\end{array}$ & $\begin{array}{c}\text { V3 } \\
\text { EA }\end{array}$ & $\begin{array}{c}\text { V4 } \\
\text { EC }\end{array}$ & $\begin{array}{c}\text { V5 } \\
\text { ERH }\end{array}$ & $\begin{array}{c}\text { V6 } \\
\text { EP }\end{array}$ & $\begin{array}{c}\text { V7 } \\
\text { ET }\end{array}$ & $\begin{array}{c}\text { V8 } \\
\text { EL }\end{array}$ & $\begin{array}{c}\text { V9 } \\
\text { EF }\end{array}$ & $\begin{array}{c}\text { V10 } \\
\text { EM }\end{array}$ & $\begin{array}{c}\boldsymbol{\Sigma} \\
\text { ICE }\end{array}$ & Orden \\
\hline Hermosillo & .43 & .57 & 00 & .62 & .29 & .34 & .18 & .55 & 0 & 1.0 & 4.1 & 2 \\
\hline Navojoa & 1.00 & 00 & .80 & .73 & .99 & 1.0 & .78 & 1.0 & .87 & .63 & 7.8 & 1 \\
\hline Nogales & .54 & 00 & .39 & .73 & .06 & .15 & .10 & 0 & .14 & .31 & 2.4 & 3 \\
\hline Caborca & .49 & .41 & .48 & .64 & .33 & .06 & .57 & .45 & .09 & 0 & 3.5 & 4 \\
\hline
\end{tabular}

Fuente: elaboración propia con valores estandarizados.

\section{Análisis de correlación}

De las diez variables independientes consideradas en esta investigación, nueve presentan un nivel medio y alto en su relación con el nivel de ICE (variable dependiente) de cada municipio, así la estrategia de recursos humanos (ERH), estrategia de producción (EP), estrategia de tecnología (ET), estrategia de logística (EL), y estrategia de finanzas (EF) presentan los valores más altos $r=0.861 \mathrm{r}^{2}=0.741 ; \mathrm{r}=0.934 \mathrm{r}^{2}=0.872 ; \mathrm{r}=0.695, \mathrm{r}^{2}=0.483$; $r=0.913 r^{2}=0.833 ; y \mathrm{r}=0.714$ y r $^{2}=0.509$ respectivamente, mientras que la estrategia de planeación estratégica empresarial (PEE), estrategia de Administración (EA), estrategia de competitividad (EC), y estrategia de mercadotecnia (EM) presentan valores medios $r=$

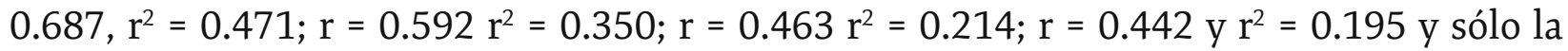
estrategia de organización (EO) presenta valores bajos en su relación con el ICE $r=-0.319$ $\mathrm{r}^{2}=0.101$, esto se ilustra en la Tabla 3 y 4.

Tabla 3. Coeficiente de correlación de Pearson.

\begin{tabular}{|l|c|c|c|c|c|c|c|c|c|c|c|}
\hline & EPE & EO & EA & EC & ERH & EP & ET & EL & EF & EM & ICE \\
\hline EPE & 1 & & & & & & & & & & \\
\hline EO & $.821^{* *}$ & 1 & & & & & & & & & \\
\hline EA & .207 & -.21 & 1 & & & & & & & & \\
\hline EC & .068 & .0998 & .344 & 1 & & & & & & & \\
\hline ERH & .454 & -.238 & $.754^{*}$ & .302 & 1 & & & & & & \\
\hline EP & $.806^{* *}$ & -.410 & .400 & .214 & $.781^{*}$ & 1 & & & & & \\
\hline ET & .532 & -.388 & 364 & .607 & .434 & .500 & 1 & & & & \\
\hline EL & .565 & -.214 & .426 & .512 & $.791^{*}$ & $.799^{* *}$ & $.799^{* *}$ & 1 & & & \\
\hline EF & .509 & -.279 & .632 & .620 & .487 & .529 & $.761^{*}$ & .656 & 1 & & \\
\hline EM & .596 & -.285 & .246 & .367 & .199 & .499 & .468 & .598 & .374 & 1 & \\
\hline ICE & $.687^{*}$ & -.319 & .592 & .463 & $.861^{* *}$ & $.934^{* *}$ & $.695^{*}$ & $.913^{* *}$ & $.714^{*}$ & .442 & 1 \\
\hline
\end{tabular}

* Correlation is significant at the 0.01 level (2-tailed) ** Correlation is significant at the 0.05 level (2-tailed)

Fuente: elaboración propia a partir de los datos. 
Tabla 4. Coeficiente de Determinación $\left(r^{2}\right)$.

\begin{tabular}{|l|c|c|c|c|c|c|c|c|c|c|c|}
\hline & EPE & EO & EA & EC & ERH & EP & ET & EL & EF & EM & ICE \\
\hline $\mathbf{R}^{2}$ & .471 & .101 & .350 & .214 & .741 & .872 & .483 & .833 & .509 & .195 & 1 \\
\hline
\end{tabular}

Fuente: elaboración propia.

Se puede observar en la Tabla 3 y 4 que las estrategias bien definidas y realizadas operativamente bien son las del recurso humano, del proceso productivo, de tecnología, de logística y de finanzas, mientras que las que están término medio y que tendrán que ajustar y mejorar son las estrategias de planeación, de administración, de competitividad y de mercadotecnia, a través de ser más puntuales en los aspectos técnicos de definición de la planeación y hacer su difusión interna ampliamente, por otro lado realizar periódicamente estudios pertinentes de mercado que apoyen las acciones de innovación y desarrollo de nuevos productos, establecer que las estrategia sean auténticamente competitivas como rasgo distintivo de sus toma de decisiones, y necesariamente impulsar un compromiso de los directivos y empleados y flexibilizar estructura organizacional que les permita obtener ventajas competitivas. La estartegia de organización es la única variable que, si bien resultó baja su relación y explicación para el ICE, es rescatable ya que se puede hacer más flexible la estructura organizacional, mejorar la comunicación y deslindar la responsabilidad y autoridad que les permita un avance hacia una mayor competitividad.

\section{Conclusión}

El modelo de competitividad empresarial presentado en la Figura 2 se podrá implementar únicamente cuando exista en las PyMES una cultura de calidad y mejora continua fuerte, orientada a la sistematización, es decir, orientada a un esfuerzo coordinado y disciplinado de todos los miembros y departamentos de una organización y del compromiso de la alta dirección.

En el municipio de Navojoa, Sonora el nivel de competitividad de las empresas es medio-alto, aun así han tenido una participación muy moderada en la penetración de mercados nacionales e internacionales. La recomendación es impulsar no sólo las empresas del subsector de alimentos, madera, plásticos y papel, sino también los subsectores no tradicionales como el de la electrónica, metalmecánica, de la química, minería, impulsando en algunos casos la constitución de clusters como la aeroespacial, de recientemente creación en el estado de Sonora con apenas año y medio, la nanotecnología, productos del mar, frutales, y turismo.

Asimismo se puede observar en la Tabla 3 y 4 que hay variables que deben ser ajustadas de forma inmediata por los empresarios de las PyMES consideradas, como el caso de la estructura organizacional, la cual requiere una revisión profunda y seguramente de flexibilizarse para ser eficientes; también se tendrán que revisar los indicadores de variables como mercadotecnia, competitividad, planeación y administración, redefinir algunos de ellos y su operación, darle seguimiento muy cerca de tal modo que les permita mejorar sus 
resultados. Se tendrá que ser más estrictos en la definición de su plan estratégico y de las acciones que generan ventajas competitivas, porque si no se corre el riesgo de no estar en posición de competir con las demás empresas, tanto nacionales como extranjeras instaladas en México.

Aunque en gran medida las variables sí explican el ICE, su eficiencia indica que las PyMES deben poner atención en plantear y llevar a cabo sus operación en su segmentos de mercado, tener un buen control en comercializar, financiar y cobrar sus operaciones con la banca y sus clientes, así mismo dar seguimiento estricto a los ajustes pertinentes para mejorar sus resultados y así obtener auténticamente ventajas competitivas.

De los resultados del modelo de Competitividad Empresarial se destaca la importancia de ICE para las PyMES en los municipios, los cuales permiten establecer que a medida que se vinculen los Centros de Investigación, Instituciones y Organismos Públicos y Privados, así como las universidades, en torno a fortalecer el ICE, será posible obtener ventajas competitivas tanto en lo interno y externo de cada empresa, permitiendo desarrollar nuevas industrias y clusters en las opciones no tradicionales para el estado de Sonora.

Finalmente, no se descarta que existan otras variables que afecten el ICE a las empresas PyMES manufactureras, aunque existen pocas aportaciones que permitan cuantificarse. Esta investigación representa un esfuerzo y primer acercamiento de medición de la ICE a niveles desagregados. 


\section{Referencias bibliográficas}

Anderson, D., Sweeney, D., William, T., Camm, J., \& Cochran, J. (2013). Statistics for Business and Economics. Salem: South Western College Pub.

Biasca R. (2000). Resultados: La fórmula para crecer en el vértigo competitivo. Argentina: Granica.

Cervantes, A. (2005). Competitividad e internacionalización de las Pequeñas y Medianas empresas Mexicanas. Tesis de grado, Facultad de Ciencias Políticas y Sociales, Universidad Nacional Autónoma de México.

Confederación Patronal de la República Mexicana (COPARMEX). (2014). Estudio de la Empresa Media. Ciudad de México: BMZ, SEQUA, FUNDES.

Foro Económico Mundial (FEM). (2014).Indice de Competitividad Empresarial. Suiza:Institute for Management Development (IMD).

Instituto Nacional de Economía, Geografía e Informática (INEGI). (2014). Presentación. Resultados definitivos. Censos económicos 2014. Recuperado de http://www.inegi.org. $\mathrm{mx} / \mathrm{est} /$ contenidos/Proyectos/ce/ce2014/doc/presentacion/pprd_ce2014.pdf

Kotler, P., \& Lane, K. (2006). Dirección de Marketing. Ciudad de México: Pearson Educación. McCarty, J., \& Perreault, W. (2014). Marketing: Un enfoque Global. Ciudad de México: McGraw Hill.

Porter, M.E. (1986). Teoría Moderna del Comercio Internacional. Ciudad de México: Editorial CECSA.

Porter, M.E. (1991). La ventaja competitiva de las naciones. Buenos Aires: Editorial Javier Vergar.

Porter, M.E. (2005). Ventaja Competitiva creación y sostenimiento de un desempeño superior. Ciudad de México: Continental.

Porter, M.E. (2007). Estrategia Competitiva: Técnicas para el análisis de los sectores industriales $y$ de la competencia. Ciudad de México: Editorial Patria. 


\title{
Capítulo 5
}

\section{Metodología para la planeación de huertos familiares en comunidades rurales}

\author{
Manuel Castro Herrera \\ Alma Elena Salazar Félix
}

Universidad Estatal de Sonora 


\section{Introducción}

La seguridad alimentaria es uno de los principales objetivos que persigue la humanidad, es por ello que los huertos familiares son una opción para el aseguramiento de alimentos de manera más económica.

La población de las comunidades rurales del municipio de Benito Juárez, en el Estado de Sonora cuenta con los recursos naturales para el desarrollo de actividades a traspatio, por tal motivo, el presente capítulo plantea una metodología para desarrollar huertos familiares que atiendan la problemática de desarrollo social y económico de las comunidades rurales del municipio.

"El término huerto familiar es un convencionalismo académico que se refiere al área que rodea a la casa habitación, e incluyéndola, contiene plantas cultivadas, animales criados e infraestructura doméstica y de trabajo familiar" (Mariaca, 2012).

Se aplicó el método científico, con el objetivo de obtener información relevante y fidedigna para entender y aplicar el conocimiento en actividades de producción agropecuaria a traspatio, definiendo una metodología para la Planeación de un prototipo de huerto familiar, que contempla el seguimiento y evaluación socioeconómica del proyecto a implementar en comunidades rurales del sur del municipio de Benito Juárez, Sonora, México.

\section{Planteamiento del problema}

El municipio de Benito Juárez se encuentra situado en el sur del Estado de Sonora, entre los paralelos $26^{\circ} 58^{\prime}$ y $27^{\circ} 14^{\prime}$ de latitud norte; los meridianos $109^{\circ} 43^{\prime}$ y $109^{\circ} 59^{\prime}$ de longitud oeste; altitud entre 0 y 100 metros sobre el nivel del mar. Colinda al norte con los municipios de Cajeme y Etchojoa; al este con el municipio de Etchojoa; al sur con el municipio de Etchojoa y el Golfo de California; al oeste con el Golfo de California y el municipio de Cajeme. Ocupa el $0.18 \%$ de la superficie del estado.

Tiene un rango de temperatura de $0-24^{\circ} \mathrm{C}$, un rango de precipitación de menos de 100-300 mm, un clima muy seco y cálido.

El uso del suelo es principalmente para agricultura (92.06\%); las zonas urbanas representan el $1.70 \%$ y "están creciendo sobre suelos del Cuaternario en llanura deltaica; sobre áreas donde originalmente había suelos denominados Vertisol y Solonchak; [...] están creciendo sobre terrenos previamente ocupados por agricultura y matorrales" (INEGI, 2009).

El municipio cuenta con una población de 22,009 habitantes, sus poblaciones con mayor densidad son su cabecera municipal Villa Juárez con 13,770 habitantes, Paredón Colorado $(2,665)$ y Paredoncito $(2,251)$; la disponibilidad de la vivienda son 5,643 con un promedio de 3.9 habitantes por vivienda, el 56.4\% cuenta con agua entubada dentro de la misma (INEGI, 2011).

La población de 15 años y más según su nivel de escolaridad está distribuida el $64.1 \%$ en nivel básico, el $18.4 \%$ en nivel medio superior, el 10.4\% nivel superior y el $6.3 \%$ sin instrucción (INEGI, 2011). 
De la población económicamente activa (PEA), el 47 \% de las personas mayores de 12 años participa en las actividades económicas, el 53\% que representa la población no activa está distribuida con el $48.8 \%$ dedicado al hogar, $34.5 \%$ son estudiantes, el $7.6 \%$ jubilados y el $6.1 \%$ con otras actividades, y el 3\% cuenta con alguna discapacidad. La situación social en lo que respecta a su situación conyugal, el $33 \%$ son casados y un $22 \%$ viven en unión libre, mientras que el $32.8 \%$ son solteros; respecto a los servicios de seguridad social el 76\% cuentan con algún servicio de salud pública o privada; profesa la religión católica el 83.8\% de la población; y el 1\% habla la lengua indígena mayo (INEGI, 2011).

De las actividades económicas que se desarrollan en el municipio, según datos de INEGI con cifras del 2011, las del sector primario contaron con una superficie de 37,355 hectáreas de las cuales 24,676 son del cultivo del trigo, 2,041 de grano de maíz, 1,620 de sorgo forrajero y el resto de otras actividades, mientras que en el sector de ganadería la producción de carne de porcino fue de 1,398 toneladas seguida por la de Bovino con 147 ton. Y gallináceas con 73 toneladas, mientras que el huevo de plato tuvo una producción de 2,960 toneladas; el sector industrial no presenta actividades y el sector de servicios cuenta con una sucursal de banca comercial y servicios de transporte de carga y pasajeros con 1,277 unidades registradas al 2014 (INEGI, 2015).

Las principales problemáticas relacionadas a insuficiencia agroalimentaria, falta de empleo y desaprovechamiento de los recursos se encuentran identificadas en el Plan Nacional de Desarrollo 2013-2018, dentro de su eje México Próspero, en el cual uno de los objetivos es "construir un sector agropecuario y pesquero productivo que garantice la seguridad alimentaria del país"; y una de las estrategias para lograrlo es "impulsar la productividad en el sector agroalimentario mediante la inversión en el desarrollo de capital físico, humano y tecnológico" con las siguientes líneas de acción (PND, 2013):

- Orientar la investigación y desarrollo tecnológico hacia la generación de innovaciones que aplicadas al sector agroalimentario eleven la productividad y competitividad.

- Desarrollar las capacidades productivas con visión empresarial.

- Impulsar la capitalización de las unidades productivas, la modernización de la infraestructura y el equipamiento agroindustrial y pesquero.

- Fomentar el financiamiento oportuno y competitivo.

- Impulsar una política comercial con enfoque de agronegocios y la planeación del balance de demanda y oferta, para garantizar un abasto oportuno, a precios competitivos, coadyuvando a la seguridad alimentaria.

- Apoyar la producción y el ingreso de los campesinos y pequeños productores agropecuarios y pesqueros de las zonas rurales más pobres, generando alternativas para que se incorporen a la economía de manera más productiva.

- Fomentar la productividad en el sector agroalimentario, con un énfasis en proyectos productivos sostenibles, el desarrollo de capacidades técnicas, productivas y comerciales, así como la integración de circuitos locales de producción, comercialización, inversión, financiamiento y ahorro. 
- Impulsar la competitividad logística para minimizar las pérdidas poscosecha de alimentos durante el almacenamiento y transporte.

- Promover el desarrollo de las capacidades productivas y creativas de jóvenes, mujeres y pequeños productores.

Por todo lo anteriormente expuesto y analizado se determina que existe la necesidad de producir alimentos para el autoconsumo, además se cuenta con los elementos necesarios para implementar un prototipo de huerto familiar en las comunidades del sur del municipio de Benito Juárez, Sonora.

\section{Marco de Referencia}

El huerto familiar es una de las principales actividades agrícolas de subsistencia, desde épocas prehispánicas los habitantes ya sembraban en los patios de sus casas para tener alimento y poder sobrevivir, es por ello que se considera que es una estrategia viable para preservar la biodiversidad el autoconsumo y la economía familiar. Un huerto familiar comprende prácticas del uso de la tierra, que incluyen el manejo deliberado de especies vegetales y animales dentro del recinto de la casa el cual es manejado intensivamente por la unidad familiar.

El término huerto familiar, de acuerdo a Mariaca (2012):

[...] es un agroecosistema con raíces tradicionales, en el que habita la unidad familiar y donde los procesos de selección, domesticación, diversificación y conservación están orientados a la producción y reproducción de flora y fauna y, eventualmente de hongos. Está en estrecha relación con la preservación, las condiciones sociales, económicas y culturales de la familia y el enriquecimiento, generación y apropiación de tecnología [...] El objeto de considerar a la familia que lo habita, es porque ella delimita la forma, estructura, diversidad y riqueza de especies, así como la historia y futuro de esta forma de producción de satisfactores. (P. 10)

El traspatio analizado como agrosistema en una comunidad del Estado de Puebla, México, está integrado por cuatro componentes: agrícola, pecuario, agua e infraestructura y equipo el $77.8 \%$ de los grupos domésticos campesinos cuenta con tres componentes, sobresaliendo los tres primeros. La superficie del área agrícola y superficie total de invernadero están asociadas a la superficie total de traspatio (González, Pérez, Ocampo, Paredes y De la Rosa, 2013).

De acuerdo a SAGARPA (2015):

El huerto familiar es la parcela en la que se cultivan hortalizas frescas en forma intensiva y continua durante el año, lo cual implica hacer siembras en forma escalonada. Un huerto familiar se puede establecer en pequeños espacios de tierra 
cerca de la casa y es fácil de atender. El tamaño del huerto depende del número de personas que forman la familia. Dos aspectos importantes que deben tomarse en cuenta para lograr buenos resultados son la disponibilidad del agua y la planeación del propio huerto. (P. 2)

Para el diseño de un prototipo de huerto familiar es necesario aplicar el procedimiento de formulación y evaluación de proyectos que consta de varias etapas.

De acuerdo a Baca (2011) son las siguientes:

- Estudio de Mercado. Sus objetivos son los siguientes: ratificar la existencia de una necesidad insatisfecha en el mercado; determinar la cantidad de bienes o servicios provenientes de una nueva unidad de producción que la comunidad estaría dispuesta a adquirir a determinados precios; conocer cuáles son los medios que se emplean para hacer llegar los bienes y servicios a los usuarios, en donde de ser insostenible cualquiera de estos aspectos a nuestros objetivos, de entrada se tronaría la factibilidad del proyecto en cuestión.

- Estudio técnico operativo. Tiene por objetivos verificar la posibilidad técnica de fabricación del producto que se pretende y analizar y determinar el tamaño óptimo, la localización óptima, los equipos, las instalaciones y la organización requeridos para realizar la producción. Por lo tanto el Estudio Técnico se divide en cuatro partes que son: tamaño físico del proyecto, localización del proyecto, ingeniería del proyecto y análisis administrativo.

- Estudio económico. El objetivo de este estudio, es ordenar y sistematizar la información de carácter monetario que proporcionan las etapas anteriores y elaborar cuadros analíticos que sirven de base para la evaluación financiera. Las bases del estudio económico son los costos totales y de la inversión inicial cuyo origen son los estudios mercado y el de ingeniería, ya que costos e inversión inicial, dependen de la producción planteada y la tecnología seleccionada; posteriormente se desarrolla el cálculo de la depreciación y amortización de toda la inversión inicial, el cálculo de Capital de Trabajo.

- Estudio financiero. El objetivo del análisis financiero tiene como finalidad aportar una estrategia que permita al proyecto allegarse de los recursos necesarios para su implantación y contar con la suficiente liquidez y solvencia, para desarrollar ininterrumpidamente operaciones productivas y comerciales. El análisis financiero aporta la información necesaria para estimar la rentabilidad de los recursos que se utilizarán, susceptibles de compararse con las de otras alternativas de inversión. 


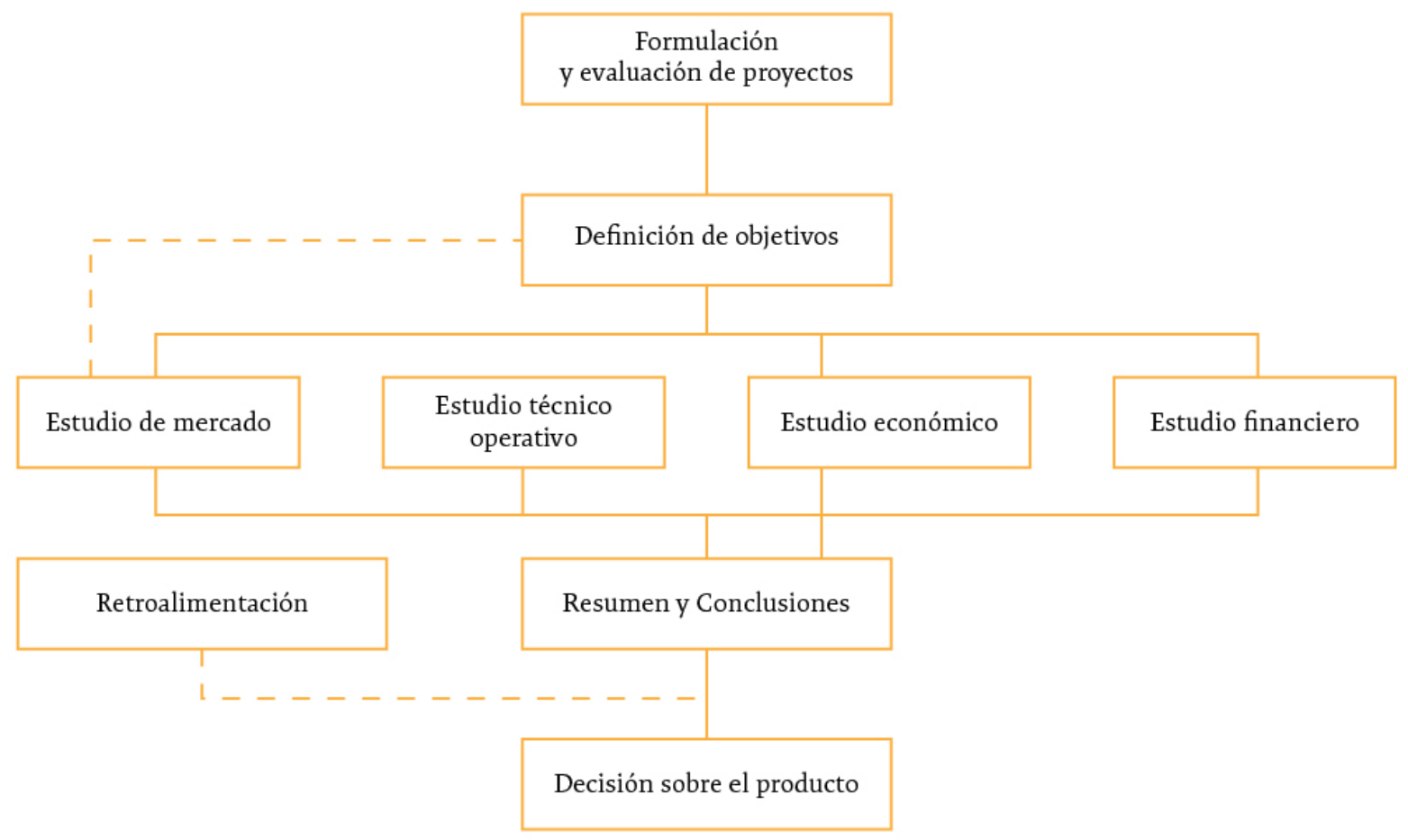

Figura 1. Esquema de formulación y evaluación de proyectos.

Fuente: Baca (2011).

\section{Metodología}

La investigación se basa en la aplicación del método científico, con el objetivo de obtener información relevante y fidedigna para entender, verificar, corregir y aplicar el conocimiento en la atención de necesidades de desarrollo social y económico de las comunidades rurales del Municipio de Benito Juárez.

El desarrollo del plan de implementación de un huerto familiar, parte de una investigación histórica con el objetivo de describir acontecimientos pasados de la cultura social y económica relacionada con las actividades de producción agropecuaria a traspatio en las comunidades rurales del municipio.

Es investigación aplicada, parte de la búsqueda de información en fuentes primarias y secundarias, mismas que fueron examinadas cuidadosamente con el fin de determinar su confiabilidad y poder conocer la existencia y factibilidad técnica y económica de implementación de actividades agropecuarias a traspatio.

Se aplica la investigación de campo ya que pretende la implementación de un prototipo de huerto familiar al interior de las comunidades rurales del municipio para su seguimiento, evaluación y análisis. 


\section{Resultados}

En la Tabla 1 se estructura la metodología para el diseño de un plan de implementación de Huertos Familiares en las comunidades rurales del Sur del Municipio de Benito Juárez, Sonora.

El diagnóstico es esencial, su objetivo es contribuir a un mayor conocimiento de la situación actual y evaluación del sector agropecuario; permite identificar programas y proyectos de inversión proporcionando elementos fundamentales para la formulación de estrategias y acciones que contribuyen a la toma de decisiones sobre el diseño del plan.

Para elaborar un buen diagnóstico es necesario identificar fuentes de información confiables como: artículos científicos, revistas especializadas, publicaciones oficiales de Instituciones de Gobierno Federales, Estatales, Municipales y de iniciativa privada.

La información, obtenida del diagnóstico de la situación demográfica de las comunidades rurales, sirve de base para el desarrollo del estudio de mercado, en el cual es necesario identificar la posible oferta y demanda así como la disponibilidad de recursos naturales, económicos y de carácter social para el establecimiento del proyecto.

Surge además, la necesidad de diseñar un instrumento de recolección de datos para determinar los espacios de terreno, sus características y su utilización, productos agropecuarios que puedan producirse, así como la disponibilidad de los habitantes para la implementación del huerto familiar.

Una vez determinada la viabilidad de continuar con el proyecto en el estudio de mercado, se procede a llevar a cabo el estudio técnico, el cual se refiere a los requerimientos necesarios para implementar el huerto familiar, tales como: ubicación del proyecto, tamaño, distribución, herramientas de trabajo, materias primas, mano de obra, organización del proyecto y aspectos legales para su desarrollo; todo ello expresado en unidades de medida, peso, condiciones y requerimientos técnicos, entre otros.

El estudio económico parte de los resultados del estudio técnico, y se refiere a los montos de la inversión inicial, fija y diferida, costo de las herramientas de trabajo, costo de las materias primas, proyección de ingresos y/o ahorro en el gasto familiar; esta información sirve de base para dar seguimiento y control al proyecto, de tal forma que sea posible determinar la rentabilidad, así como el impacto sociales y económico del proyecto. 
Tabla 1. Metodología para el diseño de un plan de implementación de huertos familiares en las comunidades rurales del sur del municipio de Benito Juárez, Sonora.

\section{Objetivo General:}

Implementar un huerto familiar que atienda la problemática de desarrollo social y económico de las comunidades rurales del municipio de Benito Juárez, Sonora.

\begin{tabular}{|c|c|}
\hline \multirow{5}{*}{ 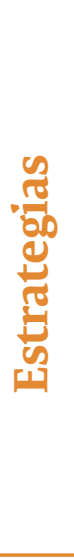 } & $\begin{array}{l}\text { 1. Diagnosticar condiciones demográficas actuales de la población de las comunidades } \\
\text { rurales del sur del municipio. }\end{array}$ \\
\hline & $\begin{array}{l}\text { 2. Diseñar proyectos que contribuyan a la atención de problemática de desarrollo social } \\
\text { y económico de las comunidades rurales del municipio, derivados del diagnóstico y las } \\
\text { actividades agropecuarias pertinentes. }\end{array}$ \\
\hline & $\begin{array}{l}\text { 3. Implementar proyecto prototipo de un huerto familiar en una comunidad del sur del } \\
\text { municipio. }\end{array}$ \\
\hline & 4. Evaluar los resultados obtenidos en la implementación del huerto familiar. \\
\hline & $\begin{array}{l}\text { 5. Capacitar a diferentes grupos familiares de las comunidades rurales del municipio para } \\
\text { desarrollar sistemas de producción agropecuaria. }\end{array}$ \\
\hline \multirow{11}{*}{ 。 } & $\begin{array}{l}\text { 1.1 Aplicar el método de investigación documental relacionadas a factores políticos, eco- } \\
\text { nómicos, sociales y tecnológicos enfocados al sector agropecuario de la región. }\end{array}$ \\
\hline & 1.2 Análisis de leyes federales y estatales relacionadas a las actividades agropecuarias. \\
\hline & $\begin{array}{l}\text { 1.3 Análisis de las instituciones gubernamentales y del sector privado relacionadas con } \\
\text { las actividades agropecuarias. }\end{array}$ \\
\hline & 2.1 Diagnóstico sobre la situación demográfica de las comunidades del sur del municipio. \\
\hline & $\begin{array}{l}\text { 2.3 Estudio técnico sobre el diseño e implementación de huerto familiar prototipo en } \\
\text { una de las comunidades del sur del municipio. }\end{array}$ \\
\hline & $\begin{array}{l}\text { 2.4 Estudio económico financiero para definir los montos de inversión inicial, fija y dife- } \\
\text { rida, así como las necesidades de capital de trabajo. }\end{array}$ \\
\hline & $\begin{array}{l}2.5 \text { Toma de decisiones sobre la viabilidad de implementar un proyecto prototipo en una } \\
\text { comunidad del sur del municipio. }\end{array}$ \\
\hline & $\begin{array}{l}\text { 3.1 Con base al diseño de proyecto, seleccionar una familia de una de las comunidades } \\
\text { del sur del municipio para la implementación del huerto familiar. }\end{array}$ \\
\hline & $\begin{array}{l}\text { 3.2 Implementar el proyecto durante un ciclo productivo anual, dando seguimiento para } \\
\text { su evaluación socioeconómica, mediante la aplicación de técnicas de evaluación financie- } \\
\text { ra, de impacto social y ambiental. }\end{array}$ \\
\hline & $\begin{array}{l}\text { 4.1 Aplicación de herramientas de evaluación de proyectos y elaboración de informe de } \\
\text { resultados. }\end{array}$ \\
\hline & $\begin{array}{l}\text { 5.1 Mediante la técnica trabajo-aprendizaje, capacitar a familias sobre la implementación } \\
\text { del huerto familiar. }\end{array}$ \\
\hline
\end{tabular}




\section{Conclusiones}

Como en un principio se comentó, el presente capítulo se constituye como el producto de una investigación documental, en la cual se revisaron las metodologías que permiten el uso simple y confiable de procedimientos para que quien acuda a la elaboración de un proyecto de inversión, tenga una guía para el desarrollo de las estrategias y acciones a implementar. Aunque definitivamente se requiere de conocimientos y un equipo multidisciplinario de profesionistas para conjuntar el proyecto desde su diseño, implementación, seguimiento y evaluación.

Se toma en consideración el Plan Nacional de Desarrollo 2013-2018 como un fundamento para diseñar proyectos que impacten en los pobladores del medio rural, asegurando la suficiencia alimentaria beneficiando a su vez la economía familiar.

Por otra parte de un análisis bibliográfico, se determinan las etapas que deben de considerarse para el desarrollo de proyectos, en este caso la implementación de huertos familiares en comunidades rurales, la metodología para la formulación y evaluación de proyectos de inversión pueden adaptarsen para lograr integrar una metodología, en donde mediante un procedimiento lógico relativamente simple, se apoye a quienes incursionen en el diseño e implementación de huertos familiares en el medio rural. 


\section{Referencias bibliográficas}

Baca, G. (2011). Formulación y Evaluación de Proyectos. Ciudad de México: McGraw-Hill.

González, F., Pérez, A., Ocampo, I., Paredes, J.A., \& De la Rosa, P. (2013). Contribuciones de la producción en traspatio a los grupos domésticos campesinos. Estudios Sociales, 146-170.

Instituto Nacional de Estadística y Geografía (INEGI). (2009). Prontuario de información geográfica municipal de los Estados Unidos Mexicanos Benito Juárez, Sonora. Recuperado de http://www3.inegi.org.mx/sistemas/mexicocifras/datos-geograficos/26/26071. pdf

Instituto Nacional de Estadística y Geografía (INEGI). (2011). Censo de Población y vivienda (2010). Panorama sociodemográfico de Sonora. Recuperado de http://www.inegi.org. $\mathrm{mx} /$ prod_serv/contenidos/espanol/bvinegi/productos/censos/poblacion/2010/ panora_socio/son/Panorama_Son.pdf

Instituto Nacional de Estadística y Geografía (INEGI). (2015). México en cifras. Información nacional, por entidad y municipios. Recuperado de http://www3.inegi.org.mx/ sistemas/mexicocifras/default.aspx

Mariaca, R. (Ed). (2012). El huerto Familiar del Sureste de México. México: ECOSUR. Recuperado de https://www.academia.edu/12936149/_Del_huerto_a_los_ jardines_y_vecindades_procesos_de_cambio_en_un_agroecosistema_de_origen_ antiguo

Plan Nacional de Desarrollo (2013). PND 2013-2018. Diario Oficial de la Federación. DOF 20-05-2013. Recuperado de http://www.dof.gob.mx/nota_detalle. php? codigo $=5299465 \&$ fecha $=20 / 05 / 2013$

Secretaría de Agricultura, Ganadería, Desarrollo Rural, Pesca y Alimentación (SAGARPA). (2015, Septiembre 17). El huerto familiar. Recuperado de http://www.sagarpa.gob. $\mathrm{mx} /$ desarrolloRural/Documents/fichasaapt/El\%20Huerto\%20Familiar.pdf 


\section{Capítulo 6}

\section{Derecho al acceso a la información, un derecho humano elemental para hacer efectiva la transparencia}

Leticia María González Velásquez Juan José García Ochoa García Modesto Barrón Wilson

Universidad de Sonora 


\section{Introducción}

Un factor fundamental en las dependencias gubernamentales, sean estos federales, estatales o municipales, es la garantía al derecho a la información, un derecho democrático por excelencia.

El derecho de acceso a la información pública es la rama del derecho a la información constituida por un conjunto de normas jurídicas que posibilitan al ciudadano el examen de los registros y datos públicos en posesión tanto de los órganos estatales como de empresas privadas que ejercen gasto público (Cruz, de la Torre, Martínez y Muñoz, 2006).

La Constitución Política de los Estados Unidos Mexicanos reconoce el derecho al acceso a la información en el artículo $6^{\circ}$, señalando: "[...] el derecho a la información será garantizado por el Estado".

Este derecho humano lo puede ejercer cualquier persona. Sin embargo hay que reconocer que el ejercicio de este derecho requiere de construcción, su implementación debe de ser cuidadosamente, con visión a largo plazo. No basta que las Entidades cuenten con leyes y reglamentos para su aplicación, requiere de actitudes, hábitos y de procesos en los cuales están trabajando las Entidades Públicas. Esto implica establecer nuevos paradigmas referidos a la transparencia gubernamental para que ayuden a las dependencias del gobierno a cumplir con sus objetivos públicos y no a objetivos privados.

De ahí el interés del presente capítulo, que lleva a inferir, exponer y fomentar la cultura de la transparencia y la rendición de cuentas en el marco de la legalidad para los sujetos.

\section{Reseña histórica en México}

Entender el derecho al acceso a la información es generar un valor humano, es interesarse por los actos gubernamentales, y es generar una democracia participativa (Mendel, 2003).

En nuestro país se hace un gran esmero por ser los impulsores de la transparencia a nivel internacional, generando mecanismos de acceso a la información por medios electrónicos que facilitan a los usuarios obtener información gubernamental.

En 1977 la adición al artículo 6 constitucional describía "El derecho a la información será garantizado por el estado." Algo que no dio mucho resultado. En México se hizo el esfuerzo por implementar el derecho al acceso a la información la primera vez en 1978 durante la gestión del presidente José López Portillo, la segunda en 1995 mediante una propuesta de María Teresa Gómez Mont y la tercera en las Legislatura del 57 (Carpizo y Villanueva, 2001). Fue hasta el 2002 cuando nace la Ley Federal de transparencia y acceso a la información pública gubernamental. Previo a esto, los estados de Jalisco y Sinaloa ya tenían su ley acceso a la información.

\section{¿Qué es el derecho al acceso a la información?}

Definiciones del derecho al acceso a la información y derecho a la información que muy acertadamente difiere entre dos derechos que no son sinónimos. 
Villanueva (2003) describe:

El derecho a la información emplea los más diversos espacios, instrumentos y tecnologías para la transmisión de hechos e ideas. Algún medio puede presentar peculiaridades propias pero las instituciones del derecho a la información son las mismas para todos ellos, aunque acomodándose a sus características. (P. 122)

Y el derecho al acceso a la información como:

[...] prerrogativa de la persona para acceder a datos, registros y todo tipo de informaciones en poder de entidades públicas y empresas privadas que ejercen gasto público o cumplen funciones de autoridad, con las excepciones taxativas que establezca la ley en una sociedad democrática. (P.131)

Villanueva (2003) difiere los dos aspectos que ayudan a entender que los sujetos obligados por las leyes de transparencia, deben mantener la información pública denominada como básica publicada a través de portales de internet o de medios de acceso de la sociedad a datos públicos, sin que exista una solicitud de información y el derecho al acceso a la información cuando la persona acuda ante una unidad de enlace a solicitar información.

Entendiendo lo que es el derecho al acceso a la información, la legislación en México deriva de su artículo $6^{\circ}$ constitucional, en el cual describe los principios para regir este derecho. El derecho al acceso a la información es un derecho humano interpretado por diversos órganos internacionales como la Organización de las Naciones Unidas (ONU), la Organización de los Estados Americanos (OEA), el Consejo Europeo (CE) (Mendel, 2003).

El derecho a la información de acuerdo con el artículo 19 de la Declaración Universal de los Derechos Humanos es la garantía fundamental que toda persona posee a atraerse información, a informar y a ser informada (Villanueva, 2003).

Entendiendo lo que es un derecho humano Nikken (1994) describe dos elementos fundamentales: "En primer lugar, se trata de derechos inherentes a la persona humana; en segundo lugar, son derechos que se afirman frente al poder público."

El artículo 133 de la Constitución Política de los Estados Unidos Mexicanos establece permisible jurídicamente celebrar contratos, tratados o pactos internacionales con otros estados. Es el caso que en 1945 representantes de 50 países se reunieron en San Francisco, California, E.U. lo que dio origen a la Organización de las Naciones Unidas (ONU). Con el cual se firmarían varios pactos internacionales fundamentales para proteger más que jurídicamente derechos inherentes del hombre; nace la Declaración Universal de Derechos Humanos en 1948, Declaración de los Derechos del Niño en 1959, la Declaración sobre la eliminación de la discriminación contra la mujer en 1967, el Pacto Internacional de Derechos Civiles y Políticos, así como el Pacto Internacional de Derechos Económicos, Sociales y Culturales en 1966, entre otros. 
La Declaración Universal de los Derechos Humanos, en su artículo 19, reconoce el derecho de todo individuo a: "[...] investigar y recibir informaciones y opiniones, y el de difundirlas, sin limitación de fronteras, por cualquier medio de expresión."

El Pacto Internacional de Derechos Civiles y Políticos, en su artículo 19, establece que "toda persona tiene derecho a la libertad de expresión; este derecho comprende la libertad de buscar, recibir y difundir informaciones e ideas de toda índole [...]."

La Convención sobre los Derechos del Niño, en el artículo 13, numeral 1, consagra:

El niño tendrá derecho a la libertad de expresión; ese derecho incluirá la libertad de buscar, recibir y difundir informaciones e ideas de todo tipo, sin consideración de fronteras, ya sea oralmente, por escrito o impresas, en forma artística o por cualquier otro medio elegido por el niño. (UNICEF, 2006)

\section{Ámbito interamericano}

La Declaración Americana de los Derechos y Deberes del Hombre consagra, en su artículo 4: "Toda persona tiene derecho a la libertad de investigación, de opinión y de expresión y difusión del pensamiento por cualquier medio" (CIDH, 1948).

A su vez, la Convención Americana de Derechos Humanos, en su artículo 13, consagra: "Toda persona tiene derecho a la libertad de pensamiento y de expresión. Este derecho comprende la libertad de buscar, recibir y difundir informaciones e ideas de toda índole, [...]" (OEA, 1969).

Así el derecho de acceso a la información y acceso a la información pública gubernamental está regido a través de diversos pactos internacionales que resguardan este derecho inherente al ser humano. En la historia de legislación nos encontramos con Suecia que desde 1766 legisla el acceso a la información denominada Ley para la libertad de prensa y el derecho de acceso a las actas públicas. Este ejemplo siguió a otros países posteriormente, Colombia (1888), Finlandia (1951), Estados Unidos (1966) y nuestro país en el 2002.

Es indispensable mantener la credibilidad de los actos gubernamentales pues de ello derivan las opiniones públicas más acertadas. La interpretación de las leyes internacionales basada constitucionalmente en el artículo 133 de la Carta Magna, y enfocándonos a las convenciones de Viena, las reglas dicen que los tratados deben ser interpretados de buena Fe. Es por eso que la interpretación que se le debe dar a los derechos humanos debe ser como principio para legislar entre los estados miembros de la Organización de las Naciones Unidas.

Según Cancado (2016) "los tratados de derechos humanos se dirigen al tratamiento dispensado por los Estados, en el ámbito de su ordenamiento jurídico interno, a todos los seres humanos sujetos a su jurisdicción [...]"

La interpretación de los principios elementales como lo son los derechos humanos no tienen un seguimiento en legislaciones municipales, pues hay leyes que se aprueban o faltan al cumplimiento de ordenamientos jurídicos supra que van en contra en este caso del derecho de acceso a la información, que si bien el derecho a ser informados o derecho 
a la información de oficio, que es la información pública básica obligatoria en el caso del Estado de Sonora, información que deben publicar básicamente en los portales de internet los sujetos obligados ejemplificando a los municipios de acorde al 3er transitorio de la reforma del artículo $6^{\circ}$ constitucional en el cual quedan sujetos los ayuntamientos con más de 70 mil habitantes, incumplen con el derecho a la información, no cumplen con el ordenamiento estatal de la Ley de acceso la información pública del estado de Sonora, artículo 14 que desprende 23 fracciones que describen la información de oficio que deben mantener en portales de internet.

Así la aplicación de los derechos con principios de derechos humanos muy difícilmente se esmeran por cumplir en legislaciones municipales, incluso hasta estatales, quizás el derecho al acceso a la información sea una cultura que ha faltado implementar de manera más coercitiva para que se cumpla, o quizás sea un derecho demasiado moderno que apenas los servidores públicos alcanzan a comprender y que pueden pensar que no es un beneficio, pero para la sociedad civil es fundamental tener ese derecho vigente y práctico, pues haciendo ejercicio de este derecho humano se facilita la detección de debilidades administrativas, por lo que se pueden generar estudios que coadyuven con mecanismos y técnicas de facilidad de publicación de información gubernamental con la finalidad de abatir posibles actos de corrupción, la esencia misma del estado es alcanzar el desarrollo social, sin embargo, éste se alcanzará a través de la eficiencia y eficacia de las dependencias gubernamentales.

Comprendiendo que el derecho al acceso a la información es un derecho humano, falta mucho para que la aplicación y comprensión del orden de gobierno municipal pueda basarse por estos principios elementales, pues la falta de servidores públicos y consejos ciudadanos que vigilen desde el centro de la administración del ayuntamiento disminuye el monitoreo para implementar los principios máximos de la Constitución Mexicana y los Tratados Internacionales.

La Conferencia Interamericana Especializada sobre Derechos Humanos, realizada en San José, Costa Rica, del 7 al 22 de noviembre de 1969, adoptó la Convención Americana sobre Derechos Humanos o "Pacto de San José de Costa Rica." Hasta ese momento la estructura institucional del sistema de protección internacional de los derechos humanos en América descansaba en instrumentos de naturaleza declarativa. A partir de entonces, con la suscripción y posterior entrada en vigor de la Convención Americana en el año 1978, llega a su culminación la evolución normativa del sistema. (Ventura, 1999, pp. 168-169)

La convención establece como medios de protección dos órganos competentes, la Comisión Interamericana de Derechos Humanos y la Corte Interamericana de Derechos Humanos.

La discrepancia que existe básicamente entre una y otra es que la Comisión recibe denuncias, tramita, investiga y emite resoluciones, al igual que la corte; sin embargo, carece 
de obligatoriedad pues la sanción máxima que da es de índole moral: la publicación. La Corte es tribunal y ejerce función jurisdiccional y consultiva y, sus decisiones en el campo jurisdiccional son obligatorias (Ventura, 1999).

Los derechos humanos y las garantías individuales no tienen el mismo sentido dogmático; los derechos Humanos son universales y las garantías individuales son generales. Es decir, el ámbito de la aplicación de las garantías individuales en un Estado soberano o país, emana principalmente de la Constitución, mientras que los derechos humanos no están sujetos al ámbito de validez de la norma de cada país sino que son universalmente válidos. La semejanza que existe entre ambos es que son inalienables, propios de cada persona desde el momento de la concepción.

La diferencia principal entre garantías individuales y derechos humanos son los sujetos; en el caso de las garantías individuales los sujetos pueden ser personas físicas y personas morales, sociedades civiles, mercantiles, entre otras. En la Constitución Política de los Estados Unidos Mexicanos se establecen las garantías individuales del artículo 1 al 29. Por otra parte, los derechos humanos tienen como único objeto de protección a la persona en calidad de ser humano.

Corroborando la cita anterior sobre el ámbito de aplicación de las garantías individuales quedó plasmada por parte de la Suprema Corte de Justicia de la Nación describiendo lo siguiente:

Las garantías individuales, en cuanto protegen derechos patrimoniales, no se conceden exclusivamente a las personas físicas, sino, en general, a las personas jurídicas, esto es, a los individuos, a las sociedades civiles y mercantiles, a las instituciones de beneficencia y a las instituciones oficiales, cuando actúan de carácter de entidades jurídicas, $y$ tan es así, que el artículo 6 de la ley reglamentaria de amparo, clara $y$ terminantemente lo dispone, indicando que deberán ocurrir ante los tribunales, por medio de sus representantes legítimos o de sus mandatarios debidamente constituidos, o de los funcionarios que designen las leyes respectivas. (SCJN, 1932, p. 1205)

El derecho al acceso a la información como un derecho humano tiene como finalidad mantener una sociedad activa en relación con el gobierno y servidores públicos, pues éstos son quienes manejan los recursos públicos; asimismo, debe mantener una sociedad informada, conservar el lazo intergubernamental en el tema de transparencia, creando mecanismo o técnicas para el manejo de la información pública, manteniendo esta información a disposición de manera que facilite este derecho humano fundamental para el desarrollo social. Una sociedad informada y activa puede contribuir a la mejora de la administración pública.

La importancia general de elevar a rango de derecho humano el derecho al acceso a la información y el derecho a la información es establecer una sociedad activa o mantener acciones sociales en tema de transparencia y mejora a la administración pública en sus tres aspectos: federal, estatal y municipal. 


\section{Finalidades del derecho a la información}

El acceso a la información es una práctica diaria, toda persona obtiene información a través de periódicos, carteles, revistas, páginas web o anuncios televisivos, etc. Los medios de comunicación masiva son una fuente de la que se obtiene información sin solicitarla, basta encender la televisión, la radio o comprar el periódico para obtenerla; sin embargo, ésta es limitada.

La información pública es aquella generada por los servidores públicos y dependencias gubernamentales, sujetos obligados en las diversas leyes de acceso a la información en el país.

El derecho a la información consiste en la facilidad de obtenerla, sin solicitarla, pues es información que debe publicarse en los medios electrónicos o medios informativos como la televisión, radio, revista, portales de internet, etc.

La cualidad del derecho a la información es que ésta no necesita ser solicitada por alguien específicamente, es información que los sujetos obligados por la ley deberán poner a disposición para la sociedad en general; un ejemplo claro que se utiliza para la publicación de esa información es el portal de internet relacionado con alguna institución, servidor público en particular o dependencia pública.

La finalidad primordial del derecho al acceso a la información es mantener informada a la sociedad, facilitándole la gestión del derecho al acceso a la información, pues este último tiene la particularidad de solicitar una información específica.

Una sociedad informada genera opiniones públicas con argumentos, su opinión estará basada en pruebas contundentes para la mejora de los servicios de las dependencias públicas y el actuar de los servidores públicos; las opiniones pueden ser críticas constructivas y críticas que denuncien, consistentes en fomentar la denuncia contra la corrupción y desarrollar mecanismos de aplicación y uso de los recursos públicos con evaluación premeditada y análisis de campo de detección de gestiones necesarias que alcancen un desarrollo igual y equitativo de la sociedad sonorense, pues son principios fundamentales demarcados en la Constitución Política Mexicana.

\section{Experiencias de la transparencia y rendición de cuentas}

La importancia que la sociedad tiene en el gobierno es que sin sociedad no existiría un gobierno, no habría a quien gobernar; si entendemos política como el gran comportamiento de las personas y lo relacionamos con gobierno, entenderemos que los representantes públicos deberán gobernar considerando las vías necesarias para realizar gestiones a través de un análisis de necesidad de la sociedad, comportándose de acuerdo a las leyes.

La participación ciudadana siempre se distinguió por su papel en el rol de elegir candidatos, pero con estas reformas de derecho al acceso a la información su participación es más frecuente al solicitar información ante los sujetos obligados que demarca la ley.

En las experiencias de la transparencia y sociedad se resaltan algunas a continuación: 
Alianza Cívica. Es una asociación civil apartidista que surgió con la finalidad de monitorear el proceso electoral de 1994, obedeciendo al reclamo general de la sociedad civil por lograr procesos electorales limpios y confiables, acorde a la ley (IFAI, 2004).

Adopte un funcionario. Es una iniciativa ciudadana impulsada en el año 1995 tendiente a establecer la vigilancia de la sociedad civil sobre la actuación de las instituciones gubernamentales y de los funcionarios responsables de llevar a cabo las acciones de gobierno. Tiene el objetivo de observar y documentar los actos de los representantes públicos y que los funcionarios rindan cuentas de sus labores.

El apoyo legal en el que se basaban era muy laxo pues el artículo 6 constitucional no estaba desarrollado, se respaldaban también por el derecho de petición en el artículo 8 de la constitución mexicana. En dicho programa al principal funcionario que se vigiló fue al presidente Ernesto Zedillo Ponce de León, los estudios de la información se basaron en la forma en que se manejaban los presupuestos públicos y la utilización de medios jurídicos para que los funcionarios entregaran la información de cómo se gastaban los recursos o el erario (IFAI, 2004).

Ley General de Equilibrio Ecológico y protección al Ambiente (LGEEPA). Uno de los temas y marcos legales pioneros en establecer el derecho al acceso a la información fue la Ley general del equilibrio ecológico y protección al ambiente en el año 1996 su reforma permitía a los usuarios de este derecho acceder a determinada información con la limitante de acreditar el interés jurídico (Bustillos y Severino, 2004).

Iniciativa de Acceso México (IA-MEX). Haciendo uso de este ejercicio una de las experiencias de transparencia fue a través de la asociación IA-MEX, la cual acudió a un estudio de la "Situación del acceso a la información, a la Participación Social y a la Justicia Ambiental en México" enfocándose a la aplicación, mecanismos y procedimientos de las leyes de acceso a la información (Bustillos y Severino, 2004).

Catorce estudios en materia ambiental. En 1999, Presencia Ciudadana Mexicana realizó 14 estudios en materia ambiental dirigida a la Secretaria del Medio Ambiente, Recursos Naturales y Pesca (SEMARNAP). Atendiendo a los ordenamientos jurídicos de la Ley general del equilibrio ecológico y protección al ambiente (Bustillos y Severino, 2004).

Veintisiete estudios del medio ambiente. En el año 2002, la IA-MEX, actualizando la información de los estudios realizados por Presencia Ciudadana Mexicana y evaluando el progreso de la ley realizaron 27 estudios dirigidos a la SEMARNAP, investigaciones del medio ambiente (Bustillos y Severino, 2004).

Iniciativa de Acceso México (IA-MEX). En el 2003 con la entrada en vigor de la Ley Federal de Transparencia y Acceso a la Información Pública Gubernamental (LFTAIPG) la herramienta 
jurídica ya estaba implementaba, sólo hacía falta ser utilizada por la asociación IA-MEX, la cual realizó 30 estudios de caso de solicitudes de información con la finalidad de evaluar el funcionamiento y la aplicación de la nueva ley.

Con esta nueva ley los usuarios ya no tienen que dirigir las solicitudes de información a una persona en particular sino que ahora se remiten a una dependencia, lo cual facilita el mecanismo para solicitarla (Bustillos y Severino, 2004).

Equidad de Género: Ciudadanía, Trabajo y Familia, A. C. Es un claro ejemplo sobre la experiencia en la transparencia en México. Como organización no gubernamental surge en 1996 con el objetivo principal de generar una mayor equidad entre los géneros, trabajando por la igualdad de oportunidades para las mujeres. Una de las áreas en la que se enfoca es la del presupuesto público, donde la tarea prioritaria es la de generar información y herramientas que sirvan de apoyo.

Esta organización junto con otras más iniciaron un proceso de análisis cuyo objetivo fue el de esclarecer presuntas asignaciones arbitrarias del presupuesto público; detectaron un desvió de 30 millones de pesos del Presupuesto de Egresos de la Federación (PEF) para el Comité Nacional Pro-vida; recursos destinados para la prevención del SIDA/VIH. A raíz de esto, varias organizaciones decidieron aliarse para monitorear dicho gasto.

Utilizando la vía de acceso a la información a través del Sistema de Solicitudes de Información (SISI), se tenía la certeza sobre la asignación de los 30 millones de pesos a los Centros de Ayuda para la Mujer de la Secretaria de Salud (Vallarta y Martínez, 2004).

Centro de Servicios Municipales Heriberto Jara, A.C. (CESEM-Veracruz). Experiencia ciudadana en práctica del derecho al acceso a la información, promovida por CESEM-Veracruz. Este es un claro ejemplo de la transparencia en los municipios y sus ayuntamientos. En Veracruz no existían instrumentos legales que establecieran la obligatoriedad de los gobiernos locales de promover espacios y formas de participación ciudadana y mucho menos supervisión ciudadana en materia presupuestaria (Domínguez y Osegueda, 2004).

Plataforma ciudadana veracruzana. El 13 de Mayo del 2003 la construcción de una plataforma ciudadana local; convoca a un grupo de ciudadanos municipalitas veracruzanos, para laborar puntos de reforma municipal. Uno de los principales puntos es el reconocimiento jurídico de la participación ciudadana sobre la toma de decisiones.

Este grupo social influyó ante el congreso del estado de Veracruz a condicionar la ley de trasparencia tomando como punto de partida esas iniciativas de leyes a consulta de la comunidad veracruzana (Domínguez y Osegueda, 2004).

Ciudadanos por municipios transparentes (CIMTRA). El programa nace en el 2002, enfocándose en los objetivos de identificar los niveles de trasparencia que poseen los gobiernos locales y construir mecanismos ante la sociedad para promover la transparencia y la rendición de cuentas. 
La finalidad primordial no era la detección de corrupción, entablar juicios a los gobiernos, sino que consistía en identificar los aspectos que sean reconocidos como acciones

y mecanismos de transparencia en el ámbito local veracruzano (Domínguez y Osegueda, 2004).

\section{Leyes de acceso a la información en el mundo}

Es importante destacar que la evolución jurídica sociológica, económica, tiende a hacer referencia a la globalización de las ideas.

Las diversas naciones que existen en nuestro planeta tienen una cultura única que las distingue de las demás, su modo de pensar puede ser diverso a las problemáticas sociales, pueden diferir por lo que se hace llevar ese conocimiento de ejemplo a los demás países para tomarlo de referencia.

En Latinoamérica la República de Chile trabaja con el llamado El triángulo virtuoso. De acuerdo a Orellana (2002):

La participación es la base de una sociedad efectivamente democrática, para que haya efectiva participación se requiere transparencia (sólo hay participación inteligente cuando se puede procesar información). A su vez, la transparencia es la base de la probidad: sólo una sociedad informada del gasto público puede fiscalizarlo.

La experiencia en diversas partes del mundo ha ayudado a detectar la corrupción; un ejemplo de ello es en el Reino Unido, los mecanismos de transparencia contribuyeron a detectar irregularidades en los gastos de los representantes, lo que llevó a que algunos involucrados decidieran no presentarse a la reelección e incluso a la apertura de causas penales.

En América Latina, la evidencia periodística sugiere la existencia de irregularidades en los poderes legislativos, que mayor transparencia podría contribuir a subsanar. Por ejemplo, desvío de fondos en la Cámara de Diputados de México o irregularidades detectadas por el informe Lupa a la Cámara en Chile.

No todos los países cuentan con leyes de acceso a información pública, incluso cuando existen leyes de acceso, éstas no siempre aplican a los congresos.

\section{Antecedentes del derecho de la información en México}

\section{Artículo $6^{\circ}$ constitucional}

Fue aquel conjunto de palabras al final de lo que era el artículo sexto de la Constitución Política de los Estados Unidos Mexicanos, reformado el 6 de diciembre de 1977, decía: "El Derecho al acceso a la información será garantizado por el Estado. Limitado a constituir, únicamente, una garantía electoral, que obligaba al Estado a permitir que los partidos políticos expusieran ordinariamente sus programas, idearios, plataformas y demás características esenciales a tales agrupaciones, a través de los medios masivos de comunicación. 
Para Burgoa (2002), "el derecho a la información significa superar la concepción exclusivamente mercantilista de los medios de comunicación...", el autor agrega que "la existencia de un verdadero derecho de la información enriquece el conocimiento que los ciudadanos requieren para una mejor participación democrática..." (pp. 672-673).

\section{Aprobación de la Ley Federal de Transparencia y Acceso a la Información Pública Gubernamental (LFTAIPG)}

Ante la necesidad de atacar la corrupción y conocer el actuar de los gobiernos era necesario impulsar la transparencia, lograr ésto no era fácil, pero con la publicación de la LFTAIPG en el Diario Oficial de la Federación (DOF) el 11 de junio del 2002, entrando en vigencia el 11 de junio del 2003, se establece el marco jurídico para obtener información.

Con esta nueva ley federal nace el Instituto Federal de Acceso a la Información Pública (IFAI), con la finalidad de impulsar y atender esta ley. Siendo el presupuesto público uno de los temas centrales, generando una serie de leyes a nivel federal y estatal.

La herramienta jurídica más detallada y definida se suscitó en la reforma al artículo 6 Constitucional del 20 de julio del 2007, a la cual se agrega un segundo párrafo y siete fracciones.

De esta última reforma, la transparencia rebasó los límites de la ley federal pues ya describía a los sujetos obligados a transparentar sus actos, estableciendo no sólo el derecho al acceso a la información sino el derecho a la información, el cual se basa en la información que deben publicar los sujetos obligados a través de su portal de internet; hay que destacar que la misma Constitución evoluciona, estableciendo medios electrónicos entrando en la era de la tecnología desde un ámbito jurídico constitucional, facilitando el acceso a la información, pues basta que los usuarios de este derecho tengan acceso a internet y den clic para obtenerla.

Otro aspecto interesante es el de la gratuidad de la información, pues al decir información gratis no significa que no tendrá algún costo, pues se establece que se pagará por la reproducción en copias, Cd, la certificación o firmas. El monto no debe rebasar el costo de la copia. La información digital es gratuita.

El derecho al acceso a la información también tiene sus limitantes, no toda la información podrá obtenerse ya que el Estado en su función de garante del derecho a la información puede prever restricciones a información que ponga en riesgo la seguridad de la nación, las relaciones del Estado con otros Estados o la protección de datos personales. La clasificación de la información en reservada o confidencial es una limitante para el usuario de este derecho.

La legislación establece la protección de datos personales a través de la Ley Federal de Protección de Datos Personales en Posesión de los Particulares, publicada el 5 de julio del 2010 en el Diario Oficial de la Federación, la cual indica la definición de lo que incluye los datos personales. 


\section{Interpretación de la Suprema Corte de Justicia de la Nación}

El organismo que debe garantizar la aplicación de las garantías individuales es la Suprema Corte de Justicia de la Nación, que es la última instancia para la aplicabilidad de la ley.

En el tema de transparencia entra el juego de los recursos de revisión por parte de los particulares, a quien por alguna u otra manera se le niega la información, obstaculizando ejercer este derecho.

Al entrar en vigor la Ley Federal de Transparencia y Acceso a Información Pública Gubernamental, no existe un mecanismo claro para la suprema corte y su rol como administrador de justicia.

Fue hasta el 2 de abril del 2004 cuando se publicó en el Diario Oficial de la Federación el Reglamento de la Suprema Corte de Justicia de la Nación y del Consejo de la Judicatura Federal, para la aplicación de la Ley Federal de Transparencia y Acceso a la Información Pública Gubernamental, con la finalidad de aplicar los principios generales.

La hermenéutica jurídica aplicable a este derecho por parte de la SCJN entiende por derecho al acceso a la información, lo siguiente:

- Garantía social consistente en que se informe por medios masivos de comunicación;

- Derecho a ser informado a que se refiere el artículo 6 Constitucional, que constituye una garantía relacionada con el respeto a la verdad.

- Garantía individual sujeta a los límites legales (intereses nacionales y los de la sociedad, así como derechos de tercero).

- Fundamento político: la salvaguarda y garantía del estado democrático.

\section{Ley Federal de Transparencia y Acceso a la Información Pública Gubernamental (LFTAIPG)}

Con la aprobación de esta ley, se abre un panorama de las actuaciones de los servidores públicos y dependencias gubernamentales, estableciendo los mecanismos para obtener información.

Los principales objetivos de la LFTAIPG es facilitar el acceso a la información, transparentar la gestión pública de los sujetos obligados, contribuir a una democratización de la sociedad mexicana, mejorar la organización, etc.

Acceder a la información de una manera rápida sería un gran reto si no existieran mecanismos electrónicos que respaldaran ese objetivo, el sistema INFOMEX, es una herramienta indispensable para solicitar información desde su casa a través de un computador e internet. Este medio electrónico advierte de las etapas de las solicitudes en cuanto al tiempo en que deben dar respuesta los sujetos obligados.

La gestión pública y la rendición de cuentas se establecen como objetivos principales de esta ley pues así la sociedad o particulares podrán evaluar el desempeño.

Uno de los puntos importantes que establece la ley es que los sujetos obligados deberán poner a disposición la información al público, actualizándola, es decir, que no sólo bastará con publicar la información generada en un determinado periodo, sino que deberán actualizarla periódicamente conforme se genere, utilizando los medios remotos o 
locales de comunicación electrónica. Establece también la información catalogada reservada o confidencial y la protección de datos personales.

La Ley Federal de Transparencia y Acceso a la Información Pública Gubernamental es la que abre camino al Instituto Federal de Acceso a la Información Pública (IFAI), órgano de la administración pública federal con autonomía operativa, presupuestaria y de decisión, encargado de dar difusión al uso de derecho al acceso a la información pública.

El proceso de reforma constitucional en materia de transparencia en el 2014, tiene avances muy importantes que garantizan el derecho de la información como un derecho humano.

De acuerdo a Presidencia de la República (2014):

Primero: El fortalecimiento del derecho de acceso a la información pública. Con la Reforma [...] se amplía el universo de sujetos obligados, al incluir a nuevas personas físicas y morales, entidades, organismos y dependencias.

Segundo: La creación de nuevas y más sólidas instituciones de transparencia. [...] en los últimos años nuestro país ha realizado importantes esfuerzos para construir el marco institucional que tutela el derecho a la información. [...] con la creación del nuevo órgano garante de la transparencia y el acceso a la información pública.

Hoy INAI (Instituto Nacional de Transparencia, Acceso a la Información y Protección de datos personales).

Se trata de una institución con autonomía constitucional, para hacer que prevalezca el interés general de los mexicanos por encima de presiones, influencias o consideraciones particulares, cuyas determinaciones serán definitivas e inatacables, salvo en casos que pongan en riesgo la seguridad nacional.

[...] la Reforma sienta las bases para crear organismos locales autónomos, garantes del derecho de acceso a la información pública y la protección de datos personales en las 32 entidades federativas.

Y tercer apartado: Se establecen nuevas facultades para el organismo garante nacional. [...] Esta nueva institución tendrá, entre otras, las siguientes facultades:

- Interponer acciones de inconstitucionalidad contra leyes mexicanas o tratados internacionales que vulneren el derecho al acceso a la información pública y la protección de datos personales.

- Revisar las determinaciones que emitan los organismos locales, a fin de homologar criterios de transparencia en los tres órdenes de Gobierno.

- Ejercer un procedimiento de atracción para conocer los recursos de revisión en el ámbito local que, por interés o trascendencia política, así lo ameriten. 
- Estandarizar los procesos de seguimiento y archivo de información de los sujetos obligados, a fin de mejorar el cumplimiento de las resoluciones.

\section{Ley General de Transparencia y Acceso a la Información Pública}

Gran evolución tuvo este derecho humano el 4 de mayo del 2015, se publicó en el DOF el decreto por el que se expidió la Ley General de Transparencia y Acceso a la Información Pública.

De acuerdo a Guillén (2015), un punto a destacar de esta Ley, es la unidad que se da al sistema en su conjunto al tener una y sólo una plataforma que incluya a todos los sujetos obligados, tal como se lee en el artículo 52 de la nueva Ley General de Transparencia y Acceso a la Información Pública:

Art. 52 El Sistema Nacional establecerá las medidas necesarias para garantizar la estabilidad y seguridad de la plataforma, promoviendo la homologación de procesos y la simplicidad del uso de los sistemas por parte de los usuarios.

Esta unificación propiciará, una vez realizada, la simplificación al usuario para solicitar información de los sujetos obligados bajo una misma plataforma y con una sola clave de acceso y contraseña; lograr esto será un reto interesante, pero sus resultados serán beneficiosos. [...] también unifica los principios, criterios y funcionamiento del sistema en su conjunto, no sólo a los entes del gobierno federal, sino también a los locales y a los municipales y demás sujetos obligados. (Guillén, 2015)

[...] la nueva ley especifica como sujetos obligados a cualquier entidad, órgano, organismo de los tres poderes federales, organismos constitucionales autónomos, partidos políticos, fideicomisos y fondos, así como cualquier persona física, moral o sindicato que reciba y ejerza recursos públicos o realice actos de autoridad, entidades federativas y municipios. (Guillén, 2015)

Una característica esencial de la reforma es que pretende dar unidad a la materia de transparencia mediante la creación de todo un Sistema Nacional de Transparencia, integrado entre otros, por el Instituto Nacional de Acceso a la Información Pública y los órganos garantes de las entidades federativas (organismos constitucionales autónomos por disposición legal), que será el encargado de dar unidad $y$ coherencia en la interpretación de la normativa en materia de transparencia $y$ acceso a la información. (Guillén, 2015) 


\section{Conclusiones}

Es importante resaltar que la protección de derechos humanos a nivel internacional, en el cual México contribuye con diversos tratados entre Estados en el mundo, protege y garantiza el derecho al acceso a la información y su gratuidad.

La Constitución Política de los Estados Unidos Mexicanos, el Código de Buenas Prácticas y Alternativas para el Diseño de Leyes de Transparencia y Acceso a la Información Pública en México, la Ley de Acceso a la Información Pública para el Estado de Sonora, son mandatos que instruyen para acceder a la información pública.

Las facilidades para obtener información pública en México es un reto, debe garantizarse el verdadero acceso a la información a través de la disposición y gratuidad.

La relación entre el Instituto de Transparencia de cada uno de los Estados y las unidades de enlace es una de las oportunidades que tiene la administración pública para generar la cultura de la transparencia, no sólo en el aspecto social sino enfocado a los sujetos obligados con estos retos para generar la transparencia en el estado de Sonora.

Actualmente nos encontramos con limitantes demasiado sutiles pero que son el impedimento a generar una cultura de relación gobierno y sociedad.

La importancia de la transparencia en México es simplemente dejar a la luz la aplicación de los recursos públicos bajo los principios que emanan de nuestra constitución federal, así como de los tratados internacionales que protegen los derechos humanos. El mayor reto de la transparencia en los Estados es tener servidores públicos que entiendan de manera previa las obligaciones que se les encomienda, pues sólo así podrán entender el concepto de servir a la sociedad y tomar decisiones que beneficien a los habitantes de una forma igual y equitativa.

Existen grandes logros en normatividad, sin embargo, no son suficientes. Se tiene que mejorar en una activa participación ciudadana, hacer énfasis en la educación incorporando en los planes de estudio estos valores fundamentales, que permitan formar verdaderos seres humanos, que con su actuar se refleje el respeto a ello. Se debe contar con funcionarios públicos con perfiles de alto nivel, no sólo en educación, sino en valores éticos, que respeten decisiones de gobierno abierto, den respuesta a la ciudadanía con una verdadera transparencia y rendición de cuentas; es así como se logrará una verdadera competitividad en nuestros país. 


\section{Referencias bibliográficas}

Burgoa, I. (2002). Las garantías individuales. Ciudad de México: Porrúa.

Bustillos, I., \& Severino, T. (2004). Diagnóstico del Acceso a la Información Ambiental en México. Experiencia de Iniciativa de Acceso México, IA-MEX. En IFAI. El derecho de acceso a la información en México: un diagnóstico de la sociedad. Ciudad de México: IFAI.

Cancado, A. (2006). El Derecho Internacional de los Derechos Humanos en el Siglo XXI. Santiago: Editorial Jurídica Chile.

Carpizo, J., \& Villanueva, E. (2001). El derecho a la información. Propuestas de algunos elementos para su regulación en México. En D. Valadés y R. Gutiérrez (coords.). Derechos humanos. Memoria del IV Congreso Nacional de Derecho Constitucional III, México, UNAM, Instituto de Investigaciones Jurídicas. Recuperado de http://biblio. juridicas.unam.mx/libros/1/94/6.pdf

Comisión Interamericana de Derechos Humanos (CIDH). (1948). Declaración Americana de los Derechos y Deberes del Hombre. En IX Conferencia Internacional Americana, Bogotá, Colombia. Recuperado de http://www.oas.org/es/cidh/mandato/Basicos/ declaracion.asp

Cruz, C., de la Torre, E., Martínez, M.A., \& Muñoz, J.L. (2006). Análisis comparativo de las leyes de Transparencia e Información Pública de 2002 y 2005 de Jalisco, desde la perspectiva de la sociedad civil. Derecho Comparado de la Información, 7. Recuperado de http://www.juridicas.unam.mx/publica/rev/decoin/cont/7/cmt/cmt6.htm

Domínguez, F., \& Osegueda, A. (2004). Dos experiencias ciudadanas desde el ámbito local en materia de transparencia gubernamental. En IFAI. El derecho de acceso a la información en México: un diagnóstico de la sociedad. Ciudad de México: IFAI.

Guillén, A. (2015). Artículo de opinión: Ley General de Transparencia y Acceso a la Información Pública. Legis de México. Recuperado de http://www.legis.com.mx/ BancoConocimiento/A/articulo_de_opinion_-_ley_general_transparencia/articulo_ de_opinion_-_ley_general_transparencia.asp

Instituto Federal de Acceso a la Información Pública (IFAI). (2004). El derecho de acceso a la información en México: un diagnóstico de la sociedad. Ciudad de México: IFAI. Recuperado de http://inicio.ifai.org.mx/Publicaciones/derecho_acceso16.pdf

Mendel, T. (2003). Libertad de información: derecho humano protegido internacionalmente. Derecho comparado de la Información, 1, 41-74. Recuperado de http://biblio.juridicas. unam.mx/revista/pdf/DerechoInformacion/1/cnt/cnt3.pdf

Nikken, P. (1994). El concepto de derechos humanos. En A. Asdrubal et al. Estudios básicos de Derechos Humanos Tomo 1. San José: Instituto Interamericano de Derechos humanos. Recuperado de http://biblio.juridicas.unam.mx/libros/libro.htm?l=1835

Orellana, P. (2002). Participación, transparencia y probidad. Revista Probidad, 20. Recuperado de http://www.revistaprobidad.info/020/001.html 
Organización de los Estados Americanos (1969). Convención Americana sobre Derechos Humanos (Pacto de San José). En Conferencia especializada Interamericana sobre Derechos Humanos, San José, Costa Rica. Recuperado de https://www.oas.org/dil/ esp/tratados_B-32_Convencion_Americana_sobre_Derechos_Humanos.pdf

Presidencia de la República (2014). Prensa. La transparencia acompañará y reforzará la transfotmación que estamos impulsando en el país: Enrique Peña Nieto. Recuperado de http://www.gob.mx/presidencia/prensa/la-transparencia-acompanara-y-reforzarala-transformacion-que-estamos-impulsando-en-el-pais-enrique-pena-nieto

Suprema Corte de Justicia de la Nación (SCJN). (1932, febrero 18). Amparo civil directo 148/29. Semanario Judicial de la Federación, Quinta Época, Tercera Sala, Tomo XXXIV, p. 1205.

UNICEF (2006). Convención sobre los derechos del niño. Madrid: UNICEF. Recuperado de http://www.un.org/es/events/childrenday/pdf/derechos.pdf

Vallarta, M., \& Martínez, M.C. (2004). Demanda ciudadana, la transparencia y rendinción de cuentas: experiencia de monitoreo de desviación de recursos públicos. En IFAI. El derecho de acceso a la información en México: un diagnóstico de la sociedad. Ciudad de México: IFAI.

Ventura, M. (1999). La convención Americana sobre Derechos Humanos. En H. Fix-Zamudio (Coord.). México y las Declaraciones de Derechos Humanos. Ciudad de México: Corte Interamericana de Derechos Humanos - UNAM. Pp. 167-173. Recuperado de http:// biblio.juridicas.unam.mx/libros/1/107/12.pdf

Villanueva, E. (2003). Derecho de acceso a la información y organización ciudadana en México. Derecho comparado de la información, 1, 119-137. Recuperado de http:// www.juridicas.unam.mx/publica/librev/rev/decoin/cont/1/cnt/cnt6.pdf 


\title{
Capítulo 7
}

\section{Violación del debido proceso legal de los migrantes en México}

\author{
Alfredo Islas Rodríguez \\ María del Rosario Molina González \\ María de Jesús Camargo Pacheco
}

Universidad de Sonora 
108 Estudios de desarrollo regional en México 


\section{Introducción}

Uno de los derechos fundamentales de rango constitucional de las personas, que se encuentra íntimamente vinculado con la posibilidad de acceder a la justicia y preservar la libertad, lo representa el debido proceso legal, el cual es un derecho subjetivo y público que contiene a su vez un conjunto de garantías procesales que aseguran la eficacia del derecho a la tutela jurisdiccional efectiva.

Actualmente el debido proceso es considerado como uno de los principales logros del ciudadano; por medio de esta conquista las personas estamos en posibilidad de exigir a las autoridades el respeto a nuestros derechos fundamentales. El debido proceso como derecho fundamental, es entendido como el conjunto de garantías sustantivas y procesales que protegen a las personas sujetas a cualquier proceso, y que les aseguran a lo largo del mismo, una recta y cumplida administración de justicia, la seguridad jurídica, la fundamentación y motivación de las resoluciones que se dicten.

Doctrinalmente se advierten argumentos respecto de si el debido proceso legal es un derecho fundamental o una garantía. El abordaje se realiza a partir de la descripción de los conceptos del debido proceso, derecho fundamental y garantía, con el objeto de estar en posibilidad de evidenciar que resultan ser conceptos diferentes y no pueden utilizarse indistintamente.

Por principio de cuentas debe precisarse que con el término "debido" que puede entenderse como el procedimiento adecuado para hacer algo, y lo adecuado, es lo que es conforme a un principio; siendo así, debido es, entonces, el proceder de conformidad con uno o varios principios; desde esta tesitura el debido proceso es la actividad judicial encaminada a resolver pretensiones, la cual se desarrolla con arreglo y observancia de principios, reunidos en el principio de justicia y particularizados en las normas y formalidades del procedimiento.

De acuerdo a la Real Academia Española (2015), proceso en la lengua castellana significa proceder, desenvolvimiento, seguir adelante, es decir, el proceso es un conjunto de operaciones o actos vinculados para lograr un fin, y así el proceso jurisdiccional con los actos del procedimiento tiende a un fin que es resolver un conflicto o contienda mediante una resolución.

En sentido literal y lógico, por proceso se entiende cualquier conjunto de actos coordinados para producir un fin, en el ámbito jurídico, se entiende por proceso una serie de actos coordinados para lograr un fin, y en el caso de proceso judicial, constituye una serie de actos que realizan las partes y el juez para resolver un conflicto jurídico suscitado entre las primeras, y para que estos actos tengan eficacia jurídica, deben realizarse de acuerdo a los procedimientos preestablecidos y orientados por el contenido sustancial de la Constitución.

Entre todos los problemas que caracterizan el tránsito migratorio por México, se optó por reflexionar sobre los aspectos jurídicos vinculados con las acciones sociales que se intentan normalizar, de inicio, desde las perspectivas de un sector en condición de vulnerabilidad, como la población en movilidad, el cual exige además de su reconocimiento 
jurídico, esto es, las garantías de que el sistema de administración e impartición de justicia, no obstante, se ha mantenido desde antaño alienado en ámbitos extra-jurisdiccionales, pero que, por lo contrario, pueda ser capaz de proporcionar a las personas migrantes, no sólo un procedimiento legal, sino además, la posibilidad real de que este procedimiento les permita el acceso a la justicia. Este análisis conceptual, normativo y factual del tránsito migratorio pone especial atención en las dificultades que se han venido sorteando por las personas migrantes indocumentadas o irregulares con el fin de acceder al derecho fundamental del debido proceso.

El debido proceso dentro del paradigma neoconstitucionalista busca asegurar o garantizar a las personas no sólo un proceso legal, sino fundamentalmente un proceso justo, entendiendo por éste, aquel que garantice que al final del mismo la o las personas afectadas recibirán la reparación o restitución, en su caso, de la afectación recibida; se busca entonces, que el debido proceso actúe como una limitación efectiva a las facultades de molestia o privación de un bien jurídico que realiza una determinada autoridad judicial o administrativa. Sobreentendido que las autoridades deberán acatar las formas jurídicas que conforman el debido proceso, a fin de que el acto de molestia no pueda llevarse a cabo, sino a condición de evitar la violación de los derechos fundamentales, es decir, se pretende garantizar la legalidad y seguridad jurídica sustantiva, que deben estar presentes en todos los actos jurisdiccionales.

\section{Un acercamiento a la construcción dogmática del debido proceso}

Los principios del debido proceso se adoptan como normas que ordenan, permiten o prohíben determinadas conductas para la "[...] valoración jurídica de la justicia y la dignidad humana, es decir, el ser humano como centro de la sociedad y su convivencia dentro de un Estado de Derecho [...] para el desarrollo y la eficacia del debido proceso (Ledesma Narváez, 2011, p. 20).

Desde esta concepción teórica, según Auquilla (2011):

El debido proceso se entiende como un principio jurídico procesal o sustantivo según el cual toda persona tiene derecho a ciertas garantías mínimas, tendientes a asegurar un resultado justo y equitativo dentro de un proceso, a permitirles tener oportunidad de ser oídas y hacer valer sus pretensiones legitimas frente al juez [o una autoridad administrativa]. (P. 9)

En los aportes teóricos del italiano Luigi Ferrajoli, se define a los derechos fundamentales en oposición a los derechos patrimoniales, como la propiedad y el crédito que son derechos singulares que adquiere cada individuo con exclusión de los demás. Estipulativamente considerado por el italiano como una definición teórica propone expresando que:

son aquellos derechos subjetivos que corresponden universalmente a todos los seres humanos en cuanto dotados del status de personas, de ciudadanos o personas con capacidad de obrar; entendiendo por derecho subjetivo cualquier expectativa 
positiva (de prestaciones) o negativa (de no sufrir lesiones) adscrita a un sujeto por la norma jurídica, y por status la condición de un sujeto prevista asimismo por una norma jurídica positiva, como presupuesto de su idoneidad para ser titular de situaciones jurídicas y/o autor de los actos que son ejercicio de ésta. (Ferrajoli, 2005)

Pilar conceptual del garantismo, el debido proceso se integra como derecho subjetivo, además previsto por la norma jurídica positiva, dado que se encuentra en la constitución mexicana dentro de los derechos fundamentales de seguridad jurídica, los que se definen por la Suprema Corte de Justicia de la Nación (SCJN), como:

aquellos derechos subjetivos públicos a favor de los gobernados que pueden ser oponibles a los órganos estatales, a fin de exigirles que se sujeten a un conjunto de requisitos previos a la comisión de actos que pudieran afectar la esfera jurídica de los individuos, para que éstos no caigan en la indefensión o la incertidumbre jurídica, lo que hace posible la pervivencia de condiciones de igualdad y libertad para todos los sujetos de derechos y obligaciones. (SCJN, 2003, p. 11)

Entendido el debido proceso como un derecho fundamental, guarda una íntima relación con otros derechos fundamentales, entre los que se podemos considerar el de ocurrir a los tribunales en demanda de justicia y actuar en estos tribunales a fin de que sean tutelados nuestros intereses legítimos sin ninguna discriminación. También el derecho a una tutela jurisdiccional efectiva, que consiste en obtener de los órganos jurisdiccionales formas adecuadas de tutela efectiva, que aseguren la plena satisfacción de los derechos e intereses legítimos que se han hecho valer.

Bajo el concepto de justiciable, se tiene el derecho a un juicio justo y público, de lo que se desprende, que los asuntos sujetos a los tribunales deben ser tratados y discutidos públicamente, en un plazo razonable, frente un juez independiente e imparcial. El derecho fundamental de defensa de los gobernados, es aquel por el cual todos tenemos garantizado, en cualquier momento del proceso, el derecho inviolable de defendernos como partes iguales en el proceso, estando aseguradas también nuestras facultades de ser representados y defendidos por un abogado y de ser asistidos por peritos.

A pesar de que el debido proceso es un derecho fundamental reconocido por sendos instrumentos de convencionalidad, y base de los sistemas jurídicos constitucionales modernos, es base del entramado de derechos procesales para la experiencia nacional. Su contenido de carácter procesal ha provocado que aún existan diversos juristas que lo consideran más como un principio procesal o una garantía procesal que como un derecho fundamental.

El debido proceso presenta un carácter complejo. Bástese revisar que la doctrina y la jurisprudencia no se ponen de acuerdo de su esencia, ya que una parte 
importante plantea que se trata de una garantía otros de un derecho e incluso que se trata de un derecho al mismo tiempo garantía. (Petit, 2011, p. 49)

Fix-Zamudio (1987), señala que el debido proceso funciona como mecanismo de eficacia de la norma:

son numerosos los constitucionalistas que consideran que la verdadera garantía de los derechos de la persona humana consiste precisamente en su protección procesal, para lo cual es preciso distinguir entre los derechos del hombre y las garantías de tales derechos, que no son otra cosa que los medios procesales por conducto de los cuales es posible su realización y eficacia.

Concluyendo, el debido proceso como derecho fundamental, protege el manejo de reglas procesales tanto en el ámbito ordinario como constitucional para tomar decisiones que puedan justificarse jurídicamente, es decir, hay que analizar el derecho al debido proceso desde el punto de vista constitucional o sustancial y no desde el simplemente legal, lo que nos permitirá revisar su eficacia con respecto a la protección de la sustancia constitucional, es decir, la protección efectiva de los derechos fundamentales. De esta manera los procedimientos específicos decididos de manera cotidiana y vueltos pautas de intervención por los funcionarios no pueden contradecir, sino guiarse, no sólo por el respeto a la Constitución sino por la protección sustantiva de ésta.

En cuanto a la dimensión sustantiva, el gran aporte al constitucionalismo por parte de la tradición jurisprudencial norteamericana, lo constituye la extensión del debido proceso, a lo que ellos llamaron el "debido proceso sustantivo o sustancial" que no es otra cosa, advierte García (2003), que la exigencia de la aplicación del principio de razonabilidad entendiendo esto como el hecho de que las leyes, otras normas o actos públicos o privados, tengan como requisito de validez el ajustarse no sólo a las normas o preceptos de la constitución, sino también al sentido de justicia contenido en ella, lo que implica necesariamente el acatamiento de exigencias fundamentales de equidad, proporcionalidad y razonabilidad.

En resumen, el concepto del debido proceso, a partir de la Carta Magna, pero muy especialmente en la jurisprudencia constitucional [...] se ha desarrollado en los tres grandes sentidos descritos: a) el del debido proceso legal, adjetivo o formal, entendido como reserva de ley y conformidad con ella en la materia procesal; b) el del debido proceso constitucional o debido proceso a secas, como procedimiento judicial justo, todavía adjetivo o formal procesal; $y$ c) el del debido proceso sustantivo o principio de razonabilidad, entendido como la concordancia de todas las leyes $y$ normas de cualquier categoría o contenido y de los actos de autoridades públicas con las normas, principios y valores del Derecho de la Constitución. (García, 2003) 
De igual forma, para Bustamante (2000) el proceso es una garantía en tanto lo concibe como el mecanismo protector no sólo de los derechos fundamentales sino también de ordenamiento jurídico en su conjunto. Haciendo también, el autor, la distinción entre proceso y procedimiento, entendiendo el proceso como el mecanismo de solución de conflictos que se someten a la decisión de un órgano jurisdiccional; y el procedimiento como:

conjunto de normas o reglas que regulan la actividad, participación, facultades y deberes de los sujetos procesales, así como la forma de los actos procesales; de tal suerte que bien puede existir procedimiento sin proceso, pero no proceso sin procedimiento. (Bustamante, 2000, p. 3)

Ese mecanismo protector de los derechos fundamentales y del ordenamiento jurídico en su conjunto no es otro que el proceso. De manera muy general podemos decir que éste es aquel mecanismo de composición o prevención de conflictos por medio del cual las partes en disputa someten su pretensión o sus intereses contrapuestos a la decisión de un tercero. Si este tercero es un órgano jurisdiccional estaremos ante un proceso propiamente dicho (interno o internacional), y si no lo es, ante un simple procedimiento (administrativo, arbitral, militar, e incluso político o particular). (Bustamante, 2000, p. 2)

El debido proceso, es entonces, el conjunto de garantías procesales y procedimentales frente a las cuales las autoridades se ven limitadas en su actuación al momento de restringir los derechos fundamentales de las personas, así, el derecho a conocer la acusación en su contra, el derecho a un juez imparcial, a gozar de un tiempo para preparar adecuadamente su defensa, a defenderse personalmente o por conducto de su abogado, a ofrecer y desahogar toda clase de pruebas, constituyen, entre otros, los requisitos que la autoridad está obligada a observar al momento de interpretar y aplicar las leyes, en el caso de las autoridades judiciales y administrativas. En el caso de poder legislativo, la limitación consiste en no afectar en la creación de leyes los contenidos de las normas constitucionales, pero principalmente en orientar la creación de estas leyes a un sentido de justicia.

En este sentido, las normas que regulan el proceso legal, contienen entonces, un conjunto de actuaciones que se encuentran coordinadas, las cuales buscan seguirse a partir de normas establecidas y que se utilizan para la protección de las personas, sus bienes y derechos; tenemos así, una serie de actos que realizan las partes ante una autoridad jurisdiccional para resolver un conflicto jurídico suscitado entre las primeras, y para que estos actos tengan eficacia jurídica, deben realizarse de acuerdo, no sólo a los procedimientos preestablecidos, sino buscando además, el desarrollo de un juicio justo, un fallo justo y razonable de acuerdo a los principios de justicia contenidos en la constitución.

Gómez (1974) advierte sobre la acepción garantista del debido proceso, entendido como un principio jurídico procesal o sustantivo según el cual toda persona tiene derecho a ciertas garantías mínimas, tendientes a asegurar un resultado justo y equitativo dentro 
del proceso, y a permitirle tener oportunidad de ser oído y hacer valer sus pretensiones frente al juez o una autoridad administrativa.

La dimensión material del debido proceso:

[...] exige que todos los actos de poder, sean normas jurídicas, actos administrativos o resoluciones judiciales inclusive, sean justos, es decir, que sean razonables $y$ respetuosos de los valores superiores, de los derechos fundamentales y de los demás bienes jurídicos constitucionalmente protegidos, a tal punto que su inobservancia debe ser sancionada con la inaplicación de aquel acto o con su invalidez. (Bustamante, 2000, p. 13)

De ese modo, un acto será considerado arbitrario, y por tanto lesivo del derecho fundamental a un debido proceso sustantivo, si no se sujeta a parámetros de razonabilidad; es decir, si su fin no es lícito -en tanto vulnera un derecho o un bien jurídico de mayor jerarquía que el que pretende protegerse y los medios para alcanzarlo no son proporcionales en tanto no respetan los principios de adecuación, necesidad y proporcionalidad en estricto-. (Bustamante, 2002 citado en García, 2003)

Por su parte Petit (2011), explica que el debido proceso puede considerarse un derecho humano donde se emanan lo demás derechos.

Entonces, en nuestro criterio el debido proceso se trata de un derecho humano como fundamental, por eso el intérprete que aplica normas procesales tiene que tener insumos suficientes para que en la construcción del derecho, haga argumentaciones a favor del hombre, nunca en contra. (Petit, 2011, p. 50)

El primer elemento de protección del debido proceso constitucional está en su fundamentación legal, que consiste en que el proceso tenga, a lo menos, bases normativas que posibiliten su eficacia; es decir, que la ley establezca enunciados claros sobre la estructura, función y desarrollo del proceso, en tanto que estos enunciados configuran los límites a que están sujetas las autoridades tanto administrativas como judiciales que lo ejecutan, fijando los derechos y obligaciones que tienen las partes que participan en el mismo. Campbell (2004), propone la definición en función de la eficacia para resolver conflictos y garantizar la eficacia del estado, y desde su perspectiva, sostiene que:

para iniciar su examen, me referiré al concepto de "debido proceso" que, generalmente, se define como aquel que cumple integralmente la función constitucional de resolver conflictos de intereses de relevancia jurídica con efecto de cosa juzgada, protegiendo y resguardando, como su natural consecuencia, la organización 
del Estado, las garantías constitucionales y en definitiva la plena eficacia del derecho. (Campbell, 2004, p. 158)

Ahora bien, Sarazá (2008) considera que:

La protección de los derechos fundamentales, asegurada por la constitución y desarrollada por la ley, corresponde, tanto al juez ordinario como al constitucional, pues tanto el uno como el otro están vinculados por esos derechos y sujetos a la aplicación de la Constitución. Así pues, no pueden separarse esos planos como si fueran compartimentos, estancos y encomendar la tutela de la Constitución a un juez y la de la ley a otro, pretendiendo que actúen de modo separado y sin ningún tipo de contacto. Todos, por el contrario, participan en el único sistema de garantía de derechos reconocidos por la norma fundamental. Por eso mismo, porque se trata de un sistema único, dentro de la unidad del ordenamiento jurídico, hace falta encomendar a alguien la última palabra. En materia de interpretación de la Constitución y, especialmente, en el ámbito de las garantías constitucionales, la última palabra la tiene en España el Tribunal Constitucional.

Definido así el debido proceso como un derecho fundamental, la pretensión de su acceso para el justiciable se justifica y extiende a la condición de persona, desde esta concepción universalista, no es relevante la condición migratoria del ser humano en la posibilidad, aspiración y pretensión de su eficacia como derecho subjetivo, por lo que no puede operar ni como elemento de exclusión o discriminación, sino como un referente de inmediata protección precisamente en atención a la situación de vulnerabilidad de la población en tránsito, que responde a un ejercicio de libertad, dado que migrar es por sí mismo un derecho y "está estrechamente relacionado con otros, como el de libre circulación, libertad personal, y el acceso a los derechos económicos y sociales" (Suprema Corte de Justicia de la Nación, 2013, p. 36).

\section{La problemática y regulación en México}

El fenómeno migratorio lo encontramos en todos los países del orbe ya sean de origen, de tránsito o destino de personas migrantes, situación que exige que en todas las naciones se regule normativamente la migración y con ella se den cumplimiento a los compromisos internacionales referidos a la protección de las personas migrantes regulares o irregulares, principalmente el compromiso de crear leyes que permitan a los migrantes extranjeros acceder a la justicia, normas jurídicas que permitan además el ejercicio efectivo del debido proceso en los procedimientos migratorios.

El fenómeno migratorio se encuentra inmerso en la globalización, en México la Ley de Migración y su Reglamento contemplan un procedimiento para definir la situación legal de las personas que entran al país en forma indocumentada, al que se le denomina procedimiento administrativo migratorio. Al cual, incorrectamente dicha ley y reglamento 
equiparan al debido proceso, creando la falsa percepción de que las personas migrantes están protegidas por éste.

La Corte Interamericana de Derechos Humanos (2003) establece que la política migratoria son todos aquellos actos, incluidas las leyes, decretos, resoluciones, directrices y demás actos administrativos que versan sobre la entrada, salida o permanencia de la población extranjera dentro el territorio.

La misma Corte IDH establece que para que exista debido proceso legal es preciso que las personas puedan "hacer valer sus derechos y defender sus intereses en forma efectiva $y$ en condiciones de igualdad procesal con otros justiciables"(Corte IDH, 2015, p. 45).

El procedimiento administrativo migratorio en México, por su propia naturaleza no incorpora los elementos del debido proceso, no hay autoridad imparcial, la resolución que se pronuncia no es revisada por un superior jerárquico, no existe igualdad procesal de las partes ya que la autoridad migratoria detiene a los migrantes indocumentados, se los presenta ella misma, admite, califica y desahoga las pruebas de los migrantes y hace lo mismo con las pruebas ofrecidas por ella misma, al grado, de que al resolver el procedimiento si existe alguna inconformidad ella misma la resuelve.

Ni la ley de migración ni su reglamento señalan específicamente quien o quienes de las autoridades migratorias tienen facultades para realizar acciones de control, verificación y revisión migratoria, así como la sustanciación de los procedimientos administrativos migratorios; siendo la Ley Orgánica de la Administración Pública Federal y el Reglamento Interior de la Secretaría de Gobernación, leyes no migratorias, las que señalan los órganos facultados para sustanciar y resolver los procedimientos migratorios. Por lo tanto, se deja a los migrantes sujetos a un procedimiento en completo estado de indefensión al no darles a conocer cuáles son las autoridades facultadas para sustanciar dicho procedimiento, se limitan a informarles que es el Instituto Nacional de Migración (INM).

Las personas migrantes en tránsito por el territorio nacional, son detectadas por el INM, tal detección actualiza la privación de la libertad de la persona, y la autoridad migratoria se la presenta a sí misma, procediendo a su alojamiento en sus instalaciones en un plazo de 15 días para resolver su situación migratoria; lo anterior en contravención del artículo 21 Constitucional que otorga competencia a las autoridades administrativas para llevar a cabo arrestos hasta por 36 horas.

\section{El debido proceso en la normativa internacional}

En el panorama internacional el debido proceso lo encontramos en constante revisión, desde el discurso normativo hasta la experiencia interpretativa y jurisprudencial en los tribunales internacionales.

Del análisis de la temática de García (2004), en su obra Panorama del proceso penal, no se pone en duda que históricamente el origen del debido proceso legal está en el derecho inglés, pero en la actualidad reconocemos estar ante la presencia de un nuevo paradigma del debido proceso como seguridad jurídica de las personas, que precisa contar con garantías procesales accesibles para proteger los derechos contenidos en los tratados y 
convenciones celebrados y aceptados por los diversos países del mundo para garantizar el derecho fundamental a la justicia.

No existe una definición uniforme del debido proceso a nivel universal, las diversas constituciones de los países contienen el debido proceso legal como una garantía en el aspecto judicial, estableciendo esta figura jurídica con menor o mayor extensión de elementos normativos protectores de los derechos humanos fundamentales.

De acuerdo a Torres (2011), la garantía del debido proceso ha sido incorporada, en forma más o menos explícita a la mayor parte de estados constitucionales modernos; además fue incluida en la Declaración Universal de los Derechos Humanos aprobada por la Asamblea de las Naciones Unidas el 10 de diciembre de 1948, en cuyo artículo 8 se establece que:

Toda persona tiene un recurso para ante los tribunales competentes que la ampare contra actos que violen sus derechos fundamentales, reconocidos por la constitución o por la ley. (ONU, 1948)

Este principio se complementa con el artículo 10, en el que se preceptúa que:

Toda persona tiene derecho, en condiciones de plena igualdad, a ser oída públicamente $y$ con justicia por un tribunal independiente e imparcial, para la determinación de sus derechos y obligaciones y para el examen de cualquier acusación contra ella en materia penal. (ONU, 1948)

Concatenadamente, el artículo 11 del mismo instrumento internacional, lo prevé para el ámbito penal, al establecer que:

Toda persona acusada de delito tiene derecho a ser oída en forma imparcial $y$ pública, a ser juzgada por tribunales anteriormente establecidos $y$ de acuerdo con leyes preexistentes y a que no se le imponga penas crueles, infamantes o inusitadas.

(ONU, 1948)

Por otro lado, el Convenio Europeo para la protección de los derechos humanos y de las libertades fundamentales (Roma, 1950) incorporó el debido proceso al señalar que todos tenemos derecho a que nuestra causa sea oída ante tribunales imparciales de forma pública y en un plazo razonable. Con el principio de presunción de inocencia y con el derecho de ser informados de las acusaciones en nuestra contra, el derecho a la defensa y a la asistencia de un intérprete cuando no se hable la lengua del tribunal.

También el Pacto Internacional de Derechos Civiles y Políticos (ONU, 1966), que entró en vigencia en 1976 en México, en su artículo 14 describe en 7 numerales, in extenso, dicho derecho, en sus vertientes fundamentales, al señalar que todas las personas son iguales ante los tribunales, teniendo derecho a ser oídas con las debidas garantías por un 
tribunal competente, independiente e imparcial, establecido por la ley para la determinación de sus derechos y obligaciones en un plano de igualdad.

En el ámbito americano, el derecho al debido proceso quedó consagrado en la Convención Americana sobre Derechos Humanos (Costa Rica, 1969) al establecer que:

Toda persona tiene derecho a ser oída, con las debidas garantías y dentro de un plazo razonable, por un juez o tribunal competente independiente e imparcial establecido con anterioridad por la ley, en la sustanciación de cualquier acusación penal formulada contra ella, o para la determinación de sus derechos y obligaciones de orden civil, laboral, fiscal o de cualquier otro carácter. (OEA, 1969)

Por su parte la Declaración Americana de los Derechos y Deberes del Hombre (Bogotá, 1948) incorporó el debido proceso al establecer en su artículo XVIII que:

Toda persona puede ocurrir a los tribunales para hacer valer sus derechos. Asimismo debe disponer de un procedimiento sencillo y breve por el cual la justicia lo ampare contra actos de la autoridad que violen, en perjuicio suyo, alguno de los derechos fundamentales consagrados constitucionalmente. (OEA,1948)

Su artículo XXVI indica: "Se presume que todo acusado es inocente hasta que se pruebe que es culpable" (OEA,1948).

Con el desarrollo del constitucionalismo el debido proceso es reconocido como un derecho fundamental no sólo en las constituciones de todos los países, sino también en diversos convenios internacionales, tanto regionales como universales, Fix-Zamudio (1987), señala que "los principios fundamentales del debido proceso legal y de la de derechos humanos defensa en juicio, en sus diversos aspectos, han sido elevados a la categoría de disposiciones internacionales, al ser consagrados por diversos convenios... ".

Por otro lado, refiriéndose a la población en tránsito se advierte que las normativas nacionales han oscilado en la producción de normas tendientes a prohibir, permitir o tolerar la migración de extranjeros en sus respectivos territorios, complementando y fundando sus legislaciones con los tratados y acuerdos internacionales sobre la materia migratoria.

Los instrumentos internacionales suscritos por México, como la Declaración Americana de Derechos y Deberes del Hombre, Pacto Internacional de Derechos Civiles y Políticos, Convención Americana de Derechos Humanos y Convención sobre Derechos del Niño, en sus diversos contenidos, que se refieren al derecho al debido proceso legal, de manera unánime establecen que el debido proceso es un derecho fundamental de aplicación inmediata que faculta a las personas a exigir un proceso público y expedito en el cual se reconozcan todas las garantías sustanciales y procesales, desarrollado ante una autoridad competente que actúe con independencia e imparcialidad, y sin tener en cuenta consideraciones distintas a las previstas en la ley. 
El debido proceso a que se refieren los instrumentos internacionales precitados, tiene como finalidad garantizar la adecuada administración de justicia, con las garantías de audiencia e igualdad ante un tribunal independiente e imparcial establecido por la ley, debido proceso que involucra una serie de preceptos que establecen una obligación para los Estados suscriptores de implementar leyes que garanticen que los procedimientos para la administración de justicia sean justos y equitativos, para asegurar la defensa de aquellos individuos que se encuentre dentro de un proceso jurisdiccional o administrativo.

$\mathrm{Si}$ bien es cierto, que los instrumentos internacionales que se refieren al debido proceso, al signarse por México son obligatorios, también lo es que, la manera en que dichos tratados deben ser interpretados, es de conformidad con el párrafo segundo del artículo primero constitucional reformado el 10 de junio de 2011, que prescribe: "Las normas relativas a los derechos humanos se interpretarán de conformidad con esta Constitución y con los tratados internacionales de la materia favoreciendo en todo tiempo a las personas la protección más amplia".

Adicionándose en el párrafo subsecuente la metodología de interpretación conforme, al señalarse que todas las normas relativas a los derechos humanos (del rango jerárquico que sea) se deberán interpretar a la luz de la propia constitución y de los tratados internacionales. Esto implica la creación del bloque de constitucionalidad (integrado no solamente por la carta magna, sino también por los tratados internacionales), a la luz del cual se deberá interpretar el conjunto del ordenamiento jurídico mexicano.

Se incorpora, además, el principio de interpretación pro persona, basamento del sistema convencional de los derechos humanos y en la práctica de los tribunales internacionales encargados de la protección y tutela de los mismos derechos.

Este principio supone que:

cuando existan distintas interpretaciones posibles de una norma jurídica, se deberá elegir aquella que más proteja al titular de un derecho humano. Y también significa que, cuando en un caso concreto se puedan aplicar dos o más normas jurídicas, el intérprete debe elegir aquella que (igualmente) proteja de mejor manera a los titulares de un derecho humano. (Carbonell, 2012)

Permite reconocer los derechos humanos e integrar sus contenidos con otras normas mediante su remisión al sujeto titular de esos derechos.

Reconoce la naturaleza jurídica de las normas sobre derechos humanos, que establecen pisos mínimos de protección, y son, por lo tanto, susceptibles de interpretación en el sentido de aplicación más favorable a las personas, que además, pueden integrarse en sus contenidos mediante un sistema de reenvíos hacia otros ordenamientos. (Caballero, 2012, p. 109) 
Aparejadamente, las reformas y adiciones estructurales en materia de los derechos humanos de 2011 en México incorporan los contenidos normativos de los tratados internacionales, los cuales son trasladados al artículo primero para adquirir un valor sustantivo de garantía y un modelo de vinculación de la función de los jueces mexicanos, acomodando el panorama del control difuso constitucionalidad/convencionalidad.

El "Control difuso de la convencionalidad" constituye un nuevo paradigma que deben ejercer todos los jueces mexicanos. Consiste en el examen de compatibilidad que siempre debe realizarse entre los actos y normas nacionales y la Convención Americana de Derechos Humanos (CADH), sus protocolos adicionales, y la jurisprudencia de la Corte Interamericana de Derechos Humanos (Corte IDH), único órgano jurisdicción interamericano de protección de los derechos humanos que interpreta de manera "última" y "definitiva" el Pacto de San José. (Ferrer, 2012, p. 340)

Así, el debido proceso a que se refieren los instrumentos internacionales, es aplicable a toda clase de actuaciones judiciales y administrativas, en el caso concreto a los procesos de verificación del estatus migratorio de los migrantes indocumentados en tránsito por el territorio nacional, ya que el debido proceso se refiere a los pasos que la ley impone a los procesos judiciales y administrativos, respecto a las formalidades propias de cada juicio o procedimiento, que están contenidas en los principios en que se fundan, el tipo de intereses en conflicto, y la calidad de los funcionarios encargados de resolver.

$\mathrm{Al}$ abrirse la posibilidad de reconocer los derechos humanos de los migrantes, sin menoscabo de su estatus de ciudadanía, se abre paso, en términos del debido proceso, tener acceso a la justicia, no sólo en el campo penal, rebasado sobre todo el concepto de la criminalización de la migración, sino también en el administrativo: "Asimismo, para aquellos trámites o procesos de índole no penal a que pueda verse sometido un trabajador migratorio debe regir un cierto quantum del debido proceso" (Díaz, 2005, p. 225).

En lo que se refiere a los tratados internacionales suscritos por México en materia migratoria, más allá de lo cuantitativo, cualitativamente en ellos se reconocen los derechos que les asisten a los extranjeros dentro del territorio nacional, como los derechos de los nacionales en países extranjeros.

Adquiere notoria relevancia referir el informe rendido ante la Comisión de Derechos Humanos de la ONU, respecto a las detenciones arbitrarias en contra de migrantes indocumentados, realizadas por las autoridades migratorias mexicanas, donde se pone de manifiesto la violación al derecho del debido proceso de migrantes con situación legal irregular, dicho informe dice:

El tema de la libertad de tránsito y su vulneración a través de detenciones arbitrarias en México ha sido objeto de un interesante informe rendido ante la Comisión de Derechos Humanos de la ONU; se trata del "Informe del Grupo de Trabajo sobre 
la Detención Arbitraria acerca de su visita a México", de fecha 17 de diciembre de 2002. (Carbonell, 2012a, p. 88)

El informe se detiene en el trato que el gobierno mexicano da a los migrantes de otros países que se encuentran en situación irregular. Sobre el punto, se afirma por lo que hace a la estación migratoria que el gobierno tiene en la delegación Iztapalapa de la Ciudad de México, que "Los ciudadanos de países latinoamericanos suelen permanecer en la estación migratoria algunas semanas antes de ser devueltos a sus países de origen. La permanencia de nacionales de países de otras regiones suele ser más larga; algunos se encontraban allí desde hacía tres o cuatro meses por problemas logísticos, y, en el caso de ciertas nacionalidades, por la ausencia de representación consular o diplomática en México, especialmente para determinar la verdadera nacionalidad". (Carbonell, 2012a, p. 89)

Con respecto al cuarto de detención de inmigrantes irregulares que existe en las instalaciones del Aeropuerto de la Ciudad de México, el informe sostiene que "el Grupo de Trabajo pudo constatar que esta estación migratoria, más parecida a una sala de espera de un aeropuerto, es inadecuada para una permanencia mayor de un día, dadas las insuficiencias detectadas en las instalaciones: ausencia de camas o literas, duchas, cocinas, comedores, etc.". (Carbonell, 2012a, p. 89)

Si la concepción dogmática y normativa de los derechos humanos descansa en los principios de universalidad, interdependencia, indivisibilidad y progresividad, y vinculado a que el artículo $1^{\circ}$ de la Constitución Política de los Estados Unidos Mexicanos indica "... todas las personas gozarán de los derechos humanos reconocidos en esta Constitución [...], así como de las garantías para su protección...", el derecho fundamental del debido proceso los derechos fundamentales arropa como justiciable a los migrantes indocumentados en tránsito por el territorio nacional, independientemente de su condición de irregularidad o no. Así la condición y legalidad de la detención de un migrante responde a los aspectos protectores y progresivos, y por tanto de no regresión de los derechos humanos, invocando así que al momento de procurar e impartir justicia, los operadores en México deben atender no sólo las cuestiones de vulnerabilidad del migrante, inclusive reconoce que:

[...] el Protocolo de Actuación para Quienes Imparten Justicia en Casos que Afecten a Personas Migrantes y Sujetas de Protección Internacional, [...] aunque no es vinculante ni tiene valor normativo para fundar una decisión jurisdiccional, constituye una herramienta que guía a los juzgadores en la tarea de impartir justicia en casos que afecten a personas migrantes y sujetas de protección internacional, porque se adecua a los criterios nacionales $e$ internacionales, a la luz de los compromisos adquiridos por el Estado Mexicano en materia de derechos humanos y establece prácticas para hacer efectivo el acceso a la justicia para este grupo vulnerable; [...] (SCJN, 2015) 
Y continúa el cuerpo argumentativo del precedente estableciendo que:

Así, los avances en materia de derechos humanos han creado un nuevo paradigma que exige que quienes imparten justicia conozcan las fuentes normativas de origen nacional e internacional; las interpreten en el sentido de maximizar la protección de los derechos humanos de las personas migrantes y sujetas de protección internacional y ejerzan, de acuerdo con los principios hermenéuticos consagrados en el artículo 1o. de la Constitución Política de los Estados Unidos Mexicanos, el control difuso de constitucionalidad y convencionalidad. (SCJN, 2015)

\section{Conclusiones}

Las reformas estructurales en el sistema jurídico y constitucional mexicano han planteado un cambio sistémico, y responde a toda una construcción teórica de los derechos humanos, fundamentales y sus garantías; donde prima como sustancia del sistema la dignidad del ser humano, la igualdad, los principios de los derechos humanos, de universalidad, indivisibilidad, interdependencia, progresividad y, por tanto de no regresión; pero más allá de una reducción a aspectos de nomenclatura, del tránsito de garantías individuales a derechos humanos y sus garantías; el capítulo primero constitucional acoge en el ámbito más protector metodologías de interpretación conforme, pro persona, y crea un bloque de constitucionalidad y convencionalidad, incluso con un control difuso, y puede decirse por tanto transversal para toda autoridad implicada en los procesos de detención de los migrantes, y por tanto, obligando a respetar los derechos fundamentales en materia de debido proceso.

Bajo el razonamiento de que la persona migrante, extranjera, y en tránsito por México, antes que extranjera, tiene la calidad de persona y con ese carácter se hace titular de todos los derechos contenidos en la Constitución Mexicana y en los Tratados Internacionales firmados por México, con la sola limitación del derecho al libre tránsito. Entre estos derechos, de los cuales es titular el extranjero, destaca el derecho a la tutela judicial efectiva y al debido proceso, que garantizan que toda persona desde el momento de su detención debe ser puesta a disposición de una autoridad judicial.

Por lo tanto, conforme a este principio, cuando una persona migrante indocumentada es detectada (privada de su libertad) para ser sujeta a un procedimiento especial, distinto del que exige el debido proceso, como es el procedimiento de verificación migratoria, se le está discriminando por su condición de extranjera indocumentada, violentando en su perjuicio el artículo primero constitucional, y ligado a ello el bloque de constitucionalidad y convencionalidad.

El debido proceso como derecho fundamental, en su núcleo integra las garantías mínimas a favor de las personas, que exigen: la existencia de una autoridad judicial imparcial, que ésta dicte una resolución conforme a derecho, y que exista una autoridad jerárquicamente superior a la que dictó la sentencia o resolución, para confirmarla, revocarla o modificarla. 
Conforme a estas exigencias, todo procedimiento -como es el caso del procedimiento administrativo de verificación migratoria - que no respete las exigencias esenciales que caracterizan el debido proceso, será sólo un "debido procedimiento".

El debido proceso permite asegurar a las personas, que sus derechos serán respetados en todo proceso y procedimiento, haciendo, de esta manera efectiva la posibilidad jurídica de proteger la "sustancia" de la Constitución, es decir, la protección efectiva de los derechos fundamentales contenidos en la ley fundamental. 


\section{Referencias bibliográficas}

Auquilla, J.S. (2011). El debido proceso en la Constitución del 2008. Tesis, Escuelas de Posgrado, Universidad de Uzuay, Cuenca, Ecuador. Recuperado de http://dspace.uazuay.edu. ec/bitstream/datos/5515/1/08525.pdf

Bustamante, R. (2000). El derecho fundamental a un proceso justo -llamado también debido proceso-. Instituto Solidaridad y Derechos Humanos. Recuperado de http://www. isdeh.org/pdf/El_derecho_fundamental.pdf

Bustamante, R. (2002). Estado de Derecho, constitución y debido proceso. Algunos comentarios a propósito de la reforma constitucional, Justicia Viva, 14.

Caballero, J.L. (2012). La cláusula de interpretación conforme y el principio pro persona (artículo 1o., segundo párrafo de la Constitución). En M. Carbonell. La reforma constitucional en materia de derechos humanos (pp. 103-133). México: IIJ-UNAM. Recuperado de http://www.corteidh.or.cr/tablas/r29010.pdf

Carbonell, M. (2012). La reforma constitucional en materia de derechos humanos: principales novedades. Recuperado de http://www.miguelcarbonell.com/articulos/novedades. shtml

Carbonell, M. (2012a). Los derechos humanos de libertad de tránsito, asilo y refugio. En D. Cienfuegos, \& G. Froto (Coord.). Los Derechos Humanos en el momento actual. Saltillo: CDH del Estado de Coahuila. Recuperado de http://biblio.juridicas.unam. $\mathrm{mx} / \mathrm{libros} / 7 / 3171 / 5 . \mathrm{pdf}$

Campbell, J.C. (2004). El debido proceso constitucional. Anuario de Derecho Constitucional Latinoamericano, 157-250. Recuperado de http://www.juridicas.unam.mx/publica/ librev/rev/dconstla/cont/2004.1/pr/pr10.pdf

Consejo de Europa. (1950). Convenio para la protección de los derechos humanos y las libertades fundamentales. Recuperado de http://www.echr.coe.int/Documents/Convention_ SPA.pdf

Corte Interamericana de Derechos Humanos. (2003). Condición Jurídica y derechos de los migrantes indocumentados, OPINIÓN CONSULTIVA OC-18/03. San José, Costa Rica: http://www.corteidh.or.cr/docs/opiniones/seriea_18_esp.pdf

Corte Interamericana de Derechos Humanos. (2015). Migrantes. Cuadernillo de Jurisprudencia, 2. San José: Corte IDH. Recuperado de http://www.corteidh.or.cr/ sitios/libros/todos/docs/migrantes4.pdf

Díaz, P. (2005). El acceso a los tribunales y debido proceso legal de las personas migrantes desde los estándares del Sistema Interamericano de Derechos Humanos. Seminario Internacional sobre los Derechos Huumanos de lo Migrantes (pp. 219-237). Boca del Río: UNAM. Recuperado de http://biblio.juridicas.unam.mx/libros/5/2480/16.pdf Ferrajoli, L. (2005). Los fundamentos de los derechos fundamentales. Madrid: Trotta. 
Ferrer, E. (2012). Interpretación conforme y control difuso de la convencionalidad. El nuevo paradigma para el juez mexicano. En $\mathrm{M}$. Carbonell. La reforma constitucional en materia de derechos humanos (págs. 339-429). México: IIJ-UNAM. Recuperado de http://www.corteidh.or.cr/tablas/r29018.pdf

Fix-Zamudio, H. (1987). Debido proceso legal. En UNAM. Diccionario jurídico mexicano. México: Porrúa.

García, L. (2003). El debido proceso y la tutela judicial efectiva. Frónesis, 10(3), 1-7. Recuperado de http://www.scielo.org.ve/scielo.php?script=sci_ arttext\&pid $=$ S1315-62682003000300005

García, S. (2004). Panorama del proceso penal. Ciudad de México: Porrúa.

Gómez, C. (1974). Teoría general del proceso. Ciudad de México: Universidad Autónoma de México.

Ledesma, M. (2011). Afectación del debido proceso por vulneración al derecho de defensa en la revisión de la pretensión revindicatoria. Trabajo de investigación II, Universidad San Martin de Porres. Recuperado de http://www2.congreso.gob.pe/sicr/cendocbib/ con4_uibd.nsf/0AAE071385B90C0405257BA90064DD78/\$FILE/AFECTACION_ DEBIDO_PROCESO_VULNERACION_DERECHO_DEFENSA.pdf

Organización de Estados Americanos (1948). Declaración americana de los derechos y deberes del hombre. Recuperado de https://www.oas.org/dil/esp/Declaraci\%C3\%B3n_ Americana_de_los_Derechos_y_Deberes_del_Hombre_1948.pdf

Organización de Estados Americanos (1969). Convención Americana de los derechos humanos (Pacto San José). Recuperado de https://www.oas.org/dil/esp/tratados_B-32_ Convencion_Americana_sobre_Derechos_Humanos.htm

Organización de las Naciones Unidas (ONU). (1948). Declaración Universal de los Derechos Humanos. Recuperado de http://www.un.org/es/documents/udhr/

Organización de las Naciones Unidas (ONU). (1966). Pacto Internacional de Derechos Civiles y Políticos. Recuperado de http://www.ohchr.org/SP/ProfessionalInterest/Pages/ CCPR.aspx

Petit, L.A. (2011). El debido proceso como derecho fundamental y humano. Revista Alcance, 16(1). Recuperado de http://www6.univali.br/seer/index.php/nej/article/ download/3269/2051

Real Academia Española. (2015). Diccionario de la lengua española. Recuperado de http:// www.rae.es/

Sarazá, R. (2008). Jueces, derechos fundamentales y relaciones entre particulares. La Rioja: Universidad de La Rioja.

Suprema Corte de Justicia de la Nación (SCJN). (2003). Las Garantías de Seguridad Jurídica. Colección Garantías Individuales. Ciudad de México: SCJN.

Suprema Corte de Justicia de la Nación (SCJN). (2013). Protocolo de actuación para quienes imparten justicia en casos que afecten a personas migrantes y sujetas de protección internacional. Ciudad de México: SCJN. Recuperado de http://www.acnur.org/t3/ fileadmin/Documentos/Publicaciones/2013/9362.pdf?view=1 
Suprema Corte de Justicia de la Nación (SCJN). (2015, marzo). Tesis Aislada (Común). Semanario Judicial de la Federación, Décima Época, Tribunales Colegiados de Circuito, Tomo III, p. 2431

Torres, J.E. (2011). El procedimiento para juzgar contravenciones penales y la violación del Debido Proceso, en la Intendencia General de Policía de Tungurahua. Proyecto de investigación, Ecuador. 


\title{
Capítulo 8
}

\section{La relación entre la popularidad de los cibermedios de Colima y su oferta informativa}

\author{
Juan Carlos Flores Carrillo \\ Rodolfo Antonio Mejía Villaseñor \\ Juan Flores Preciado
}

Universidad de Colima 
128 Estudios de desarrollo regional en México 


\section{Introducción}

Este capítulo parte de la interrogativa que conlleva a cuestionar qué se necesita para que un cibermedio llegue a alcanzar reconocimiento y popularidad.

Según Said y Arcila (2012), "los cibermedios en América Latina experimentan un desarrollo desigual en términos de calidad" y mencionan algunas diferencias que encontraron en su ranking con respecto a medios de comunicación digital en varios países como Colombia y México -los mejor valorados- con respecto a Chile y Bolivia - peor valorados-, "lo que hace necesario una revisión profunda e individual de cada uno de los países de la región, basándose en criterios homogéneos para poder compararlos entre sí" (p. 282).

Al tomar en cuenta algunas de sus características, de acuerdo a los cibermedios han coadyuvado a la descentralización, diversificación y personalización de la información con respecto a los medios de comunicación de masas tradicionales (Spectus, 2004).

Pero la pregunta es: ¿Qué hace un cibermedio para hacer diferencia ante una gran diversidad de opciones que tiene el lector?

En este análisis se describe un panorama general de algunos puntos teóricos relacionados con el reconocimiento y la popularidad de los cibermedios; luego se contrastan los resultados que tienen los medios digitales de Colima con respecto al ranking que establece el sitio Alexa.com, uno de los más utilizados para medir el tráfico de los cibermedios a nivel nacional y que se utiliza como referente en el ofrecimiento de publicidad a los anunciantes.

\section{Cibermedios}

La tecnología digital está afectando profundamente todos los órdenes de la vida de los hombres junto a sus profesiones, porque está modificando los procesos tradicionales de investigación, elaboración, difusión de los mensajes periodísticos; de hecho hasta la propia barrera entre periodistas y público; emisor y receptor, se difumina.(Urdaneta, 2007)

Utiliza un lenguaje combinado entre el texto, la imagen y el video como lo hacen los medios tradicionales como la radio, la televisión y la prensa. De acuerdo a Cebrián (2009) se entiende por «cibermedio»:

el proceso que va de un productor-emisor de contenidos y servicios informativos mediante estrategias y técnicas periodísticas específicas y adecuadas a las exigencias de la plataforma Internet y con la potencialidad incorporada por ésta como el uso integrado de varios sistemas expresivos: escrito, gráfico, icónico, auditivo, audiovisual y multimedia, hasta llegar a unos usuarios que pueden seguir, manejar o producir otras informaciones y entablar diálogo o intercambiarse los papeles con el emisor. Se parte, pues, de una concepción de los cibermedios como procesos diferentes a los de los medios de comunicación tradicionales. No obstante, no se 
plantean como radicalmente opuestos, sino que se establecen diversas vinculaciones entre unos y otros. (P. 16)

Pueden diferenciarse tres modalidades de cibermedios: a) Cibermedios matriciales: son los presentes en Internet cuyo origen se inicia previamente en papel como la prensa o mediante difusión electrónica como la radio y la televisión. Desarrollan una evolución desde su matriz hasta la plena adecuación a Internet; b) Cibermedios nativos: son los nacidos dentro de Internet sin referencia matricial alguna. (P. 16)

El lenguaje que utilizan los cibermedios son heredados de la prensa (Cely, 2001 citado en Urdaneta, 2007) en donde además se agrega el hipertexto o el hiperdocumento, definido por Chirinos (2006) como "aquellos documentos digitales organizados en forma hipertextual que permiten la micronavegación (al interior del propio documento) y la macronavegación (entre éste y otros documentos), hecho que posibilita diversas formas de interactividad".

Larrondo (2005) afirma que los cibermedios han buscado:

[...] elaborar productos diferenciados, afanándose en consolidar su propia identidad. Al mismo tiempo, fueron surgiendo otras formas de comunicación ajenas al periodismo, y la rapidez con la que se han ido sucediendo todos estos cambios ha dejado poco tiempo a la reflexión, aún cuando la mayoría de estos productos no han alcanzado siquiera la madurez. (P. 2)

\section{Interacción y participación}

De acuerdo a Urdaneta (2007) "la hipertextualidad, la multimedialidad y la interactividad son, precisamente los rasgos que mejor caracterizan al periodismo de las tecnologías digitales" en donde el usuario busca un medio de comunicación capaz de satisfacer la demanda de información profunda, imagen y sonido, un producto multimedia.

Son los usuarios los que encuentran la diferencia con respecto a medios tradicionales: la interactividad y cada uno de los nuevos elementos que ofrecen los cibermedios. De acuerdo a Navaro (2013), "el usuario consulta en cualquier momento y a cualquier hora los últimos acontecimientos que a él le interesan, tanto en el espacio local, como en el global". Este autor menciona que:

la interactividad que ofrece Internet permite a los usuarios opinar e intervenir directamente en el cibermedio. Conocer a los editores, cuestionarles y ser parte de su trabajo al proporcionarles información. Se logra la interactividad al menos en potencia. La comunicación es unidireccional. No se siente alejado, psicológicamente es parte de un producto. (Navaro, 2013) 
Pero no sólo la interactividad influye en un cibermedio para lograr la popularidad o el reconocimiento, como indica Iglesias (2012):

[...] tiene muchas vertientes que influyen en su manera de hacer información. Por una parte, existe como la complejidad de organizar los recursos humanos y técnicos, estar al día de los cambios tecnológicos, etc. Por otro lado, la rapidez con que se transmite la información hace que la actualización continuada de las noticias sea uno de sus elementos fundamentales. (P. 12)

Para Chirinos (2006):

La jerarquía de los contenidos de información periodística (CIP) y las respectivas secciones que los conforman pueden evaluarse de dos formas: con relación al destaque de las informaciones, aspecto relacionado directamente con la propia relevancia de la noticia, y en cuanto a su ubicación en el Sitio, referido al diseño y disposición de las informaciones en orden descendente.

Los contenidos que jerarquiza Chirinos (2006) en su investigación fueron tomados como referencia para este análisis como:

a) las fuentes, b) la edición, c) la importancia de la noticia, d) las noticias del día, e) la ocurrencia de los hechos, f) la edición impresa, g) titulares, h) dibujo-mancheta, i) verso, j) suplementos $y$, $k$ ) la encuesta en línea. Estos pueden o no estar identificados como secciones.

Los CIP agrupados bajo el criterio de las fuentes están distribuidos en cuatro secciones: a) Noticias, que se dividen, a su vez, en Política, Economía, Aldea Global, Zulia y Sucesos; b) Opinión, que comprende Opinión, Editoriales e Investigación (subdividida en "Reportes especiales"); c) Vida, que se subdivide en Espectáculos, Estrategia y Mercado, Turismo y Sociales d) Deportes, que abarca únicamente los deportes en términos generales y e) Noticia de sucesos, que es una única información de sucesos dispuesta en el titular de una sola línea. (Chirinos, 2006)

\section{Popularidad}

La visibilidad y la popularidad de un cibermedio pueden ser medidas por el número de enlaces que recibe de otros sitios web, del número de páginas publicadas e indexadas por este medio; así como por el número de visitas que recibe un sitio y el número de páginas servidas por éste (Said y Arcila, 2012).

Los cibermedios han visto cómo debían incorporar nuevas rutinas productivas en la planificación, la cobertura y la elaboración de los mensajes informativos que 
generaban. A ello se ha unido el gran potencial de la web social para la difusión y la promoción de contenidos en la Red. De este modo, los cibermedios se han apresurado para incorporar en sus plataformas espacios dialógicos dirigidos a fomentar el carácter colaborativo, horizontal y democratizador propio de la web social. (Tejedor, 2010, p. 16)

La popularidad y el reconocimiento son elementos muy importantes para un cibermedio pues incide en el modelo de negocio ya que la gran mayoría están basados en la gratuidad en el acceso a los contenidos y en la publicidad como la gran fuente de ingresos (Parra, Edo, Flores, García-Alonso y Marcos, 2008).

Lo que sí parece evidente es que la clave del triunfo o fracaso radicará en el concepto de valor añadido: sólo si los propietarios de los ciberperiódicos son capaces de aportar dicho valor añadido a la comunidad internauta, ésta aceptará pagar por dichos contenidos. Pero no es menos cierto que una empresa periodística puede ganar dinero optando por obtener ingresos a través de la publicidad y vía patrocinio de contenidos que se ofrecen gratuitamente en la Red. (Parra et al., 2008)

En el caso del análisis de este estudio, los 7 cibermedios analizados tienen como modelo de negocio la venta de publicidad como la principal fuente de ingresos por lo que los contenidos no se cobran al usuario, de ahí la importancia que implica ser un medio de comunicación con alto reconocimiento y popularidad pues a medida que sea más reconocido los anunciantes querrán comprar espacios publicitarios.

Se contrastó la valoración de sus contenidos con respecto al ranking que obtuvieron en el sitio Alexa.com en la medición del tráfico del mes de diciembre de 2015 como se muestra a continuación:

Tabla 1. Ranking de cibermedios de Colima.

\begin{tabular}{|c|c|c|}
\hline alexa.com & Ranking mundial & Ranking México \\
\hline Ángel Guardián & 210882 & 3460 \\
\hline Colima Noticias & 210565 & 3284 \\
\hline Diario de Colima & 290933 & 6127 \\
\hline Perriodismo & $1,326,720$ & 27659 \\
\hline El Comentario & Sin datos & Sin datos \\
\hline AF Medios & 73153 & 1007 \\
\hline
\end{tabular}

Fuente: Alexa.com

Como se observa en la Tabla 1, el medio de comunicación más popular es AF Medios, seguido de Colima Noticias, Ángel Guardián, Diario de Colima y Perriodismo. 
Del periódico El Comentario no se pudieron obtener los datos pues está almacenado en el servidor de la Universidad de Colima y el sitio Alexa.com mide todo el tráfico del servidor.

\section{Metodología}

El objetivo de esta investigación es observar la relación entre los contenidos que ofrecen los cibermedios de Colima y la popularidad de estos portales, medida a través del sitio web Alexa.com. Para ello, primero se seleccionaron los principales cibermedios: Diario de Colima, El Comentario, Ângel Guardián, Perriodismo, Colima Noticias y AF Medios.

Los cibermedios Diario de Colima y El comentario funcionan aún como periódicos impresos, es decir, como lo menciona Cebrián (2009) son cibermedios matriciales pues ofrecen sus contenidos en línea y cuentan con una versión impresa diariamente.

En lo que respecta a Ángel Guardián, funciona como portal de noticias en internet y a la vez genera información a través de su plataforma tradicional que es una frecuencia de radio con alcance regional, la 98.9 FM.

Por su parte, Perriodismo, Colima Noticias y AF Medios son cibermedios "nativos", es decir, que no tienen una plataforma tradicional como medio de comunicación como es una versión impresa, radio o televisión.

Para el análisis, se observó el trabajo de la información durante los meses de octubre y noviembre del 2015, se determinaron 6 apartados: secciones, especiales, opinión, géneros, infografía y redes sociales.

En el apartado de "secciones", se analizó qué tipo de clasificación de la información ofrece, de manera regular, el cibermedio: local, nacional, internacional, deportes, espectáculos, culturales, etc.

En el apartado "especiales", se determinó analizar aquella información exclusiva que de manera esporádica ofrece el medio de comunicación a sus lectores sobre un tema específico, como: elecciones, tecnología, autos, ciencia, etc.

En el apartado "opinión" se analizó el número de periodistas que ofrecen sus opiniones, de manera regular, sobre temas específicos o de actualidad.

En cuanto a "géneros", se observó el número de géneros periodísticos con los que el medio de comunicación trabaja, como: nota, columna, artículo, entrevista, reportaje, crónica, editorial, reseñas y cartones humorísticos.

En el apartado "infografía", se analizó si el medio de comunicación ofrece la información trabajada de manera gráfica, como infografía sobre temas particulares para una mejor comprensión de los hechos por parte de los lectores.

Finalmente, en el apartado "Redes Sociales", se analizó cuántas redes sociales utiliza el medio de comunicación para difundir la información y el número de seguidores en cada de estas redes.

Para la valoración de cada uno de los apartados, se utilizó una escala del 0 al 5 donde el 0 es la ausencia de cualquier contenido y el 5 significa que es el medio de información con mayor contenido. 
Tabla 2. Contenido periodístico de los cibermedios de Colima (2015).

\begin{tabular}{|c|c|c|c|c|c|c|}
\hline MEDIO & SECCIONES & $\begin{array}{c}\text { ESPECIA- } \\
\text { LES }\end{array}$ & OPINIÓN & GÉNEROS & INFOGRAFÍA & $\begin{array}{c}\text { REDES } \\
\text { SOCIALES }\end{array}$ \\
\hline 杂 & $\begin{array}{l}\text { Estado: política } \\
\text { y gobierno, } \\
\text { seguridad, clima, } \\
\text { salud y educa- } \\
\text { ción, publicidad, } \\
\text { policiacas, } \\
\text { agronomía. } \\
\text { Negocios } \\
\text { Nacional: presi- } \\
\text { dencia. } \\
\text { Soft news: } \\
\text { deportes, redes, } \\
\text { cartones. }\end{array}$ & $\begin{array}{l}\text { Editorial } \\
\text { Manos y } \\
\text { monos. } \\
\text { Artistas para } \\
\text { recordar } \\
\text { Así decimos } \\
\text { en Colima }\end{array}$ & El análisis de Alberto Carvajal & $\begin{array}{l}\text { Nota } \\
\text { Crónica } \\
\text { Reportaje } \\
\text { Entrevista } \\
\text { Editorial }\end{array}$ & $\begin{array}{l}\text { Se realiza uno para } \\
\text { cada evento impor- } \\
\text { tante. } \\
\text { Ejemplo: el huracán } \\
\text { Patricia }\end{array}$ & $\begin{array}{l}\text { FACEBOOK: } \\
76446 \\
\text { seguidores } \\
\text { INSTAGRAM: } \\
1726 \\
\text { seguidores } \\
\text { TWITTER: } \\
19100 \\
\text { seguidores }\end{array}$ \\
\hline 录 & $\begin{array}{l}\text { Política } \\
\text { Policiaca } \\
\text { Municipios } \\
\text { Deportes } \\
\text { Estado } \\
\text { Mundo } \\
\text { Educación } \\
\text { Cultura } \\
\text { Salud } \\
\text { Tecnología } \\
\text { Destacadas } \\
\text { Últimas Noticias }\end{array}$ & $\begin{array}{l}\text { Ojo ciu- } \\
\text { dadano } \\
\text { Elecciones } \\
2015\end{array}$ & $\begin{array}{l}\text { Abel González, Alberto } \\
\text { Lati, Alex Carbajal, Alfredo } \\
\text { Cocoletzi, Amador Contreras, } \\
\text { André Marín, Bertha Santana, } \\
\text { Candelario González, Carlos } \\
\text { Orozco, Christian Martinoli, } \\
\text { Daniel Miranda, David Faite- } \\
\text { lson, David Medrano, Édgar } \\
\text { Rodríguez, Edgard Saúl Díaz, } \\
\text { El Francotirador, El Teniente } \\
\text { de la cancha, Eric Ramírez, } \\
\text { Felipe Díaz, Florencio Llamas, } \\
\text { Gerardo Palafox, Gerardo } \\
\text { Velázquez de León, Gustavo } \\
\text { López, Héctor Jesús Lara, } \\
\text { Heriberto Murrieta, Jaime Pi- } \\
\text { zano, Jonás Larios Deniz, Jorge } \\
\text { García, Jorge Martínez, José } \\
\text { Ángel Brambila, José Gilberto } \\
\text { Ibáñez, José Luis Santana, } \\
\text { José Luis Santana, Juan Carlos } \\
\text { Bernal, Juan Ramón Negrete, } \\
\text { Luis Ávila, Luis García, Ma- } \\
\text { nuel Agustín Trujillo, Manuel } \\
\text { Olvera, Marco Ruelas, Mario } \\
\text { Acevedo, Mauricio Castillo, } \\
\text { Miguel Gurwitz, Noé Guerra, } \\
\text { Pepe Naranjo, Priscila Casillas } \\
\text { de la Rosa, Raúl García, Raúl } \\
\text { Orvañanos, Roberto Quinta- } \\
\text { nar, Rodrigo Rosales, Rogelio } \\
\text { Guedea, Rubén Martínez } \\
\text { “Tawa”, Salvador García Soto. }\end{array}$ & $\begin{array}{l}\text { Entrevista } \\
\text { Reportaje } \\
\text { Crónica } \\
\text { Nota }\end{array}$ & $\begin{array}{l}\text { En cada evento } \\
\text { importante. } \\
\text { Normalmente son } \\
\text { estatales nada más. }\end{array}$ & $\begin{array}{l}\text { FACEВОOK: } \\
8138 \\
\text { seguidores } \\
\text { TWITTER: } \\
8081 \\
\text { seguidores }\end{array}$ \\
\hline
\end{tabular}


Tabla 2. Contenido periodístico de los cibermedios de Colima (2015)... continuación.

\begin{tabular}{|c|c|c|c|c|c|c|}
\hline MEDIO & SECCIONES & ESPECIALES & OPINIÓN & GÉNEROS & INFOGRAFÍA & $\begin{array}{c}\text { REDES } \\
\text { SOCIALES }\end{array}$ \\
\hline 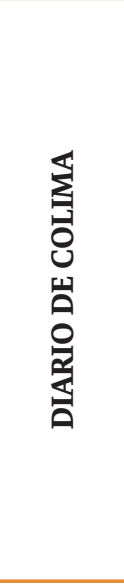 & $\begin{array}{l}\text { Municipios } \\
\text { Armeria y } \\
\text { Tecoman } \\
\text { Orden público } \\
\text { Deportes } \\
\text { Nacional } \\
\text { Internacional } \\
\text { Finanzas }\end{array}$ & $\begin{array}{l}\text { Escenario } \\
\text { Niños } \\
\text { Glorieta } \\
\text { Cartón }\end{array}$ & $\begin{array}{l}\text { "Opinan" } \\
\text { Algunos de los que es- } \\
\text { criben en éstas seccio- } \\
\text { nes son: Armando Mar- } \\
\text { tínez de la Rosa, Sergio } \\
\text { Briceño González, Juan } \\
\text { José Gómez Santos, } \\
\text { Héctor Sánchez de la } \\
\text { Madrid, Manuel Godina } \\
\text { Velasco, Jorge Fernán- } \\
\text { dez Menéndez, Sabina } \\
\text { de la Luz Urzúa, Carlos } \\
\text { Ramírez. Manzanillo: } \\
\text { Víctor Córdoba Herrero, } \\
\text { Ramón Larrañaga } \\
\text { Torróntegui, Gabriela } \\
\text { Benavides Cobos }\end{array}$ & $\begin{array}{l}\text { Informativos } \\
\text { Noticia } \\
\text { Entrevista } \\
\text { De opinión } \\
\text { Editorial } \\
\text { Artículos } \\
\text { Columnas } \\
\text { Reseña o } \\
\text { critica } \\
\text { Investigativo } \\
\text { Crónica }\end{array}$ & No tiene & $\begin{array}{l}\text { FACEВOOK: } \\
\text { 14,936 } \\
\text { seguidores } \\
\text { TWITER: } \\
\text { 1,011 } \\
\text { seguidores }\end{array}$ \\
\hline 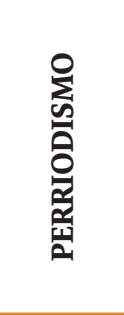 & $\begin{array}{l}\text { Colima } \\
\text { Universidad } \\
\text { México } \\
\text { Mundo } \\
\text { Cartelera } \\
\text { Opinión }\end{array}$ & No tiene & $\begin{array}{l}4 \text { Columnistas: } \\
\text { Marisa Mesina, César } \\
\text { Barrera Vázquez, Héctor } \\
\text { Gutiérrez Magaña y } \\
\text { Alejandra Zamora } \\
\text { Chávez. }\end{array}$ & $\begin{array}{l}\text { Notas } \\
\text { Reportajes } \\
\text { Crónicas } \\
\text { Entrevistas } \\
\text { Infografias }\end{array}$ & Ocasional & $\begin{array}{l}\text { FACEBOOK: } \\
16423 \\
\text { seguidores } \\
\text { TWTTTER: } \\
1110 \\
\text { seguidores. } \\
\text { YouTube: } \\
258 \\
\text { suscriptores. }\end{array}$ \\
\hline 四总 & $\begin{array}{l}\text { Colima } \\
\text { Internacionales } \\
\text { México } \\
\text { Deportes }\end{array}$ & Universitarios & $\begin{array}{l}\text { Amador Contreras } \\
\text { Robles } \\
\text { José Levy } \\
\text { Adalberto Carvajal } \\
\text { Anónimo } \\
\text { Raúl Sánchez }\end{array}$ & $\begin{array}{l}\text { Editorial } \\
\text { Columnas } \\
\text { Artículos } \\
\text { Notas } \\
\text { Crónica } \\
\text { Entrevista } \\
\text { De opinión }\end{array}$ & No tiene & $\begin{array}{l}\text { FACEBOOK:- } \\
\text { más de } 500 \\
\text { seguidores }\end{array}$ \\
\hline 兽 & $\begin{array}{l}\text { Estado } \\
\text { Política } \\
\text { Justicia } \\
\text { Nacional } \\
\text { Internacional } \\
\text { Deportes } \\
\text { Reporte AF } \\
\text { Productos AF }\end{array}$ & $\begin{array}{l}\text { Tecnología AF } \\
\text { Salud AF } \\
\text { Fotonotas } \\
\text { Mujer AF } \\
\text { Gente AF } \\
\text { Autos AF } \\
\text { Para comer } \\
\text { Especiales -Info- } \\
\text { grafías }\end{array}$ & $\begin{array}{l}56 \text { personas han escrito } \\
\text { en la sección opinión y } \\
\text { también tienen edito- } \\
\text { riales. } \\
\text { Lo hacen periódicamen- } \\
\text { te, aproximadamente } \\
\text { cada dos semanas, } \\
\text { aunque a veces cada } 3 \\
\text { días. }\end{array}$ & $\begin{array}{l}\text { Noticia } \\
\text { Artículo } \\
\text { de opinión } \\
\text { Reportaje } \\
\text { Crónica }\end{array}$ & $\begin{array}{l}\text { Utilizan frecuente- } \\
\text { mente infografías } \\
\text { de varios temas } \\
\text { locales y nacionales }\end{array}$ & $\begin{array}{l}\text { FACEBOOK: } \\
\text { 107,853 likes } \\
\text { TWITTER: } \\
\text { 12,243 } \\
\text { seguidores } \\
\text { INSTAGRAM: } \\
\text { 290 segui- } \\
\text { dores/312 } \\
\text { publicaciones } \\
\text { YouTube: } \\
\text { 1,776 suscrip- } \\
\text { tores }\end{array}$ \\
\hline ๘ & $\begin{array}{l}\text { Policiacas } \\
\text { Deportes Muni- } \\
\text { cipios Culturales } \\
\text { Nacionales } \\
\text { Internacionales } \\
\text { Suplementos } \\
\text { Interés público }\end{array}$ & $\begin{array}{l}\text { Deportes } \\
\text { Policiacas } \\
\text { Culturales } \\
\text { Interés público }\end{array}$ & $\begin{array}{l}\text { Teresa Valdés Betan- } \\
\text { court, Rodrigo Rosales } \\
\text { Escobar, Abraham } \\
\text { Rodríguez Fletes, Sofía } \\
\text { del Carmen Carvajal } \\
\text { Gómez, Alfonso Polanco } \\
\text { Terríquez. }\end{array}$ & $\begin{array}{l}\text { Nota } \\
\text { De etiqueta } \\
\text { Cartones } \\
\text { Columnas } \\
\text { Nota por } \\
\text { etiqueta } \\
\text { Opinión } \\
\text { Informativo } \\
\text { Interpreta- } \\
\text { tivo. }\end{array}$ & No tiene & $\begin{array}{l}\text { TWITTER: } 121 \\
\text { seguidores } \\
\text { FACEBOOK: } \\
\text { 10,830 segui- } \\
\text { dores } \\
\text { YouTube: } 311 \\
\text { suscripciones }\end{array}$ \\
\hline
\end{tabular}




\section{Resultados y discusión}

A continuación se procederá a discutir los resultados de acuerdo a la valoración que se estableció, en los cuales se hizo un análisis de todo el contenido del sitio y se describieron cada uno de los apartados.

Como se puede observar en la Tabla 2, los cibermedios de Colima analizados tienen una diversidad de contenidos, aunque existen similitudes, por ejemplo, en el apartado de secciones donde la coincidencia entre los cibermedios para organizar la información (local, nacional, internacional, deportes, etc.) es recurrente.

También se observó que la gran mayoría trabaja diversos géneros de información, como la nota, la crónica y el reportaje, pero descuidan la parte de opinión donde Colima Noticias cuenta con el mayor número de periodistas que publican sus opiniones en columnas o artículos.

Los cibermedios de Colima analizados utilizan al menos una red social como Facebook o Twitter para difundir sus contenidos, pero los apartados con menor contenido fueron los llamados "Especiales" e "Infografía"

Tabla 3. Valoración de los contenidos de los cibermedios de Colima 2015.

\begin{tabular}{|l|c|c|c|c|c|c|c|}
\hline \multicolumn{1}{|c|}{ MEDIO } & SECCIONES & ESPECIALES & OPINIÓN & GÉNEROS & INFOGRAFÍA & $\begin{array}{c}\text { REDES } \\
\text { SOCIALES }\end{array}$ & TOTAL \\
\hline $\begin{array}{l}\text { ÁNGEL } \\
\text { GUARDIÁN }\end{array}$ & 5 & 5 & 0 & 3 & 5 & 4 & 22 \\
\hline $\begin{array}{l}\text { COLIMA } \\
\text { NOTICIAS }\end{array}$ & 5 & 2 & 5 & 5 & 1 & 2.5 & 20.5 \\
\hline $\begin{array}{l}\text { DIARIO DE } \\
\text { COLIMA }\end{array}$ & 2.5 & 3 & 5 & 5 & 0 & 1.5 & 17 \\
\hline PERRIODISMO & 2 & 0 & 0.5 & 4.5 & 0 & 2 & 9 \\
\hline EL COMENTARIO & 2 & 0.5 & 2 & 4 & 0 & 0.5 & 9 \\
\hline AF MEDIOS & 5 & 5 & 3 & 4 & 5 & 5 & 27 \\
\hline
\end{tabular}

Fuente: elaboración propia.

Una vez analizados los contenidos de los cibermedios de Colima -como se observa en la Tabla 3 - se procedió a asignar un valor del 0 al 5 , donde el número 0 significa que no existe ningún contenido, mientras que el 5 significa que el cibermedio ofrece el mayor contenido.

De los resultados obtenidos, el sitio AF Medios obtuvo la mayor calificación al contar con diversidad de secciones, un uso variado de especiales, infografía y redes sociales -es el que utiliza más redes sociales y tiene mayor número de seguidores-además de trabajar casi todos los géneros periodísticos (no utiliza editorial). 
El segundo lugar en la valoración de contenidos fue para Ángel Guardián por su amplitud de secciones, uso frecuente de infografías y especiales, difusión en varias redes sociales, aunque con poca opinión y poco trabajo en géneros periodísticos como reportaje y crónicas.

Colima Noticias logró el tercer lugar en la valoración por su uso amplio de secciones, opinión y géneros periodísticos, pero obtuvo menor calificación en especiales, infografía y redes sociales.

El cuarto lugar fue para Diario de Colima que obtuvo la más alta calificación en el apartado de Opinión y Géneros Periodísticos, pero demostró tener menos amplitud de secciones, nulo uso de infografías y pocos seguidores en las redes sociales Facebook y Twitter.

Empatados en el quinto lugar estuvieron el sitio Perriodismo y El comentario, pues no cuentan con secciones variadas, uso frecuente de infografías, poca opinión y pocos seguidores en las redes sociales como Facebook y Twitter principalmente.

\section{Conclusiones}

Al hacer una comparativa entre el ranking que muestra el sitio Alexa.com de los cibermedios de Colima analizados, respecto al estudio de contenido, se puede observar que hay una relación entre quién ofrece más productos periodísticos con respecto a la popularidad.

De acuerdo a Alexa.com, el sitio mejor posicionado es AF Medios (número 1007del ranking a nivel nacional) y fue el que obtuvo un mayor porcentaje en la valoración de contenido de esta investigación; posteriormente Colima Noticias -que está en segundo lugar de popularidad rankeado 3284- logró el tercer en el análisis de contenido muy cerca de Ángel Guardián -rankeado 3460- que quedó en segundo.

De hecho, estos dos sitios -Colima Noticias y Ângel Guardián- están casi empatados en los dos rankings.

Finalmente, completan la lista Diario de Colima -el medio impreso más vendido en el estado- que obtuvo el cuarto lugar como cibermedio; Perriodismo y El comentario.

Los resultados de ambos rankings -en cuanto al lugar que obtuvieron- son casi idénticos pues sólo hubo una diferencia entre Colima Noticias que obtuvo el tercer lugar en el análisis de contenido y Ángel Guardián que obtuvo el segundo.

Lo anterior confirma lo establecido por Parra et al. (2008) quienes aseguran que la clave del triunfo o fracaso radicará en el concepto de valor añadido aunque es imprescindible que se mejoren las metodologías en el análisis de los cibermedios para conocer, con mayor puntualidad, los aspectos que generan este valor y que los usuarios puedan aportar el reconocimiento a los medios de comunicación digitales. 


\section{Referencias bibliográficas}

Cebrián, M. (2009). Comunicación interactiva en los cibermedios. Comunicar, 17(33), 15-24. Recuperado de http://www.revistacomunicar.com/index. php? contenido $=$ detalles\&numero $=33 \&$ articulo $=33-2009-03$

Chirinos, E. (2006). Nuevas etapas evolutivas de los cibermedios: caso www.laverdad.com. Revista de Artes y Humanidades UNICA, 7(17), 109-137. Recuperado de http://www. redalyc.org/pdf/1701/170118739006.pdf

Iglesias, M. (2012). Rutinas productivas de un cibermedio nativo digital. Cuadernos de Información, 30, 9-20. Recuperado de http://cuadernos.info/index.php/CDI/article/ view/424/401

Larrondo, A. (2005). Presencia del formato weblog en los cibermedios: una aproximación a sus usos y funciones. Revista Latina de Comunicación Social, 60. La Laguna, Tenerife. Recuperado de http://www.redalyc.org/pdf/819/81986007.pdf

Navaro, L. (2013). La interactividad en los géneros periodísticos de los cibermedios. Razón y Palabra, 84. Recuperado de http://www.razonypalabra.org.mx/N/N84/V84/09_ Navaro_V84.pdf

Parra, D., Edo, C. Flores, J., García-Alonso, P., \& Marcos, J.C. (2008). Proceso de transformación de los cibermedios: los retos de las empresas periodísticas. Revista Latina de Comunicación Social, 11, 63.

Said, E., \& Arcila, C. (2012). El desarrollo de los cibermedios venezolanos. Investigación $\&$ Desarrollo, 20(2), 280-301. Recuperado de http://www.redalyc.org/ $\mathrm{html} / 268 / 26824854003 /$

Spectus, Grupo. (2004). Poder y medios. Comunicar, 22,165-170. Recuperado de http:// www.redalyc.org/html/158/15802225/

Tejedor, S. (2010). La Web 2.0: Herramienta de marketing y posicionamiento de los cibermedios iberoamericanos. Cuadernos de Información, 27, 15-24.

Urdaneta, J. (2007). Redacción en Cibermedios para Comunicadores en Formación. Razón y Palabra, 57. Recuperado de http://www.razonypalabra.org.mx/anteriores/n57/ jurdaneta.html 


\title{
Capítulo 9
}

\section{Factores de la contaminación del aire, agua, suelo y normas de regulación}

\author{
María Magdalena Zayas Esquer \\ Francisco Espinoza Morales \\ Lidia Amalia Zallas Esquer
}

Universidad de Sonora 
140 Estudios de desarrollo regional en México 


\section{Introducción}

El planeta Tierra es nuestro único hogar y en los últimos años se ha visto afectado drásticamente por el alto incremento de la población, y como consecuencia una mayor demanda de vivienda, alimentos, y otros productos. Debido a este crecimiento de la población mundial, las actividades antropogénicas también han aumentado, trayendo consigo gran contaminación en la atmósfera, agua y suelos, de igual manera la contaminación ha llegado a los ecosistemas y la gran cantidad de especies de animales y plantas, están desapareciendo sin precedente alguno. El incremento en la demanda de alimentos, producto del aumento de la población mundial, ha requerido que el sector agrícola también sea más eficiente en sus sistemas de producción, por lo que el suelo y el agua han sido objeto de sobreexplotación y contaminación.

La contaminación del aire es una realidad, es un problema en las grandes ciudades y en las zonas de gran actividad industrial, es en estos lugares donde se liberan grandes cantidades de contaminantes (SEMARNAT, 2007). La contaminación del agua superficial (ríos, arroyos y canales) y de los mantos freáticos (aguas subterráneas) también es un problema apremiante que aqueja a la población por sus múltiples actividades.

Actualmente, la contaminación de los suelos, agua y atmósfera causa cada vez mayor preocupación entre los ambientalistas, debido al riesgo de gran consideración provocando principalmente impactos en la salud humana y ocasionando grandes desastres ecológicos.

\section{Planteamiento del problema}

Existen diversos factores de contaminación y formas asociadas a las actividades antropogénicas, que podrían minimizarse con la aplicación de las normas que actúan como medidas regulatorias especificando límites máximos permisibles de contaminación, para proteger la salud de la población y reducir el impacto al medio ambiente; sin embargo, para lograrlo se requiere en las personas una actitud consciente, que permita ser receptivo del conjunto normativo que controla el medio ambiente respecto a la aplicación de ese marco jurídico, en el cual también deben participar las instituciones públicas, privadas y el mismo gobierno.

$\mathrm{Al}$ enfrentar el problema de la contaminación se está promoviendo el uso adecuado de los fertilizantes y químicos en el campo, del tratamiento de las aguas residuales, del agua marítima y la atmósfera.

Por ello es importante el cumplimiento de las disposiciones normativas y que la Procuraduría Federal de Protección al Ambiente (PROFEPA) sea eficiente e incorruptible, que cumpla con sus funciones; además se tiene que impulsar en las instancias de gobierno y organizaciones no gubernamentales (ONG's) la educación ambiental ecológica. Por tal motivo, se platea la siguiente pregunta de investigación: ¿Cuál es el impacto que tiene en la población la contaminación en la atmósfera, agua y suelo?

\section{Justificación}

Existe un cambio en las condiciones climáticas de nuestro planeta que está causando problemas ecológicos y por consecuencia en la salud humana. Dicho cambio climático ha 
tenido efectos en muchos lugares del planeta, creando condiciones que jamás se habían presentado en algunas regiones, como una mayor incidencia y frecuencia de los huracanes, terremotos, tifones y sequías.

Es importante señalar que el suelo, el agua y el aire, elementos vitales para el ser humano, guardan una estrecha relación que hace que el problema de contaminación de cada uno de éstos deba tomarse con el mismo interés. Debido a esta relación, es importante protegerlos y preservarlos en buenas condiciones. Y aunque existe contaminación provocada de manera natural, considerada menos común y de menor impacto, la mayor contaminación está relacionada con las actividades antropogénicas.

\section{Objetivo general}

Analizar el impacto que tiene en la población la contaminación en la atmósfera, agua y suelo.

\section{Objetivos específicos}

- Analizar los reglamentos y normas que se establecen como medida de protección a la salud de la población y del ambiente.

- Hacer una descripción de los factores que influyen en el transporte y destino de contaminantes e impactos que pueden ocasionar.

\section{Marco teórico}

"En la mayoría de las ocasiones, la contaminación es producida de una manera artificial por la actividad humana, pero también puede ser ocasionada de una forma natural, aunque ésta no sea la más común" (Ambientum, 2001).

La contaminación puede ser dividida en tres grandes ramas: contaminación del aire o atmosférica, contaminación del agua y contaminación del suelo.

\section{Contaminación del Aire}

Este tipo de contaminación es producto del crecimiento poblacional y, con ello, del cambio climático, que se ha acentuado en las zonas urbanas, tal y como lo señala SEMARNAT (2007):

Hoy es una realidad que la contaminación del aire es un problema en las grandes ciudades y en las zonas con actividades industriales, ya que es en estos lugares donde se liberan grandes cantidades de contaminantes a la atmósfera. Precisamente son estos contaminantes los que nos causan molestias en los ojos, piel y vías respiratorias y forman esas "brumas" que en la Ciudad de México nos impiden ver los cerros y volcanes que la rodean. (P. 122)

[...] el aire se contamina con gases y partículas que afectan la salud humana y de los ecosistemas, principalmente por los siguientes contaminantes: 
MONÓXIDO DE CARBONO: Resultante de la combustión incompleta de combustibles fósiles (petróleo, gas y carbón), especialmente en vehículos de motor. Aún aniveles relativamente bajos afecta a personas conproblemas cardiovasculares.

BIÓXIDO DE AZUFRE: Resultante de la combustión de derivados del petróleo con altos contenidos de azufre, especialmente de las plantas termoeléctricas. Afecta en mayor grado a enfermos con bronquitis, enfisema y asma.

OXXIDO DE NITRÓGENO: Resultante de la quema de combustibles fósiles a altas temperaturas como en vehículos de motor, hornos y turbinas. Causa bronquitis y pulmonía y agrava enfermedades cardiovasculares.

PARTICCULAS EN SUSPENSIÓN: Son partículas de polvo, hollín, actividad vehicular y de procesos industriales, con diámetro de 1 a 100 micras. Afectan al sistema respiratorio, especialmente las más pequeñas: Partículas Menores a 10 Micras (PM10) y Partículas Menores a 2.5 Micras (PM2.5), así como las de Plomo $(\mathrm{Pb})$. Propicia el agravamiento de enfermedades respiratorias y cardiovasculares. (IPN, 2016, p. 3)

La Norma Oficial Mexicana (NOM) es el instrumento que indica las cuantías máximas permisibles (para proteger la salud) de los contaminantes de la atmósfera, se miden en partes por millón (PPM) o en microgramos por metro cúbico de aire ( $\mu \mathrm{g} /$ m3 ), pero para facilitar su manejo y compresión se multiplican por algoritmos que los expresan en el Índice Metropolitano de Contaminación del Aire (IMECA), con cifras de 0 a 250, siendo 100 IMECA el límite para no hacer daño a la salud humana, aunque entre 51 y 100 IMECA pueden presentarse molestias en niños, adultos mayores y personas con afectaciones respiratorias; mientras que de 101 a 150 IMECA se considera Mala la calidad del aire afectando a niños y adultos mayores con afectaciones respiratorias y cardiovasculares. Ya con 151 - 200 IMECA (condición muy mala) son mayores las afectaciones a la salud, especialmente de niños y adultos mayores y de llegar a 201 o más IMECA (sería la condición extremadamente mala) pueden presentarse afectaciones graves, especialmente en niños y adultos mayores con enfermedades respiratorias y/o cardiovasculares. (IPN, 2016, p. 4-5)

\section{Contaminación del agua}

Uno de los elementos esenciales en la naturaleza es el agua; se considera un contribuyente para el bienestar de la población humana, por tal motivo es responsabilidad de todos cuidarla y evitar su contaminación.

El agua que utilizamos sigue un movimiento cíclico que se llama ciclo hidrológico o ciclo del agua, que es el proceso de circulación del agua entre los distintos compartimentos de la hidrósfera; comienza con la evaporación del agua desde la superficie del océano y a medida que se eleva, el aire humedecido se enfría y el vapor se condensa, dando lugar a la formación de nubes y posteriormente a la precipitación en forma de lluvia, nieve o granizo. 
Una parte del agua que llega a la tierra será aprovechada por los seres vivos; otra escurrirá por el terreno hasta llegar a un río, un lago o el océano. Otro poco del agua se filtrará a través del suelo, formando capas de agua subterránea. Este proceso es la percolación. Más tarde o más temprano, toda esta agua volverá nuevamente a la atmósfera, debido principalmente a la evaporación. (Olmos, 2015)

Mientras el agua pasa por el ciclo hidrológico, disuelve minerales y también lleva pequeñas partículas de tierra y polvo. La calidad del agua varía de un lugar al otro, con la estación y con los tipos de rocas y de suelos con los cuales entra en contacto. Mayormente, la calidad del agua es afectada por causas naturales. Sin embargo, las actividades humanas también tienen un impacto sobre ésta.

Según la Organización Mundial de la Salud (OMS) la contaminación del agua se presenta cuando no reúne las condiciones necesarias para su uso, debido a que su composición ha sido alterada o modificada, lo cual implica condiciones perjudiciales para la salud.

Es triste ver cómo el constante crecimiento de las ciudades es en gran parte responsable de la contaminación del agua, debido a que la población vierte sus desechos domésticos, industriales y toda clase de basura en el agua, provocando que ésta no pueda utilizarse y por lo tanto se desperdicie.

Diariamente las industrias desechan residuos contaminantes; algunos son altamente peligrosos ya que contienen mercurio, plomo, arsénico, fenol, plata, cromo, plaguicidas, entre otros, los cuales tienen un fuerte impacto sobre el medio ambiente. Todos esos desechos son vertidos o arrojados a los canales, ríos y mares, provocando la degradación del ambiente marino que trae como consecuencia efectos en los organismos; muchos animales marinos y aves mueren por ingestión de alguno de estos productos. Otra consecuencia es la contaminación de los mantos freáticos que posteriormente afectan la salud humana.

Además, el problema de escasez de agua, provoca una situación difícil y grave por ser indispensable para la vida. Es apremiante tomar medidas para el buen uso y manejo del agua, mediante la concientización y la aplicación de normas y leyes.

\section{Contaminación del Suelo}

El suelo es un conjunto de materiales biogeoquímicos sobre los cuales pueden crecer las plantas; teniendo propiedades estructurales y biológicas que los distinguen de las rocas y sedimentos, de los cuales ellos son originados (Pierzynski, Sims y Vance, 2000). El suelo está compuesto de materiales sólidos, con tamaños que van desde fragmentos de rocas hasta materiales finos como las arcillas.

El suelo puede definirse, de acuerdo con el glosario de la Sociedad Americana de la Ciencia del Suelo (1984), como el material mineral no consolidado en la superficie de la tierra, que ha estado sometido a la influencia de factores genéticos y ambientales (material parental, clima, macro y microorganismos y topografía), actuando durante un determinado periodo. (SEMARNAT, 2004, p. 120) 
Los suelos tienen seis papeles importantes, el primero es que sirven de sostén para el crecimiento de plantas superiores, porque proporcionan un medio para las raíces y suministran elementos nutritivos que son esenciales para todas las plantas. La naturaleza de la vegetación es determinada principalmente por las propiedades del suelo y, de manera indirecta, el número y especies animales que la vegetación puede sostener. En segundo lugar, están sus propiedades que son los principales factores que controlan el destino del agua en el sistema hidrológico. La pérdida de agua, utilización, contaminación y purificación son afectados por el suelo. En tercer lugar, el suelo funciona como sistemas de reciclaje natural. En los suelos, los productos de desecho como materia orgánica muerta, son asimilados y sus elementos básicos se tornan disponibles para la próxima generación de la vida. Como cuarto papel importante, es que los suelos proveen hábitats para los organismos vivos, desde pequeños mamíferos, reptiles e insectos, hasta células microscópicas de una cantidad y diversidad inimaginable. Quinto, los suelos influencian la composición y condición física de la atmósfera, tomando y liberando grandes cantidades de dióxido de carbono, oxígeno, metano y otros gases a la atmósfera. El sexto y último, los suelos juegan un papel importante como ingenieros del medio en ecosistemas construidos por humanos. El suelo no es solamente un importante material de construcción en forma de rellenos de tierra y ladrillos (suelo horneado), sino que también provee la base para virtualmente construir cada camino, aeropuerto y casa que construimos.

El suelo se considera contaminado cuando su composición ha sido alterada o modificada por la presencia de sustancias y/o factores físicos, químicos y/o biológicos. El hombre a través de los años ha utilizado el suelo de manera indiscriminada, lo que ha afectado sus propiedades naturales y por lo mismo ha perdido su capacidad de regenerarse de manera natural.

La normatividad en México referente a contaminación de suelos se considera escasa, sólo en dos Normas Oficiales Mexicanas se especifican límites máximos permisibles de contaminantes en suelo, una de las normas es la NOM-138-SEMARNAT/SS-2003, en la que se especifican los límites máximos permisibles de hidrocarburos en suelos y la otra es la NOM-147-SEMARNAT/SSA1-2004, que establece criterios para determinar las concentraciones de remediación de suelos contaminados por arsénico, bario, berilio, cadmio, cromo hexavalente, mercurio, níquel, plata, plomo, selenio, talio y/o vanadio. En la NOM-021RECNAT-2000 no se establecen límites permisibles de contaminantes, pero sí se establecen especificaciones de salinidad de suelos a través de mediciones de conductividad eléctrica en extractos de saturación de suelos y se indican los efectos, desde efectos despreciables de la salinidad a efectos no despreciables cuando el suelo es muy fuertemente salino. Estas normas sólo consideran hidrocarburos, metales y conductividad eléctrica (como medida indirecta de la concentración de sales). Para compuestos como los agroquímicos no existen normas oficiales mexicanas que especifiquen límites máximos permisibles en suelo por lo que a la hora de querer evaluar el grado de contaminación de estos compuestos en suelo se tiene que recurrir a guías internacionales, por ejemplo, las Normas de calidad de suelo canadiense para la Protección del Medio Ambiente y la Salud Humana (CCME, 1999). 
Se tienen identificadas en el país diferentes áreas en las cuales el crecimiento y desarrollo desordenado de obras y actividades de competencia federal han ocasionado la contaminación del suelo (PROFEPA, 2010). Uno de ellos es el sector petrolero a través de emisiones líquidas, como son aguas negras, lodos de perforación, aceites, lubricantes e hidrocarburos; en el caso del sector industrial, es principalmente a través de plantas químicas, de celulosa y papel, metalúrgicas y cementeras. En el sector agrícola con el uso de agroquímicos en los suelos se ha reportado la presencia de diferentes tipos de contaminantes; los agroquímicos se utilizan para eliminar plagas y/o ayudar a los suelos a recuperar sus nutrientes perdidos o los que los cultivos necesitan. De acuerdo a Huerta, Contreras-Valadez, Palacios-Mayorga, Miranda y Calva-Vásquez (2002) la concentración de metales pesados en suelos irrigados con agua residual, exceden la concentración crítica acorde a regulaciones ambientales.

La degradación de agroquímicos puede llevarse a cabo a través de reacciones biológicas y químicas. La degradación biológica o biodegradación ocurre a través de la actividad microbiana y es considerada el principal proceso por el cual se transforman los plaguicidas en el suelo. Durante la biodegradación, los microorganismos pueden utilizar los agroquímicos como fuente de energía y de nutrientes (Alexander, 1994). A los fenómenos de erosión, se le suma la degradación de suelos ocasionada por actividades humanas, entre las que destacan la degradación química, física y biológica.

\section{Metodología}

La presente investigación es de carácter descriptivo y exploratorio (Hernández, Fernández y Baptista, 2014); busca determinar aquellos rasgos que identifican los procedimientos para que los habitantes tengan mayores beneficios y mejor calidad de vida. Es una investigación con referentes de indagación empírico, sostenida en una sólida fundamentación teórica. Desde esta perspectiva se estudian fenómenos empíricos, personas y objetos; los productos generados se llegan a clasificar sobre la base de los resultados esperados, es decir, se vuelven un estudio teórico empírico.

El procedimiento específico se aborda a partir de la formulación del problema y la posible respuesta a la interrogante que guía el estudio, lo que permite definir y limitar el problema, ubicar el estudio en una perspectiva histórica, relacionar hallazgos propios con los de otros estudios y sugerir líneas de investigación posteriores.

Se buscan formas novedosas que permitan ofrecer alternativas de desarrollo factible con una clara orientación de responsabilidad con el medio ambiente.

\section{Resultados}

El agua, suelo y aire tienen contaminantes que proceden de la actividad humana, así como otros de origen natural. Algunos contaminantes son fácil de identificar, descifrando su procedencia; sin embargo, existen otros difíciles de identificar ya que podrían ser de diverso origen. 
Por ser el agua un elemento esencial para la vida y un factor clave para el desarrollo económico del país, su manejo y preservación han sido identificados como asuntos estratégicos y de seguridad nacional: "Crecimiento económico sostenido, reducción de la brecha social, protección a los más necesitados, conservación y restauración del patrimonio agua y bosques, son sólo algunos aspectos que hacen de los recursos hidráulicos parte central de la seguridad nacional" (CNA, 2001).

La disponibilidad del agua se vuelve un problema social, por la falta de equidad en el acceso al recurso, debido a la escasez de infraestructura para su distribución y el alto costo económico que esto genera para las poblaciones marginadas.

El capítulo III de la Ley General del Equilibrio Ecológico y la Protección al Ambiente, habla de la prevención y control de contaminación del agua y de los ecosistemas acuáticos; en su artículo 117 considera los siguientes criterios:

- La prevención y control del agua es muy importante para evitar que se reduzca su disponibilidad y proteger los ecosistemas.

- Prevenir la contaminación de ríos y cuencas entre otros incluyendo las aguas subterráneas.

- El aprovechamiento del agua en actividades productivas susceptibles de contaminarse, deben ser tratadas para su reincorporación y reutilización.

- Las aguas de origen urbano deber ser tratadas previamente a su descarga en ríos, cuencas entre otros, incluyendo al subsuelo.

- La responsabilidad y participación social es una condición indispensable para evitar la contaminación del agua.

Algunas de las normas oficiales mexicanas para el control de contaminación del agua son las siguientes: NOM-001-ECOL 1996, NOM- 002-ECOL 1996, NOM-003-CNA-1996, NOM-004-CNA-1996, NOM-127-SSAI-1994 y La NOM-003-1997; la primera establece los límites máximos permisibles de contaminación en las descargas de agua residuales en aguas y bienes nacionales; la segunda, sobre las descargas de aguas residuales en sistemas de alcantarillado; la tercera, sobre la construcción de pozos de extracción para prevenir la contaminación de acuíferos; la cuarta, sobre la protección de los acuíferos durante el mantenimiento y rehabilitación de pozos de extracción de agua y para el cierre de pozos en general; la quinta, sobre el agua para uso y consumo humano; y la última norma es para los límites máximos permisible para las aguas residuales tratadas. En materia de prevención y control de contaminación del agua, es elemental la regulación de las descargas residuales.

El deterioro de los suelos es en gran medida por el desconocimiento de cómo aprovechar el recurso en función de su disposición y capacidad, así como las técnicas adecuadas de aplicación para su uso y protección. La sustentabilidad del suelo dependerá del conocimiento sobre la aplicación de las leyes y normas, programas ambientales sectoriales que contribuyan a su protección y no a su rápida degradación, que permitiría una gran pérdida irreversible. 
Las Normas Oficiales Mexicanas donde se especifican límites máximos permisibles de contaminantes en suelo: son la NOM-138-SEMARNAT/SS-2003 y la NOM-147-SEMARNAT/SSA1-2004; la primera especifica los límites permisibles de hidrocarburos en suelo; $y$ la segunda establece criterios para determinar las concentraciones de remediación por arsénico, bario, berilio, cadmio, cromo hexavalente, mercurio, níquel, plata, plomo, selenio, talio y vanadio.

No es sino hasta la publicación de la Ley General del Equilibrio Ecológico y la Protección al Ambiente (LGEEPA) en 1988, y particularmente después de sus reformas de 1996, que la protección jurídica de los suelos se aborda desde una perspectiva ambiental más amplia. (Carmona, 2003 citado en SEMARNAT, 2004)

En la LGEEPA se establecen:

[...] los principios y criterios ambientales que deben aplicarse en las actividades que mayor impacto están teniendo en ellos, $y$ en la regulación y control de los procesos específicos que provocan su contaminación y que involucran el manejo de materiales (plaguicidas, fertilizantes y sustancias tóxicas) y residuos peligrosos. (Brañes, 2000 citado en SEMARNAT, 2004).

El problema de control y prevención de la contaminación atmosférica es complejo sobre todo para la protección de la salud de la población, debido al alto costo de las acciones, la carencia de programas para enfrentar el aumento de la población de manera acelerada y desordenada que además repercute en los demás factores para elevar los niveles de contaminación.

En el caso de la contaminación de la atmósfera existe el reglamento de la LGEEPA, la cual es:

[...] de aplicación nacional y que establece las obligaciones de las autoridades de orden federal y local. La Ley en su título IV Protección al Ambiente, capítulos I y II establecen los artículos sobre prevención y control de la contaminación de la atmósfera. En ellos se hace referencia específica a los instrumentos de política, mecanismos y procedimientos necesarios para controlar, reducir o evitar la contaminación de la atmósfera. (INECC, 2012)

El reglamento rige en todo el territorio nacional y en las zonas donde la nación ejerce su soberanía y jurisdicción, tiene por objeto reglamentar la Ley General del Equilibrio Ecológico y la Protección al Ambiente en lo que se refiere a la prevención y control de la contaminación atmosférica. (INECC, 2012) 
Cabe decir que derivado de los cambios relativamente recientes a la LGEEPA, se inició la aplicación de nuevos mecanismos de regulación directa de las actividades industriales, de tal forma que se creó una Licencia Ambiental Única (LAU) y una Cédula de Operación Anual (COA), de carácter inmediato. (INECC, 2012)

La SEMARNAT emite una serie de Normas Oficiales Mexicanas (NOM) que regulan las emisiones de contaminantes provenientes de fuentes fijas (como por ejemplo, la industria química, la industria del vestido, la industria mineral metálica, etc.) y fuentes móviles (como por ejemplo, autos particulares, camiones, etc.); dichas normas están dirigidas a restringir a ciertos niveles las emisiones de óxidos de azufre, óxido de nitrógeno, partículas, compuestos orgánicos volátiles y monóxido de carbono. También establece la normatividad que regula la calidad de los combustibles y establece los requerimientos técnicos de los métodos empleados para medir los contaminantes más comunes en el aire. (INECC, 2012)

Existen diferentes tipos de normas, algunas pueden ser para fuentes fijas y otras para fuentes móviles.

Para fuentes fijas se encuentran las siguientes: NOM-039-ECOL-1993, NOM-O40ECOL-1993, NOM-043-ECOL-1993, NOM-046-ECOL-1993, NOM-075-ECOL-1995, NOM085-ECOL-1994, NOM-093-ECOL-1995, NOM-097-ECOL-1995, NOM-105-ECOL-1996, NOM-121-ECOL-1997, NOM-123-ECOL-1998.

Para fuentes móviles: NOM-041-ECOL-1993, NOM-O42-ECOL-1993, NOM-044ECOL-1993, NOM-045-ECOL-1993, NOM-047-ECOL-1995, NOM-048-ECOL-1994, NOM049-ECOL-1995, NOM-050-ECOL-1995 y la NOM-076-ECOL-1996.

\section{Conclusiones}

- El agua es el único líquido vital y es un recurso natural no renovable, que debemos conservar, evitando su contaminación y haciendo un buen uso de ella, con el propósito de alcanzar un manejo sustentable de este recurso para el futuro.

- Los avances tecnológicos han traído consigo fuertes cambios en la vida del ser humano, pero también un gran deterioro al medio ambiente.

- La LGEEPA establece las obligaciones referentes a la protección, prevención y control de contaminación de la atmósfera. Se hace referencia específica a los instrumentos de política, mecanismos y procedimientos necesarios para controlar, reducir o evitar la contaminación de la atmósfera, por lo que solamente es cuestión de aplicarla de una manera justa y responsable.

- La definición e implementación de estrategias de prevención y control de las emisiones de partículas, gases y presión sonora permitirá contar con diagnósticos del ambiente y crear una cultura de auto cuidado y de corrección de problemas de contaminación atmosférica que puedan llegar a presentarse y que afecten la salud de la población. 
- Comúnmente se aplica una gran cantidad de fertilizantes y plaguicidas, que repercute en la calidad del agua de riego, lo cual es un riesgo para la salud de la población expuesta, ya que la mayoría de las poblaciones, utilizan el agua superficial de los canales de riego para uso doméstico, recreativo y en algunos casos para beber; resultando más vulnerables unas zonas que otras. Por lo que debería haber un mejor manejo acorde a las normas ya establecidas.

- La Ley General del Equilibrio Ecológico y la Protección al Ambiente (LGEEPA) indica que "la utilización de plaguicidas, fertilizantes y sustancias tóxicas, debe ser compatible con el equilibrio de los ecosistemas y considerar sus efectos sobre la salud humana a fin de prevenir los daños que pudieran ocasionar".

- La contaminación del suelo debería ser uno de los principales temas por considerar en las políticas de sustentabilidad ambiental, por la frecuente aplicación de agroquímicos en zonas agrícolas, así como el desarrollo e implementación de soluciones para mejorar el estado actual del ambiente y no perjudicar a las futuras generaciones.

- Es importante analizar cuál es el estado actual de los suelos en México, con el fin de saber la situación en la que prevalecen por el impacto ocasionado por la sobreexplotación en los últimos años.

- La legislación ambiental que intenta regular, no va acorde a la problemática actual ya que hay una deficiencia en la aplicación jurídica y desempeño de las autoridades así como la falta de valoración social. 


\section{Referencias bibliográficas}

Alexander, M. (1994). Biodegradation and Bioremediation. San Diego: Academic Press. Ambientum. (2001). Suelos contaminados. Generalidades. Revista Ecotimes. Recuperado de http://www.ambientum.com/revista/2001_27/2001_27_SUELOS/SUELOSCCC1. htm

Canadian Council of Ministers of the Environment (CCME). (1999). Canadian Soil Quality Guidelines for the Protection of Environmental and Human Health. Winnipeg: CCME.

Carmona, M.C. (2003). Ley General del Equilibrio Ecológico y la Protección al Ambiente. ComentariosyConcordancias. Ciudadde México:PROFEPA/Institutode Investigaciones Jurídicas UNAM.

Comisión Nacional del Agua (CNA). (2001). Programa Nacional Hidráulico 2001-2006. Ciudad de México: CNA. Recuperado de http://www.colsan.edu.mx/investigacion/ aguaysociedad/proyectofrontera/Programa\%20Nacional\%20Hidr\%C3\%A1ulico. pdf

Hernández, R., Fernandez, C., \& Baptista, P. (2014). Metodología de la Investigación. Ciudad de México: McGraw-Hill.

Huerta, L., Contreras-Valadez, R., Palacios-Mayorga, S., Miranda, J., \& Calva-Vásquez, G. (2002). Total elemental composition of soils contaminated with wastewater irrigation by combining IBA techniques. Nuclear Instruments and Methods in Physics Research B, 189, 158-162.

Instituto Politécnico Nacional (IPN). (2016). Contaminación atmosférica en la Zona Metropolitana del Valle de México. Modificaciones emergentes al programa Hoy No Circula. Ciudad de México: IPN. Recuperado de http://www.sustentabilidad.ipn.mx/ ES/Documents/Folletos/2016/2016_Contaminacion_Atmosferica_2_2016.pdf

Instituto Nacional de Ecología y Cambio Climático (INECC). (2012). Normatividad. Recuperado de http://www.inecc.gob.mx/calaire-informacion-basica/564-calairenormatividad

Ley General del Equilibrio Ecológico y la Protección al Ambiente. (1988, enero 28). Diario Oficial de la Federación, DOF 28-01-1988. Recuperado de http://www.oas.org/dsd/ fida/laws/legislation/mexico/mexico_1988.pdf

Norma Oficial Mexicana (2002). NOM-021-RECNAT-2000. Que establecelas especificaciones de fertilidad, salinidad y clasificación de suelos. Estudios, muestreo y análisis. Diario Oficial de la Federación, DOF 31-12- 2002.

Norma Oficial Mexicana NOM-138-SEMARNAT/SS-2003 (2005). Límites máximos permisibles de hidrocarburos en suelos y las especificaciones para su caracterización y remediación. Diario Oficial de la Federación, DOF 29-03- 2005.

Norma Oficial Mexicana NOM-147-SEMARNAT/SSA1-2004 (2007). Que establece criterios para determinar las concentraciones de remediación de suelos contaminados por arsénico, bario, berilio, cadmio, cromo hexavalente, mercurio, níquel, plata, plomo, selenio, talio y/o vanadio. Diario Oficial de la Federación, DOF 02 -03- 2007. 
Olmos, V. (2015). Nuestro mundo cambiante. Breve recopilación y adaptación de artículos sobre las ciencias de la naturaleza y el hombre. Barcelona: Me gusta escribir.

Organización Mundial de la Salud (OMS). (2003). Health Aspects of Air Pollution with Particulate Matter, Ozone and Nitrogen Dioxide. Recuperado de http://www.euro.who. int/_data/assets/pdf_file/0005/112199/E79097.pdf

Pierzynski, G.M., Sims, T. y Vance, G.F. (2000). Soils and Environmental Quality. Boca Raton: CRC Press.

Procuraduría Federal de Protección al Ambiente (PROFEPA). (2010). Sectores productivos de competencia federal. Recuperado de http://www.profepa.gob.mx/ innovaportal/v/1398/1/mx.wap/diagnostico.html

Secretaría de Medio Ambiente y Recursos Naturales (SEMARNAT). (2004). Perspectivas del medio ambiente en México. GEO México 2004. Ciudad de México: SEMARNAT. Recuperado de www.pnuma.org/deat1/pdf/GEOMéxico2004.pdf.

Secretaría de Medio Ambiente y Recursos Naturales (SEMARNAT). (2007). ¿ Y el ambiente? Problemas en México y el mundo. Ciudad de México: SEMARNAT. Recuperado de http:// biblioteca.semarnat.gob.mx/janium/Documentos/Ciga/libros2009/CG007297.pdf 


\title{
Capítulo 10
}

Fundamentos para la elaboración de un proyecto de educación ambiental para la sostenibilidad desde el ámbito municipal*

\author{
Julio César Duarte Ruiz
}

Lamberto Castro Arce

Universidad de Sonora 
*Una versión previa de este capítulo fue publicado:

Duarte, J.C. (2013). Educación ambiental para el desarrollo sostenible en el ámbito municipal. Memorias del Coloquio sobre Cultura, Historia e Identidad del Sur de Sonora, 18(17), pp. 358-371. Recuperado de https://memoriascoloquio.files.wordpress. com/2014/01/memorias_coloquio_xvii2.pdf 


\section{Introducción}

Mucho es lo que se ha escrito sobre la importancia de la educación ambiental (EA) y el desarrollo sostenible en el mundo, prácticamente desde la definición de desarrollo sustentable que lanzara la Comisión Brundtland, "[la satisfacción de] las necesidades del presente sin comprometer la capacidad de las futuras generaciones para satisfacer las propias" (ONU, 1987). Un concepto muy comprometido, pero en ese momento no fijaba las bases para que este se hiciera realidad en el corto o mediano plazo, es decir, no se partió desde la raíz del problema que significaba avanzar en ese objetivo empezando por el tipo de educación que habrían estado recibiendo las generaciones de jóvenes de la segunda mitad del siglo XX. No obstante, algo cambió al finalizar el siglo, que hizo a los gobiernos de los países del mundo industrializado y de los llamados "emergentes", lograr acuerdos en el sentido de emprender acciones que redujeran los efectos del cambio climático y la contaminación en el planeta, la Conferencia de las Partes en Kyoto Japón (1997) fue un ejemplo claro de esta preocupación (Meira, 2006). Sin embargo, los países que más contribuyen con la emisión de gases de invernadero principalmente de $\mathrm{CO}_{2}$ a la atmósfera no signaron este acuerdo: Estados Unidos de Norteamérica y la República Popular China. No son pocos los foros, encuentros, conferencias y tratados internacionales donde se han asumido compromisos para reducir los efectos del cambio climático, pero lo cierto es que los intereses económicos y políticos de las grandes potencias, han evitado el avance en un acuerdo global para contener el deterioro del ambiente y la destrucción de los ecosistemas naturales por las actividades antropogénicas (Foladori y González, 2001).

Por otra parte, se puede decir que la EA no es ninguna novedad en México, aunque su implementación ha sido limitada por la falta de políticas públicas impulsoras de programas educativos que contemplen la instrucción sobre el cuidado y el aprovechamiento de los recursos naturales, en el marco de un proyecto gubernamental de desarrollo para la sostenibilidad, que incluya tanto a la empresa pública como privada con el fin de lograr estos objetivos que deben ser comunes para toda la comunidad.

\section{Desarrollo sostenible}

Optar por el desarrollo sostenible desde lo local, es la meta principal que todo proyecto ambiental debe tener presente para que sus objetivos, estrategias y acciones tengan éxito, es decir, se debe tener claridad sobre las ideas y los conceptos que sean objeto de enseñanza para lograr un aprendizaje que lleve a los educandos a cambiar realmente sus estilos de vida y mejore su aprovechamiento como estudiante para convertirse en agente transformador de la sociedad actual. "La necesaria 'reconversión' de la educación hacia el desarrollo sostenible puede y debe ser un factor estratégico que incida en el modelo de desarrollo establecido para reorientarlo hacia la sostenibilidad y la equidad" (UNESCO Etxea, 2009). Los proyectos de EA son de relevante importancia para la formación educativa de niños y adolescentes, al adquirir un aprendizaje que les impulse a relacionarse con un profundo respeto por el resto de las especies y por el conjunto de los elementos que constituyen el ambiente físico: agua, suelo y aire, así como tomar conciencia de los esfuerzos que realizan la mayoría de los 
países del mundo por resolver los problemas ambientales que trae consigo nuestro propio desarrollo. Las propuestas, compromisos y acuerdos que se alcancen para permitirnos la convivencia de todos los seres humanos en un mejor entorno que nos lleve a la satisfacción de nuestras necesidades, sin poner en riesgo la existencia de las demás especies y el agotamiento de los recursos que impidan el desarrollo sostenible de las presentes y futuras generaciones.

\section{Principios básicos que deberá atender un proyecto de educación ambiental para la sostenibilidad}

- La educación en general y la EA en lo particular, responden a un derecho social básico que debiera ser contemplado en la Constitución Política de los Estados Unidos Mexicanos, de recibir educación ambiental desde los niveles de educación básica.

- Cualquier planteamiento estratégico educativo debe contemplar la dimensión ambiental, para que mediante la EA los participantes adquieran nuevos valores que les permita asumir una nueva conducta en el uso racional de los recursos y mejorar su calidad de vida (Caride y Meira, 2000).

- Proponer el diseño de estrategias educativas locales, nacionales y regionales sin perder de vista la escala global para avanzar en el logro de la sustentabilidad. El proyecto deberá ser diseñado para su aplicación a nivel municipal, donde se deben involucrar los diversos sectores de la sociedad incluyendo a las autoridades locales, padres de familia, instituciones educativas y la comunidad en general.

- Una definición de educación ambiental que sienta las bases del proyecto sería la siguiente: "La educación ambiental es un proceso educativo en el cual los participantes adquieren nuevos conocimientos, valores, actitudes y habilidades, que les permiten afrontar de un modo consciente, autónomo y libre las consecuencias del deterioro ambiental, con el propósito de tener un cambio en sus estilos de vida y lograr la satisfacción de sus necesidades sin poner en riesgo los recursos que impidan el desarrollo sostenible de las presentes y futuras generaciones" (Definición de los autores fundamentada en un concepto de Meira, 2006).

\section{Fundamentos teóricos del proyecto de educación ambiental}

Existen dos enfoques centrales en el debate sobre la EA: el enfoque conservacionista cuyo precursor Aldo Leopold, quien a mediados del siglo XX ya reclama una educación ecológica orientada a concienciar a la población sobre la necesidad de conservar un entorno degradado por la presión de una mercantilización progresiva de la naturaleza, quien sin hablar de una educación ambiental, pugnaba por una dimensión entre la formación ecológica basada en atribuir a las especies y a los ecosistemas un valor moral (Foladori, 2001). Este enfoque coincide con la visión reduccionista del medio ambiente cuestionada en la reunión preparatoria (1968) de la Conferencia de Estocolmo, pues estaba orientada sólo a la preservación de los recursos naturales y a los espacios dotados de un valor estético o ecológico singular; la cual era defendida por los países más desarrollados. 
Por otro lado estaba el enfoque alternativo, que trataba de vincular las soluciones a la degradación ecológica con medidas que coadyuven al desarrollo económico y social de los pueblos más desfavorecidos. Este último vinculado al enfoque estratégico surgido de los planteamientos críticos al reduccionismo de la Conferencia de Estocolmo (1972), que dio pie a que la Organización de las Naciones Unidas para la Educación, la Ciencia y la Cultura (UNESCO) y el Programa de las Naciones Unidas para el Medio Ambiente (PNUMA) promovieran un Programa Internacional de Educación Ambiental (PIEA), el cual centró sus iniciativas en todos los ámbitos y niveles educativos con la intención de mejorar los dispositivos curriculares e interdisciplinario y la necesidad de llegar a todos los sectores de la población (Caride y Meira, 2000).

En el Seminario de Belgrado (1975) se retoma el PIEA y reclaman una EA congruente con la adopción de una nueva ética para hacer frente a la pobreza y a la degradación ambiental, la conceptualiza como un proceso educativo continuo, multidisciplinar, integrado en las diferencias regionales y volcado hacia las realidades sociales (Carta de Belgrado) uno de los documentos más trascendentes de la EA. Posteriormente, la Reunión de Tbilisi (1977) le da una importancia crucial al desarrollo institucional de la EA en su Declaración Capítulo 13, la estrategia alude a la EA y a la participación pública como una medida necesaria para mejorar la gestión de los recursos naturales. Con este propósito, se señala que deberá cooperar en la transformación de una nueva ética en relación con las plantas, los animales e incluso los seres humanos. Se presenta un programa vinculado al enfoque estratégico donde se establecen una serie de directrices en una clara asociación de la tarea educativo-ambiental con la transformación de los comportamientos individuales (Caride y Meira, 2000).

Ese enfoque hará eco en el Informe Brundtland donde se vincula la crisis ambiental con el desarrollo humano, aunque el tema educativo todavía ocupará un papel secundario en su redacción; sin embargo, este informe influirá decisivamente en la Conferencia de las Naciones Unidas sobre el Medio Ambiente y el Desarrollo celebrada en Río (1992) conocida como Cumbre de la Tierra. Lo relevante de la Cumbre es el señalamiento en que para luchar eficazmente contra la degradación ambiental no será suficiente adoptar soluciones científicas o tecnológicas; será preciso, además, tener en cuenta los factores económicos, sociales y culturales, que junto a las decisiones políticas influyen decisivamente en el medio ambiente. En este sentido, la Agenda 21 se revela como la aportación más sustantiva para la EA en la cumbre de Río, donde se hacen propuestas por primera vez en materia de Fomento de la Educación, la Capacitación y la Toma de Conciencia (UICN, 2004).

Ambos enfoques, tanto el conservacionista como el alternativo, cumplen con los requerimientos básicos que debe contemplar un proyecto de educación ambiental para la sostenibilidad. El enfoque conservacionista para educar en la conservación de los recursos naturales, concienciar como decía Leopold (2005) para la formación ecológica con una nueva dimensión del valor de las especies o de los ecosistemas; y por otra parte, fundamentarse en el enfoque alternativo, el cual hace suyo el señalamiento de la Cumbre de la Tierra (1992) que "para luchar eficazmente contra la degradación ambiental es necesario tomar 
en cuenta los factores políticos, económicos y sociales de las comunidades", retomando los puntos de la Agenda 21 de la cumbre de Río (Caride y Meira, 2000).

En el mismo sentido, se deben incorporar de manera importante las nuevas ideas sobre la EA para el desarrollo humano sostenible y los elementos tecnológicos de actualidad, las tecnologías de la información y la comunicación (TIC) para la mejor comprensión y concienciación. El uso de los medios de comunicación, prensa, radio y televisión para la difusión de los programas educativos. La vinculación entre organizaciones civiles, instituciones educativas y gobiernos municipales. Esto último permitirá hacer extensivo el proyecto a los ámbitos local y regional (Solano, 2009). Los conceptos de sustentabilidad han ido en los últimos decenios transformando la geografía del mundo, entre aquellos países que han pugnado por mejores condiciones de desarrollo para los pueblos y en contraparte, aquellos que se han opuesto a considerar la reducción de las emisiones de gases de invernadero por mencionar sólo un aspecto de la geografía política; en ese sentido, el proyecto debe contribuir a la adquisición de una nueva cultura para la participación democrática de los ciudadanos del presente y también del futuro tal como lo plantea Morin (1999).

Así, un proyecto de EA necesita afrontar la magnitud de las problemáticas ambientales desde una perspectiva histórico-política y filosófica que le permitan clarificar los factores estructurales con las que está trabajando; debe analizar el papel colectivo de los destinatarios de la EA y sus posibilidades de emancipación e influencia en su entorno; $y$ requiere delinear con cierta nitidez los fundamentos y los modelos educativos, pedagógicos y comunicacionales con que trabaja.

(Nieto-Caraveo, 2001)

\section{Los ejes temáticos}

Los conceptos, teorías y enfoques de la temática de un proyecto de educación ambiental para la sostenibilidad se fundamentan en el ecocentrismo social, con una tendencia hacia la concienciación del individuo para asumir cambios de conducta en sus prácticas cotidianas y transformar su relación con el entorno en que vive para alcanzar mejores condiciones de vida. En éste se desarrollan relaciones de interdependencia entre los agentes institucionales externos y los contextos, entre discursos a partir de las temáticas, los problemas, ideas y acciones (Díaz, 2005). Esto permitirá la estructuración de un proyecto con un sentido de pertinencia social vinculado a la construcción de redes pedagógicas constituyendo tareas de autogestión.

Por otra parte, el proyecto sería cercano al concepto de Currículum Integrado, propuesto por Torres (1994), dadas las características combinadas del mismo sobre educación formal en el aula (33\%) y no-formal en actividades prácticas (67\%), considerando también a las instituciones implicadas, al tipo de educandos (niños y adolescentes de educación básica o jóvenes de educación media o superior), a los instructores (profesores y estudiantes universitarios) y a miembros de la comunidad (padres de familia) quienes tendrían participación activa, así como la injerencia de organizaciones sociales y autoridades municipales. 

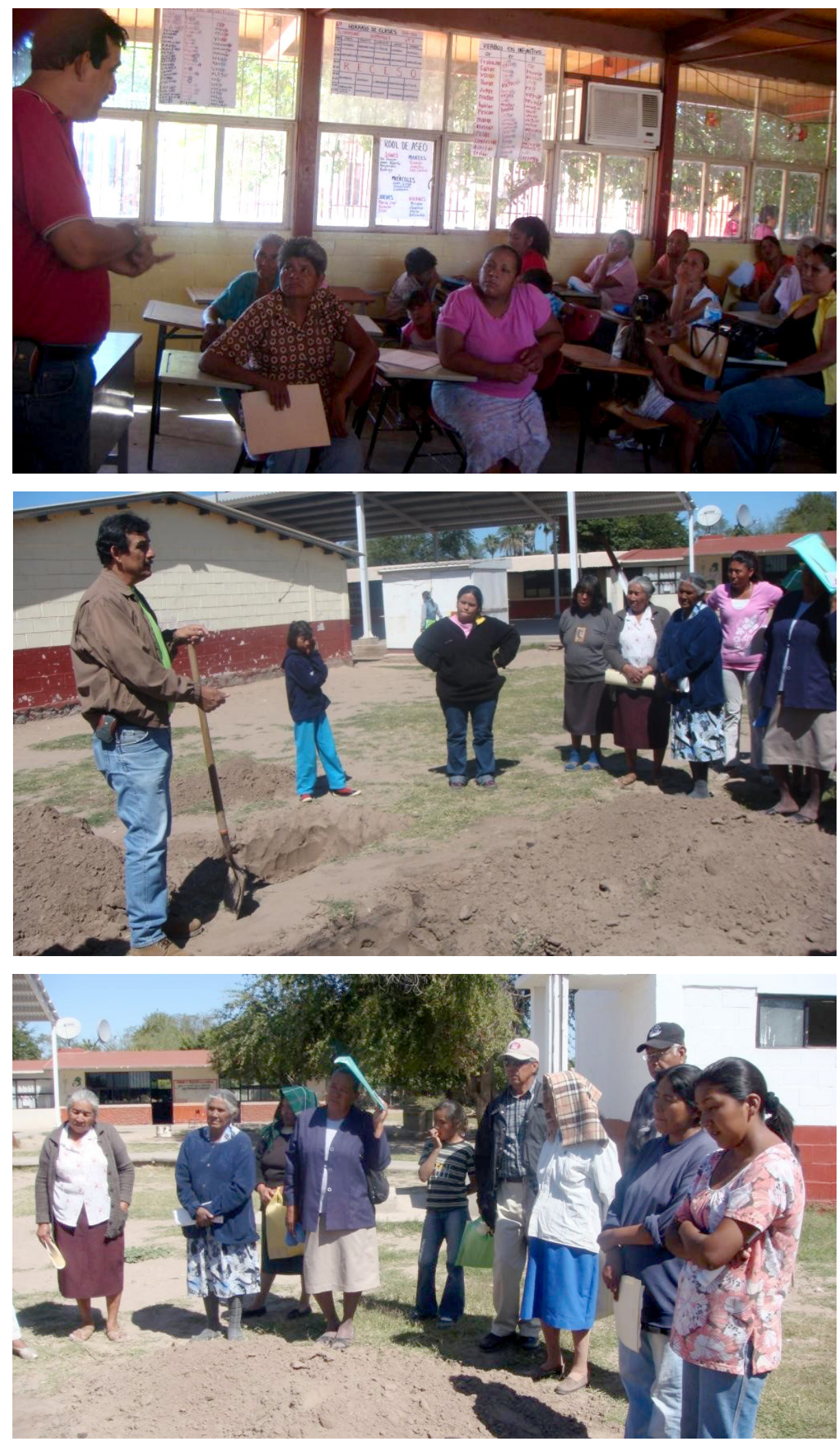

Figura 1. Taller de educación ambiental en escuelas primarias. 


\section{Estrategias para la enseñanza y el aprendizaje}

El conocimiento, la sensibilización, la conciencia y las actitudes son importantes para desarrollar comportamientos proambientales (Nieto-Caraveo, 2004); todo como parte de un proceso para lograr cambios de hábitos y conductas en las personas, así como en el desarrollo de competencias que se nutren de comportamientos proactivos para alcanzar objetivos muy concretos que permitan a las personas o comunidades mejorar su calidad de vida, definiendo a las competencias como: las habilidades adquiridas por los individuos o grupos de personas debido a procesos de aprendizaje basados en el conocimiento, sensibilización y el cambio de comportamientos para ser más eficientes en el trabajo o empresa que desarrollen (Nieto-Caraveo, 2004).

No obstante, Nieto-Caraveo (2004) señala que no basta la concienciación y sensibilización con respecto a los grupos de educandos a quienes va dirigido el proyecto para obtener respuestas proambientales, pero son factores que inciden constructivamente para la elaboración de estrategias adecuadas en el diseño de situaciones de aprendizaje que sean eficientes para lograr los objetivos. Esto puede presentarse en el ámbito de la zona rural y áreas de las colonias marginadas de la zona urbana, por esta razón, un proyecto de EA deberá lograr ese cambio de actitud mediante la participación activa tanto de jóvenes y adolescentes como de los miembros de la comunidad (padres de familia) con una instrucción muy práctica, no compleja y con las herramientas que ellos dispongan.

Por otra parte, los factores externos son los que pueden tener consecuencias de mayor impacto en el proceso de enseñanza-aprendizaje, porque son la fuente de los recursos tanto materiales como financieros para la consecución de los objetivos propuestos. No es de gran utilidad el diseñar estrategias y acciones que pudieran ser las más adecuadas para lograr objetivos de aprendizaje, si no se cuenta al mismo tiempo con los recursos necesarios para alcanzarlos. En este sentido y considerando experiencias anteriores, se propone la realización de convenios entre instituciones educativas responsables de proyectos y las administraciones municipales. La conjunción de esfuerzos entre las instituciones, harán posible el éxito del proyecto.

Con respecto a la capacitación de los instructores, los conceptos de didáctica y transposición didáctica de Buchelli y Marín (2009), nos obligan a replantear el papel que deben jugar los instructores en un proyecto de EA, considerando que la intervención del docente en la transmisión de los conocimientos es fundamental para su éxito. Los maestros y estudiantes de las Instituciones de Educación Superior (IES) que sean instructores, deberán desarrollar habilidades para lograr la modificación cualitativa de los saberes, para que a su vez estos se transformen en nuevos conocimientos que también sean un producto didáctico no-material como resultado del proceso educativo, así como la creación de nuevos métodos o procedimientos adecuados a las condiciones que presente el ámbito donde se desarrolle el proyecto. 


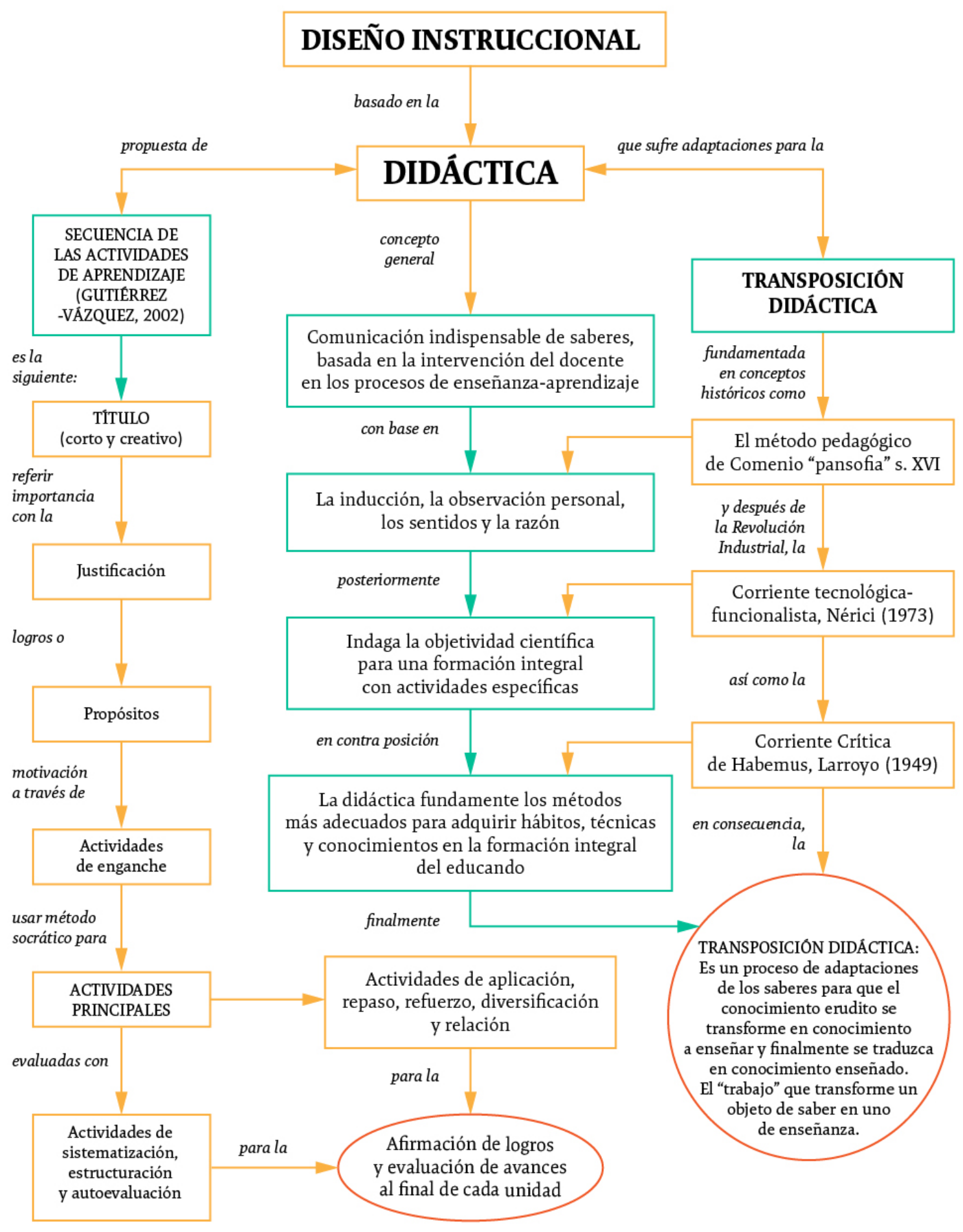

Figura 2. Diseño instruccional para las actividades de aprendizaje.

Fuente: Elaboración propia con fundamento en el concepto de transposición didáctica de Buchelli y Marín (2009). 


\section{Proceso de evaluación}

El proceso de evaluación retomará las propuestas de la teoría constructivista que señalan Díaz-Barriga y Hernández-Rojas (2002), aplicando los instrumentos y procedimientos de evaluación basadas en las tres dimensiones: técnicas informales, semiformales y formales; desde la observación, exploración, ejercicios y prácticas en campo, mapas conceptuales, pruebas de ejecución y listas de verificación. Son aplicables los tipos de evaluación inicial y puntual, la formativa y la sumativa para certificar el grado de acreditación conseguido. Se considera poner énfasis en el proceso de evaluación de manera permanente durante el desarrollo del proyecto, inclusive para replantear de ser necesario los objetivos del mismo tomando en cuenta las condiciones que se presenten durante el proceso. Es decir, adaptar el proyecto de acuerdo a los hechos concretos que se presenten al momento de ejecutar cada una de sus etapas, para esto, analizar cómo llevar a cabo el proceso de evaluación considerando tanto factores internos como externos. Actividades de sistematización, estructuración y autoevaluación, tal como lo plantea Gutiérrez-Vázquez (2002). El ámbito en que se presenta el proyecto de acuerdo a las dimensiones ética, política y técnica, para replantear el diseño del objeto y el proceso de evaluación (Nieto-Caraveo y Buendía-Oliva, 2009).

De Alba y González (1997) abordan la evaluación definiéndola como un proceso de comprensión y valoración que se constituye en sí misma como aprendizaje. Señalan el establecer relaciones entre lo que ya se sabe y lo aprendido, lo cual implica encontrarle sentido a lo que se aprende, que se traduce en la construcción activa de significados. En última instancia, aprender es construir nuevos significados. Abordan también las pautas de evaluación, definiéndola como una orientación general que permite guiar nuestras intenciones y acciones de evaluación hacia un rubro específico, y realizar valoraciones, comparaciones y estudios cuantitativos y cualitativos con una base mínima común.

\section{Impacto del proyecto}

El impacto debe ser en primera instancia educativo, luego, deberá tener una repercusión en lo económico y social. Lograr un cambio de conducta en las formas y estilos de vida de los estudiantes y ciudadanos involucrados, lo cual permitirá que las instituciones impulsoras del proyecto desarrollen programas bajo el concepto de desarrollo sostenible para una gestión ambiental adecuada de los recursos naturales y los servicios municipales prestados en beneficio de toda la comunidad en general.

De Alba y González (1997) señalan que el impacto de los programas ambientales en la comunidad puede tener un alcance significativo. Este impacto puede ser directo, a través de las actividades realizadas con la comunidad o indirecto por efecto de la acción de niños y adolescentes en los otros miembros, mediante las diversas acciones individuales o de grupo que se realicen sobre la comunidad y que posteriormente se den a conocer. Un ejemplo de impacto indirecto se observa cuando los adultos cambian actitudes, valores y hasta hábitos y conductas, debido a la influencia educativa de los niños y los adolescentes, aunque elimpacto es difícil de registrar, su importancia es nodal pues se puede tomar como un indicador de cambio. 


\section{Referencias bibliográficas}

Buchelli,G.A., \& Marín, J.J. (2009). Transposición Didáctica: Bases para repensar la enseñanza de una disciplina científica. I parte. Revista Académica e Institucional, Páginas de la UCPR, 85, 17-38.

Caride, J.A., \& Meira, P.A. (2000). La Construcción Paradigmática de la Educación Ambiental: Educar para una Racionalidad Alternativa. En Educación Ambiental y Desarrollo Humano (pp.189-248). Barcelona: Ariel Educación.

De Alba A., \& González, E. (1997). Evaluación de programas de educación ambiental: experiencias en América Latina y el Caribe. Ciudad de México: CESU-UNAM, UNESCO, SEMARNAP.

Díaz-Barriga, F., \& Hernández-Rojas, G. (2002). Constructivismo y evaluación psicoeducativa. En Estrategias docentes para un aprendizaje significativo: una interpretación constructivista (pp. 349-425). Ciudad de México: McGraw-Hill.

Díaz, V.M. (2005). Integración, Formación y Propuestas Educativas. Diplomado: Flexibilidad Curricular en Educación Superior. Cuaderno de Trabajo. Cali.

Foladori, G. (2001). Una tipología del pensamiento ambientalista. En N. Pierri, \& G. Foladori. ¿Sustentabilidad? Desacuerdos sobre el desarrollo sustentable. Uruguay: Trabajo y Capital. (Pp. 27-79)

Foladori, G., \& González, E. (2001). En pos de la Historia en Educación Ambiental. Tópicos en Educación Ambiental, 3(8), 28-43.

Gutiérrez-Vázquez J.M. (2002). Secuencia de las actividades de aprendizaje. Sugerencias para la estructuración de materiales educativos para adultos. Decisio, 1(1). Ciudad de México: CREFAL. Recuperado de http://www.crefal.edu.mx/decisio/images/pdf/ decisio_1/decisio1.pdf

Leopold, A. (2005). Una ética de la tierra. Madrid: Libros de la Catarata.

Meira, P. (2006). Crisis ambiental y globalización: Una lectura para educadores ambientales en un mundo insostenible. Trayectorias, 8(20-21), 110-123.

Morin, E. (1999). Siete saberes para la educación del futuro. Cómo educar para un futuro sostenible. París: UNESCO.

Nieto-Caraveo, L.M. (2001). Modalidades de la educación ambiental: diversidad y desafíos. Presentación. En J. E. Dos Santos y M. Sato (coord.). A Contribuição da Educação Ambiental à Esperança de Pandora. São Carlos: Rima.

Nieto-Caraveo, L.M. (2004). ¿Cuál es el papel de la Educación Ambiental? Revista Universitarios, 8(2), 56-61.

Nieto-Caraveo, L.M., \& Buendía-Oliva, M. (2009). Guía para la evaluación de proyectos de educación ambiental y para la sustentabilidad. Documento interno de trabajo. Diplomado en Diseño de Proyectos de Educación Ambiental, Módulo 5, UASLP.

Organización de las Naciones Unidas (ONU). (1987). Informe de la Comisión Mundial sobre Medio Ambiente y Desarrollo (Informe Brundtland). Recuperado de http://www. un.org/es/comun/docs/?symbol=A/42/427 
Solano, D. (2009). Gestión del desarrollo y su relación con la Comunicación y Educación para el Desarrollo Sostenible. En Estrategias de comunicación y educación para el desarrollo sostenible (pp. 15-23). Santiago: Oficina Regional de Educación de la UNESCO para América Latina y el Caribe. Recuperado de http://unesdoc.unesco. org/images/0015/001595/159531S.pdf

Torres, S.J. (1994). Globalización e Interdisciplinariedad: el Currículum Integrado. Madrid: Morata.

UNESCO Etxea (2009). Manual de Educación para la Sostenibilidad. España: UNESCO etxea - Centro UNESCO País Vasco, Fundación Iberdrola. Recuperado de http://www. unescoetxea.org/ext/manual_EDS/unesco.html

Unión Internacional para la Conservación de la Naturaleza (UICN). (2004). Voces para un diálogo de futuro. El debate sobre el Desarrollo Sostenible en América Latina. Quito: IUCN. 


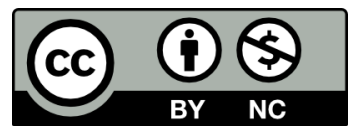

Esta obra está bajo una Licencia Creative Commons Atribución-NoComercial 4.0 Internacional.

https://creativecommons.org/licenses/by-nc/4.0/deed.es

Estudios de desarrollo regional en México

ISBN 978-607-96359-8-5

DOI 10.29410/QTP.16.04

Esta publicación digital se terminó de producir en el mes de junio de 2016. Su diseño y edición estuvieron a cargo de:

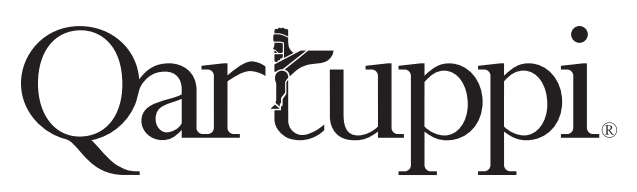

Qartuppi, S. de R.L. de C.V. http://www.qartuppi.com 

